\title{
Total Synthesis of the Diazobenzofluorene Antibiotic (-)-Kinamycin C
}

\author{
Xiaoguang Lei and John A. Porco, Jr. *
}

Department of Chemistry and Center for Chemical Methodology and Library Development (CMLD-BU),Boston University, 590 Commonwealth Avenue, Boston, Massachusetts 02215

E-mail:porco@bu.edu

\section{Supporting Information}

\begin{tabular}{|l|l|}
\hline & Page \\
\hline I) Experimental Section. & \\
\hline a) General information & $\mathrm{S} 2$ \\
\hline b) Detailed experimental procedures & $\mathrm{S} 3-\mathrm{S} 12$ \\
\hline $\begin{array}{l}\text { c) Detailed procedure for the preparation of kinamycin C from } \\
\text { natural kinamycin D }\end{array}$ & $\mathrm{S} 13$ \\
\hline II) Comparison of natural and synthetic kinamycin C & $\mathrm{S} 14-\mathrm{S} 19$ \\
\hline III) ${ }^{\mathbf{1}}$ H and ${ }^{\mathbf{1 3}}$ C NMR spectra & $\mathrm{S} 20-\mathrm{S} 40$ \\
\hline IV) X-ray crystallographic data & $\mathrm{S} 41-\mathrm{S} 43$ \\
\hline
\end{tabular}




\section{I) Experimental Section}

\section{a) General information:}

${ }^{1} \mathrm{H}$ NMR spectra were recorded on a $400 \mathrm{MHz}$ spectrometer at ambient temperature with $\mathrm{CDCl}_{3}$ as the solvent unless otherwise stated. ${ }^{13} \mathrm{C}$ NMR spectra were recorded on a $300 \mathrm{MHz}$ spectrometer $(75 \mathrm{MHz})$ at ambient temperature with $\mathrm{CDCl}_{3}$ as the solvent unless otherwise stated. Chemical shifts are reported in parts per million relative to chloroform $\left({ }^{1} \mathrm{H}, \delta 7.24 ;{ }^{13} \mathrm{C}, \delta\right.$ 77.00). Data for ${ }^{1} \mathrm{H}$ NMR are reported as follows: chemical shift, multiplicity (app = apparent, $\mathrm{s}$ = singlet, $\mathrm{d}=$ doublet, $\mathrm{t}=$ triplet, $\mathrm{q}=$ quartet, $\mathrm{m}=$ multiplet, $\mathrm{br}=$ broad), integration and coupling constants. All ${ }^{13} \mathrm{C}$ NMR spectra were recorded with complete proton decoupling. Infrared spectra were recorded on a Nicolet Nexus 670 FT-IR spectrophotometer. Low and high-resolution mass spectra were obtained in the Boston University Mass Spectrometry Laboratory using Finnegan MAT-90 or Waters Q-TOF API US spectrometers. Optical rotations were recorded on an AUTOPOL III digital polarimeter at $589 \mathrm{~nm}$ and are recorded as $[\alpha]_{\mathrm{D}}{ }^{22}$ (concentration in grams $/ 100 \mathrm{~mL}$ solvent). Analytical thin layer chromatography was performed using $0.25 \mathrm{~mm}$ silica gel 60-F plates. Chiral and analytical HPLC analysis was performed on a Agilent 1100 series utilizing Chiralcel OD and Agilent Zorba $(4.6$ × $75 \mathrm{~mm})$ columns, respectively. Flash chromatography was performed using 200-400 mesh silica gel (Scientific Absorbents, Inc.). Yields refer to chromatographically and spectroscopically pure materials, unless otherwise stated. Methylene chloride, tetrahydrofuran, toluene, benzene were purified by passing through two packed columns of neutral alumina (Innovative Technology, Inc.). All reagents were used as supplied by Sigma-Aldrich, Fluka, and Strem Chemicals. Trityl hydroperoxide $\left(\mathrm{Ph}_{3} \mathrm{COOH}\right)^{\mathrm{S} 1}$ was prepared from trityl alcohol according to the literature procedure. $4 \AA \mathrm{MS}$ was freshly activated at $150{ }^{\circ} \mathrm{C}$ in vacuo for $24 \mathrm{~h}$. Natural kinamycin $\mathrm{D}$ was generously provided by Professor Philip Proteau (Oregon State University). Authentic kinamycin C was prepared from natural kinamycin D. ${ }^{\text {S2 }}$ All reactions were carried out in oven-dried glassware under an argon atmosphere unless otherwise noted. The Arthur ${ }^{\mathrm{TM}}$ Suite Reaction Planner (Symyx, Inc.) was used for experimental procedure planning.

\footnotetext{
${ }^{\text {S1 }}$ Bissing, D. E.; Matuszac, C. A.; McEwen, W. E. J. Am. Chem. Soc. 1964, 86, 3824.

S2 For experimental details, see page S12.
} 


\section{b) Detailed experimental procedures:}

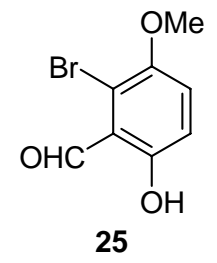

Bromobenzaldehyde 25. To hydroquinone 10 (15.5 g, $71.8 \mathrm{mmol}), \mathrm{Me}_{3} \mathrm{OBF}_{4}$ (11.2 g, $75.6 \mathrm{mmol}$ ), Proton Sponge (1,8-bis(dimethylamino)naphthalene) (16.2 $\mathrm{g}, 75.6 \mathrm{mmol})$, and activated $4 \AA \mathrm{MS}(1.5 \mathrm{~g}, 10 \mathrm{wt} . \%)$ was added $300 \mathrm{~mL}$ of anhydrous $\mathrm{CH}_{2} \mathrm{Cl}_{2}$ and the reaction was stirred at $\mathrm{rt}$ under argon for $12 \mathrm{~h}$. The reaction was quenched with water and extracted with $\mathrm{CH}_{2} \mathrm{Cl}_{2}$. The organic layers were combined, washed $4 \mathrm{X}$ with aqueous $1 \mathrm{~N} \mathrm{HCl}$ and brine, dried over $\mathrm{MgSO}_{4}$, filtered, and concentrated in vacuo. Purification on silica gel (hexane : EtOAc $=4: 1$ ) provided $14.0 \mathrm{~g}(61.0 \mathrm{mmol}, 85 \%)$ of bromobenzaldehyde 25 as a yellow solid. m.p. 73-74 ${ }^{\circ} \mathrm{C}$; ${ }^{1} \mathrm{H} \quad \mathrm{NMR}\left(400 \mathrm{MHz}, \mathrm{CDCl}_{3}\right) 11.6(\mathrm{~s}, 1 \mathrm{H}), 10.4(\mathrm{~s}, 1 \mathrm{H}), 7.16(\mathrm{~d}, 1 \mathrm{H}, J=9.6 \mathrm{~Hz}), \quad 6.92(\mathrm{~d}, 1 \mathrm{H}$, $J=9.6 \mathrm{~Hz}), 3.87(\mathrm{~s}, 3 \mathrm{H}) ;{ }^{13} \mathrm{C} \mathrm{NMR} \quad\left(100.0 \mathrm{MHz}, \mathrm{CDCl}_{3}\right) \delta 198.3,158.1,149.4,122.4,118.1$, 117.8, 116.4, 57.8; IR (thin film) vmax 3741, 2960, 2838, 1649, 1580, 1468, 1270, 1180, 1063 $\mathrm{cm}^{-1}$; CIHRMS $[\mathrm{M}+\mathrm{H}]^{+}$calculated for $\mathrm{C}_{8} \mathrm{H}_{8} \mathrm{BrO}_{3}$ : 230.9658, found: 230.9657 .

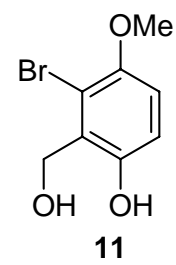

4-Methoxyphenol 11. Bromobenzaldehyde 25 (14.0 g, $61.0 \mathrm{mmol})$ was dissolved in $100 \mathrm{~mL}$ of EtOH and cooled to $0^{\circ} \mathrm{C}, \mathrm{NaBH}_{4}(2.8 \mathrm{~g}, 73.0 \mathrm{mmol})$ was added over $10 \mathrm{~min}$ and the reaction was stirred at $0{ }^{\circ} \mathrm{C}$ for a further $1 \mathrm{~h}$. The reaction was quenched with acetic acid and extracted with EtOAc $(600 \mathrm{~mL})$. The organic layers were combined, washed with brine, dried over $\mathrm{MgSO}_{4}$, filtered, and concentrated in vacuo to provide $13.9 \mathrm{~g}(60.3 \mathrm{mmol}, 99 \%)$ of 11 as a white solid. m.p. $220-221{ }^{\circ} \mathrm{C} ;{ }^{1} \mathrm{H} \quad \mathrm{NMR}\left(400 \mathrm{MHz}, \mathrm{CDCl}_{3}\right) 7.80(\mathrm{~s}, 1 \mathrm{H}), 6.78(\mathrm{~d}, 1 \mathrm{H}, J=$ $8.0 \mathrm{~Hz}), \quad 6.76(\mathrm{~d}, 1 \mathrm{H}, J=8.0 \mathrm{~Hz}), 5.11(\mathrm{~s}, 2 \mathrm{H}), 3.82(\mathrm{~s}, 3 \mathrm{H}) ;{ }^{13} \mathrm{C} \mathrm{NMR} \quad\left(100.0 \mathrm{MHz}, \mathrm{CD}_{3} \mathrm{OD}\right)$ $\delta 150.8,148.5,125.7,116.2,112.9,109.6,62.9$, 56.4; IR (thin film) vmax 3225, 3007, 2940, $2838,1473,1436,1256,1062,755 \mathrm{~cm}^{-1}$; CIHRMS $[\mathrm{M}+\mathrm{H}]^{+}$calculated for $\mathrm{C}_{8} \mathrm{H}_{10} \mathrm{BrO}_{3}$ : 232.9813, found: 232.9828 .

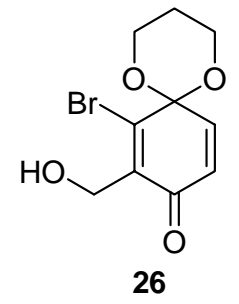

Cyclic ketal 26. Compound $11(8.80 \mathrm{~g}, 37.8 \mathrm{mmol})$ was dissolved in $100 \mathrm{~mL}$ of $\mathrm{MeOH}$ and cooled to $0{ }^{\circ} \mathrm{C}, \mathrm{PhI}(\mathrm{OAc})_{2}(13.4 \mathrm{~g}, 41.6 \mathrm{mmol})$ was added over $10 \mathrm{~min}$ and the reaction was stirred at $\mathrm{rt}$ for a further $30 \mathrm{~min}$. The reaction was quenched with sat. $\mathrm{NaHCO}_{3}$ and extracted with EtOAc. The organic layers were combined, washed with brine, dried over $\mathrm{MgSO}_{4}$, filtered, and concentrated in vacuo. The crude product $(9.93 \mathrm{~g}, 37.8 \mathrm{mmol})$, and 1,3-propanediol $(18.0 \mathrm{~g}, 236.8 \mathrm{mmol})$ were placed in a round-bottomed flask and dissolved in $180 \mathrm{~mL}$ of anhydrous DME. To this solution was added $\mathrm{BF}_{3} \cdot \mathrm{Et}_{2} \mathrm{O}(5.0 \mathrm{~mL}, 39.7 \mathrm{mmol})$ dropwise at $0{ }^{\circ} \mathrm{C}$ over $0.5 \mathrm{~h}$, and the reaction was stirred for a further $3 \mathrm{~h}$ at $\mathrm{rt}^{\mathrm{S} 3}$ The reaction was quenched by addition of $100 \mathrm{~mL}$ of sat. $\mathrm{NaHCO}_{3}$ and extracted with $600 \mathrm{~mL}$ of EtOAc. The combined organic layers were washed with sat. $\mathrm{NaHCO}_{3}$, brine, dried over $\mathrm{MgSO}_{4}$, filtered, and concentrated in vacuo. Purification on silica gel (hexane : EtOAc $=1: 1)$ provided $8.30 \mathrm{~g}(30.2 \mathrm{mmol}, 80 \%)$ of cyclic ketal 26 as a yellow solid. m.p. $112-113{ }^{\circ} \mathrm{C} ;{ }^{1} \mathrm{H} \quad \mathrm{NMR}\left(400 \mathrm{MHz}, \mathrm{CDCl}_{3}\right) 7.71(\mathrm{~d}, 1 \mathrm{H}, J=10.0 \mathrm{~Hz}), 6.29(\mathrm{~d}, 1 \mathrm{H}, J=10.0 \mathrm{~Hz})$, $4.61(\mathrm{~s}, 2 \mathrm{H}), 4.22(\mathrm{~m}, 2 \mathrm{H}), 4.12(\mathrm{~m}, 2 \mathrm{H}), 2.74(\mathrm{~s}, 1 \mathrm{H}), 2.39(\mathrm{~m}, 1 \mathrm{H}), 1.60(\mathrm{~m}, 1 \mathrm{H}) ;{ }^{13} \mathrm{C}$ NMR

S3 Pirrung, M. C.; Nunn, D.S. Tetrahedron Lett. 1992, 33, 6591-6594. 
$\left(100.0 \mathrm{MHz}, \mathrm{CDCl}_{3}\right) \delta 214.3,183.2,146.9,139.1,138.6,126.8,89.7,61.6,61.3,24.6$; IR (thin film) vmax 3485, 3055, 2975, 2886, 1666, 1635, 1393, 1307, 1142, 1096, 1001, $928 \mathrm{~cm}^{-1}$; CIHRMS $[\mathrm{M}+\mathrm{H}]^{+}$calculated for $\mathrm{C}_{10} \mathrm{H}_{12} \mathrm{BrO}_{4}: 274.9920$, found: 274.9932.

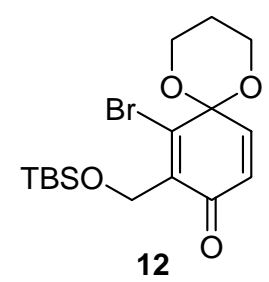

Quinone monoketal 12. Quinone monoketal 26 ( $8.30 \mathrm{~g}, 30.2 \mathrm{mmol})$, TBSCl (4.78 g, $31.7 \mathrm{mmol})$, and imidazole $(2.16 \mathrm{~g}, 31.7 \mathrm{mmol})$ were dissolved in 50 $\mathrm{mL}$ of anhydrous of $\mathrm{CH}_{2} \mathrm{Cl}_{2}$, and the reaction was stirred at $\mathrm{rt}$ for $6 \mathrm{~h}$. The reaction was quenched by addition of $\mathrm{pH} 7$ buffer and extracted with $\mathrm{CH}_{2} \mathrm{Cl}_{2}$. The combined organic layers were washed with brine, dried over $\mathrm{MgSO}_{4}$, filtered, and concentrated in vacuo. Purification on silica gel (hexane : EtOAc $=4: 1)$ provided $10.6 \mathrm{~g}(27.2 \mathrm{mmol}, 90 \%)$ of 12 as a yellow oil. ${ }^{1} \mathrm{H}$ NMR (400 MHz, $\left.\mathrm{CDCl}_{3}\right) 7.66(\mathrm{~d}, 1 \mathrm{H}, J=10.4 \mathrm{~Hz}), 6.28(\mathrm{~d}, 1 \mathrm{H}, J=10.4 \mathrm{~Hz}), 4.56(\mathrm{~s}, 2 \mathrm{H}), 4.25$ $(\mathrm{m}, 2 \mathrm{H}), 4.13(\mathrm{~m}, 2 \mathrm{H}), 2.37(\mathrm{~m}, 1 \mathrm{H}), 1.58(\mathrm{~m}, 1 \mathrm{H}), 0.88(\mathrm{~s}, 9 \mathrm{H}), 0.09(\mathrm{~s}, 6 \mathrm{H}) ;{ }^{13} \mathrm{C}$ NMR $(100.0$ $\left.\mathrm{MHz}, \mathrm{CDCl}_{3}\right) \delta 181.3,148.0,139.1,137.8,127.1,89.9,61.5,59.7,26.1,24.7,18.6,-5.0 ; \mathrm{IR}$ (thin film) vmax 2952, 2883, 1672, 1644, 1466, 1389, 1307, 1253, 1146, 1083, 1001, $835 \mathrm{~cm}^{-1}$; CIHRMS $[\mathrm{M}+\mathrm{H}]^{+}$calculated for $\mathrm{C}_{16} \mathrm{H}_{26} \mathrm{BrO}_{4}: 389.0784$, found: 389.0744 .

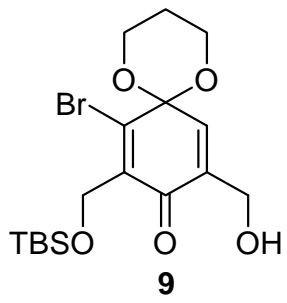

Quinone monoketal 9. Compound 12 (9.56 g, $24.6 \mathrm{mmol}), \mathrm{La}(\mathrm{OTf})_{3}(720.0$ $\mathrm{mg}, 1.23 \mathrm{mmol})$, and $\mathrm{N}\left(\mathrm{CH}_{2} \mathrm{CH}_{2} \mathrm{OH}\right)_{3}(1.84 \mathrm{~g}, 12.3 \mathrm{mmol})$ were placed in a $500 \mathrm{~mL}$ 2-necked round-bottomed flask and dissolved in $250 \mathrm{~mL}$ of anhydrous $\mathrm{CH}_{2} \mathrm{Cl}_{2}$. The reaction mixture was cooled to $-78{ }^{\circ} \mathrm{C}$. Another $50 \mathrm{~mL}$ round-bottomed flask containing paraformaldehyde $(7.34 \mathrm{~g}, 246$ mmol) was connected to the reaction flask via cannula and was heated at $150{ }^{\circ} \mathrm{C}$ to transfer the paraformaldehyde to the reaction flask as gaseous formaldehyde. $\mathrm{Et}_{3} \mathrm{P}(3.6 \mathrm{~mL}, 24.6 \mathrm{mmol})$ was added dropwise to the reaction mixture at $-78{ }^{\circ} \mathrm{C}$ for $30 \mathrm{~min}$ and the reaction was stirred at $-20{ }^{\circ} \mathrm{C}$. After $6 \mathrm{~h}, \mathbf{1 2}$ was shown to be fully consumed by TLC analysis. The reaction mixture was filtered through a Celite pad, washed with $\mathrm{CH}_{2} \mathrm{Cl}_{2}$, and concentrated in vacuo. Purification on silica gel (hexane : EtOAc $=1: 1)$ provided $7.22 \mathrm{~g}(17.2 \mathrm{mmol}, 70 \%)$ of quinone monoketal 9 as a yellow solid. m.p. 97-98 ${ }^{\circ} \mathrm{C} ;{ }^{1} \mathrm{H}$ NMR $\left(400 \mathrm{MHz}, \mathrm{CDCl}_{3}\right) 7.58(\mathrm{~s}, 1 \mathrm{H}), 4.48(\mathrm{~s}, 2 \mathrm{H}), 4.36(\mathrm{~s}, 2 \mathrm{H}), 4.18(\mathrm{~m}, 2 \mathrm{H}), 4.00(\mathrm{~m}$, $2 \mathrm{H}), 2.25(\mathrm{~m}, 1 \mathrm{H}), 1.48(\mathrm{~m}, 1 \mathrm{H}), 0.79(\mathrm{~s}, 9 \mathrm{H}), 0.01(\mathrm{~s}, 6 \mathrm{H}) ;{ }^{13} \mathrm{C}$ NMR $\left(100.0 \mathrm{MHz}, \mathrm{CDCl}_{3}\right) \delta$ 214.3, 181.8, 148.7, 138.9, 136.1, 132.6, 90.0, 61.5, 60.4, 59.7, 26.1, 25.9, 24.7, 18.7, -5.0; IR (thin film) vmax 3424, 2932, 2883, 1651, 1464, 1388, 1252, 1086, 999, $840 \mathrm{~cm}^{-1}$; CIHRMS $[\mathrm{M}+\mathrm{H}]^{+}$calculated for $\mathrm{C}_{17} \mathrm{H}_{28} \mathrm{BrO}_{5} \mathrm{Si}$ : 419.0889 , found: 419.0849 .

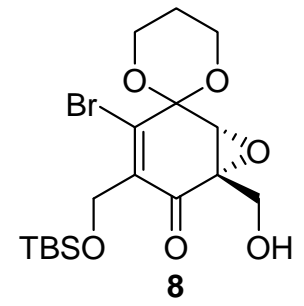

Epoxy ketone 8. $\mathrm{Ph}_{3} \mathrm{COOH}(6.07 \mathrm{~g}, 22.0 \mathrm{mmol})$ and activated $4 \AA \mathrm{MS}$ (400 mg) were dissolved in $60 \mathrm{~mL}$ of anhydrous toluene and $20.0 \mathrm{~mL}$ (20.0 mmol) of 1.0 M NaHMDS in THF was added at rt. After $20 \mathrm{~min}$, (1.87 g, $8.0 \mathrm{mmol}) \mathrm{D}$-DIPT in $40 \mathrm{~mL}$ of toluene was added, the reaction mixture was stirred for $20 \mathrm{~min}$ at $\mathrm{rt}$, and then cooled to $-78{ }^{\circ} \mathrm{C}$. Compound $9(1.68 \mathrm{~g}, 4.0 \mathrm{mmol})$ in $30 \mathrm{~mL}$ toluene was added dropwise and the reaction mixture was stirred at $-65{ }^{\circ} \mathrm{C}$ for $72 \mathrm{~h}$. The reaction was quenched with water and extracted with EtOAc. The combined organic layers were washed with brine, dried over $\mathrm{MgSO}_{4}$, filtered, and concentrated in vacuo. 
Purification on silica gel (hexane : EtOAc $=1: 1)$ provided $1.64 \mathrm{~g}(3.8 \mathrm{mmol}, 94 \%)$ of epoxide 8 as a colorless oil; ${ }^{1} \mathrm{H}$ NMR $\left(400 \mathrm{MHz}, \mathrm{CDCl}_{3}\right) 4.56(\mathrm{~d}, 1 \mathrm{H}, J=10.8 \mathrm{~Hz}), 4.49(\mathrm{~s}, 1 \mathrm{H}), 4.45(\mathrm{~d}$, $1 \mathrm{H}, J=10.8 \mathrm{~Hz}), 4.37(\mathrm{~m}, 2 \mathrm{H}), 4.10(\mathrm{~m}, 4 \mathrm{H}), 2.30(\mathrm{~m}, 1 \mathrm{H}), 1.85(1 \mathrm{H}, \mathrm{m}), 1.66(\mathrm{~m}, 1 \mathrm{H}), 0.85(\mathrm{~s}$, 9H), $0.07(\mathrm{~s}, 6 \mathrm{H}) ;{ }^{13} \mathrm{C} \mathrm{NMR} \quad\left(100.0 \mathrm{MHz}, \mathrm{CDCl}_{3}\right) \delta 190.4,146.2,137.3,92.8,61.6,61.4,60.6$, 59.5, 58.2, 53.8, 26.1, 24.4, 21.2, 18.6, 14.4, -5.08, -5.10; IR (thin film) vmax 3433, 2929, 2857, $1684,1622,1464,1250,1143,1086,841 \mathrm{~cm}^{-1}$; CIHRMS $[\mathrm{M}+\mathrm{H}]^{+}$calculated for $\mathrm{C}_{17} \mathrm{H}_{28} \mathrm{BrO}_{6} \mathrm{Si}$ : 435.0839 , found: $435.0827 ;[\alpha]_{\mathrm{D}}^{23}=-68^{\circ}\left(\mathrm{c}=0.1, \mathrm{CHCl}_{3}\right)$. The ee was determined to be $90 \%$ by HPLC analysis using a Regis chiral HPLC column (R,R) whelk-O1 $(25 \mathrm{~cm} \times 4.0 \mathrm{~mm}(3 \%$ isopropanol in hexane, retention times: 36.05 min (major enantiomer) and 43.78 min (minor enantiomer)).

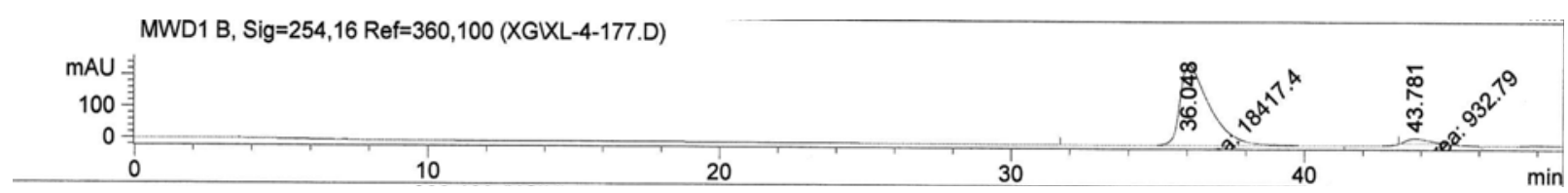

Signal 3: MWD1 B, Sig=254,16 Ref=360,100

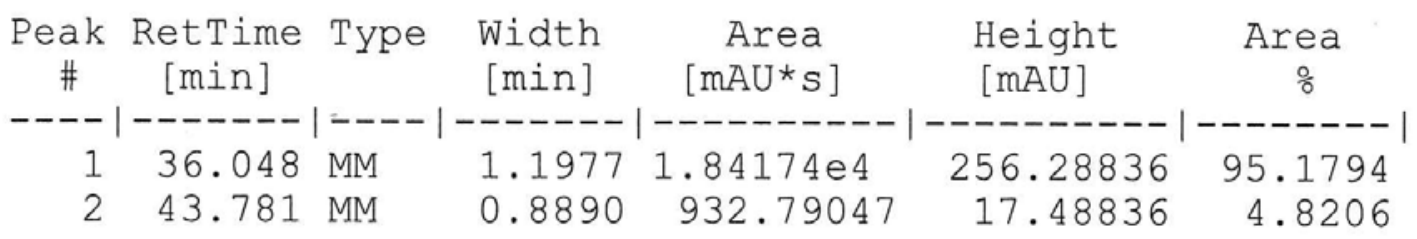

Totals : $\quad 1.93501 e 4 \quad 273.77672$

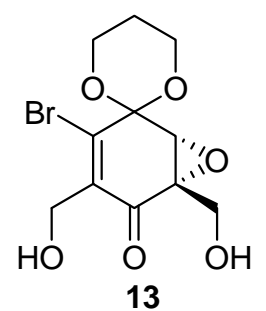

Epoxy alcohol 13. Epoxide 8 (43.5 $\mathrm{mg}, 0.1 \mathrm{mmol})$ was dissolved in $0.5 \mathrm{~mL}$ of anhydrous $\mathrm{CH}_{3} \mathrm{CN}$. To the reaction mixture was added triethylamine trihydrofluoride $\left(\mathrm{Et}_{3} \mathrm{~N}-3 \mathrm{HF}, 80 \mu \mathrm{L}, 0.5 \mathrm{mmol}\right)$. The reaction was stirred at $\mathrm{rt}$ for $12 \mathrm{~h}$, and concentrated in vacuo. Purification on silica gel (hexane : EtOAc $=1: 3)$ provided $31.5 \mathrm{mg}(0.098 \mathrm{mmol}, 98 \%)$ of 13 as a white solid. $\mathrm{mp}$ 174- $175^{\circ} \mathrm{C}$; ${ }^{1} \mathrm{H}$ NMR $\left(400 \mathrm{MHz}, \mathrm{CDCl}_{3}\right) 4.51$ (s, 2H), $4.35(\mathrm{~m}, 2 \mathrm{H}), 4.24(\mathrm{~m}$, $2 \mathrm{H}), 4.11(\mathrm{~m}, 3 \mathrm{H}), 2.36(\mathrm{~s}, 1 \mathrm{H}), 2.30(\mathrm{~m}, 1 \mathrm{H}), 1.82(\mathrm{~s}, 1 \mathrm{H}), 1.67(1 \mathrm{H}, \mathrm{m}) ;{ }^{13} \mathrm{C}$ NMR (100.0 MHz, CD $\left.{ }_{3} \mathrm{OD}\right) \delta 190.5,146.1,137.0,133.1,92.8,61.2,59.0$, 58.3, 57.1, 53.7, 24.3; IR (thin film) vmax 3347, 2926, 2857, 1650, 1458, 1240, 1120, $1079 \mathrm{~cm}^{-1}$; CIHRMS $[\mathrm{M}+\mathrm{H}]^{+}$calculated for $\mathrm{C}_{11} \mathrm{H}_{14} \mathrm{BrO}_{6}: 320.9975$, found: $320.9989 ;[\alpha]_{\mathrm{D}}{ }^{23}=-73^{\circ}(\mathrm{c}=$ $0.15, \mathrm{CH}_{3} \mathrm{OH}$ ). A suitable crystal of $\mathbf{1 3}$ for X-ray crystal structure analysis (see page S39) was obtained by slow evaporation from methanol.

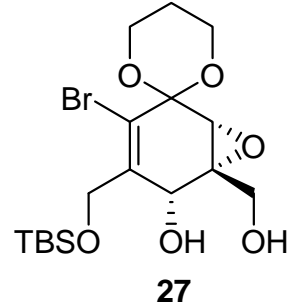

Diol 27. $\mathrm{Me}_{4} \mathrm{NBH}(\mathrm{OAc})_{3}(5.08 \mathrm{~g}, 19.3 \mathrm{mmol})$ and $\mathrm{AcOH}(3.0 \mathrm{~mL}, 49.0$ mmol) were dissolved in $15 \mathrm{~mL}$ of anhydrous $\mathrm{CH}_{3} \mathrm{CN}$, and epoxide 8 $(1.40 \mathrm{~g}, 3.2 \mathrm{mmol})$ in $15 \mathrm{~mL}$ of anhydrous $\mathrm{CH}_{3} \mathrm{CN}$ was added dropwise at $0{ }^{\circ} \mathrm{C}$. The reaction mixture was stirred at $0{ }^{\circ} \mathrm{C}$ for $24 \mathrm{~h}$. The reaction was quenched with sat. $\mathrm{NaHCO}_{3}$ and extracted with EtOAc. The combined organic layers were washed with brine, dried over $\mathrm{MgSO}_{4}$, filtered, and 
concentrated in vacuo. Purification on silica gel (hexane : EtOAc $=1: 2$ ) provided $1.27 \mathrm{~g}$ (2.9 mmol, $90 \%$ ) of diol 27 as a colorless oil. ${ }^{1} \mathrm{H}$ NMR $\left(400 \mathrm{MHz}, \mathrm{CDCl}_{3}\right) 4.68(\mathrm{~s}, 1 \mathrm{H}), 4.61(\mathrm{~d}, 1 \mathrm{H}$, $J=10.0 \mathrm{~Hz}), 4.48(\mathrm{~d}, 1 \mathrm{H}, J=10.0 \mathrm{~Hz}), 4.27(\mathrm{~m}, 3 \mathrm{H}), 4.12(\mathrm{~m}, 2 \mathrm{H}), 3.87(\mathrm{~d}, 1 \mathrm{H}, J=13.2 \mathrm{~Hz})$, $3.79(\mathrm{~s}, 1 \mathrm{H}), 2.50(\mathrm{~s}, 1 \mathrm{H}), 2.25(\mathrm{~m}, 1 \mathrm{H}), 1.56(\mathrm{~m}, 1 \mathrm{H}), 0.90(\mathrm{~s}, 9 \mathrm{H}), 0.12(\mathrm{~s}, 3 \mathrm{H}), 0.11(\mathrm{~s}, 3 \mathrm{H})$; ${ }^{13} \mathrm{C} \mathrm{NMR}\left(100.0 \mathrm{MHz}, \mathrm{CDCl}_{3}\right) \delta 137.9,121.8,93.1,67.1,65.8,62.3,61.8,61.3,61.1,52.8,26.0$, 24.5, 18.4, -5.2, -5.3; IR (thin film) vmax 3439, 2952, 2884, 1466, 1379, 1251, 1146, 1084, $1009,838 \mathrm{~cm}^{-1}$; CIHRMS [M+H] $]^{+}$calculated for $\mathrm{C}_{17} \mathrm{H}_{30} \mathrm{BrO}_{6} \mathrm{Si}: 437.0995$, found: 437.0990 ; $[\alpha]_{\mathrm{D}}^{23}=-75^{\mathrm{o}}\left(\mathrm{c}=0.1, \mathrm{CHCl}_{3}\right)$.

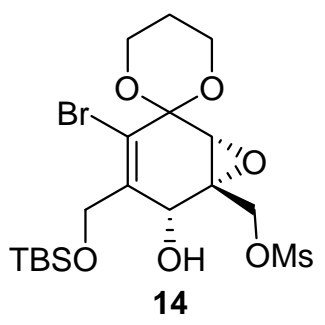

Epoxy mesylate 14. Diol $27(1.27 \mathrm{~g}, 2.9 \mathrm{mmol})$ was dissolved in $60 \mathrm{~mL}$ of anhydrous $\mathrm{CH}_{2} \mathrm{Cl}_{2}$. To this mixture was added $2,4,6$-collidine $(3.8 \mathrm{~mL}$, $29.0 \mathrm{mmol})$ at $\mathrm{rt}$. The reaction mixture was cooled to $0{ }^{\circ} \mathrm{C}$ and $\mathrm{MsCl}(240$ $\mu \mathrm{L}, 3.0 \mathrm{mmol}$ ) was added dropwise. The reaction mixture was stirred at $5{ }^{\circ} \mathrm{C}$ for $8 \mathrm{~h}$, then quenched with water and extracted with $\mathrm{CH}_{2} \mathrm{Cl}_{2}$. The combined organic layers were washed with brine, dried over $\mathrm{MgSO}_{4}$, filtered, and concentrated in vacuo. Purification on silica gel (hexane : EtOAc $=2: 1)$ provided $1.26 \mathrm{~g}(2.5 \mathrm{mmol}, 85 \%)$ of $\mathbf{1 4}$ as a colorless oil. ${ }^{1} \mathrm{H}$ NMR (400 MHz, $\left.\mathrm{CDCl}_{3}\right) 4.75(\mathrm{~s}, 1 \mathrm{H}), 4.72(\mathrm{~d}, 1 \mathrm{H}, J=12.0 \mathrm{~Hz}), 4.58(\mathrm{~d}, 1 \mathrm{H}, J=14.0 \mathrm{~Hz}), 4.45$ $(\mathrm{d}, 1 \mathrm{H}, J=14.0 \mathrm{~Hz}), 4.35(\mathrm{~d}, 1 \mathrm{H}, J=12.0 \mathrm{~Hz}), 4.25(\mathrm{~m}, 2 \mathrm{H}), 4.20(\mathrm{~s}, 1 \mathrm{H}), 4.11(\mathrm{~m}, 2 \mathrm{H}), 3.95(\mathrm{~d}$, $1 \mathrm{H}, J=4.4 \mathrm{~Hz}), 3.06(\mathrm{~s}, 3 \mathrm{H}), 2.24(\mathrm{~m}, 1 \mathrm{H}), 1.56(\mathrm{~m}, 1 \mathrm{H}), 0.86(\mathrm{~s}, 9 \mathrm{H}), 0.10(\mathrm{~s}, 3 \mathrm{H}), 0.09(\mathrm{~s}, 3 \mathrm{H})$; ${ }^{13} \mathrm{C} \mathrm{NMR}\left(100.0 \mathrm{MHz}, \mathrm{CDCl}_{3}\right) \delta 137.3,121.0,93.0,68.0,66.6,66.3,61.8,61.4,60.0,54.1,38.1$, 26.0, 24.4, 18.3, -5.2, -5.3; IR (thin film) vmax 3491, 2952, 2860, 1466, 1357, 1252, 1175, 1079 , $1009,837 \mathrm{~cm}^{-1}$; CIHRMS [M+H] ${ }^{+}$calculated for $\mathrm{C}_{18} \mathrm{H}_{32} \mathrm{BrO}_{8} \mathrm{SSi}: 515.0771$, found: 515.0803 ; $[\alpha]_{\mathrm{D}}^{23}=-45^{\mathrm{o}}\left(\mathrm{c}=0.1, \mathrm{CHCl}_{3}\right)$.

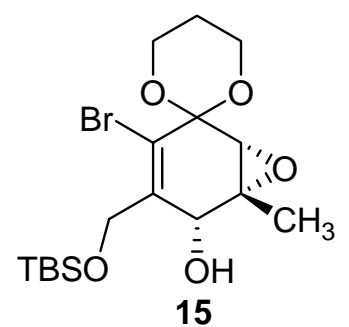

Epoxy alcohol 15. Compound 14 (1.26 g, $2.5 \mathrm{mmol})$ was dissolved in $25 \mathrm{~mL}$ of anhydrous dichloroethane and $8.8 \mathrm{~mL}(8.8 \mathrm{mmol})$ of Super-Hydride (1.0 M in THF) was added at $60{ }^{\circ} \mathrm{C}$. After stirring for 30 $\min$ at $60{ }^{\circ} \mathrm{C}$, the reaction mixture was quenched with sat. aqueous $\mathrm{NH}_{4} \mathrm{Cl}$ and extracted with $\mathrm{CH}_{2} \mathrm{Cl}_{2}$. The combined organic layers were washed with brine, dried over $\mathrm{MgSO}_{4}$, filtered, and concentrated in vacuo. Purification on silica gel (hexane : EtOAc $=3: 1$ ) provided 980 $\mathrm{mg}(2.3 \mathrm{mmol}, 95 \%)$ of $\mathbf{1 5}$ as a colorless oil. ${ }^{1} \mathrm{H}$ NMR $(400 \mathrm{MHz}$, $\left.\mathrm{CDCl}_{3}\right) 4.60(\mathrm{~d}, 1 \mathrm{H}, J=13.6 \mathrm{~Hz}), 4.53(\mathrm{~s}, 1 \mathrm{H}), 4.46(\mathrm{~d}, 1 \mathrm{H}, J=13.6 \mathrm{~Hz}), 4.26(\mathrm{~m}, 2 \mathrm{H}), 4.12(\mathrm{~m}$, 2H), $3.88(\mathrm{~s}, 1 \mathrm{H}), 2.25(\mathrm{~m}, 1 \mathrm{H}), 1.60(\mathrm{~s}, 3 \mathrm{H}), 1.56(\mathrm{~m}, 1 \mathrm{H}), 0.90(\mathrm{~s}, 9 \mathrm{H}), 0.11(\mathrm{~s}, 3 \mathrm{H}), 0.10(\mathrm{~s}$, $3 \mathrm{H}) ;{ }^{13} \mathrm{C} \mathrm{NMR}\left(100.0 \mathrm{MHz}, \mathrm{CDCl}_{3}\right) \delta 138.5,121.3,93.3,70.0,65.9,61.8,61.2,59.9,56.7,26.0$, 25.8, 24.6, 20.2, 18.4, -5.2, -5.3; IR (thin film) vmax 3465, 2932, 2860, 1465, 1380, 1251, 1147 , 1078, 1007, $837 \mathrm{~cm}^{-1}$; CIHRMS $[\mathrm{M}+\mathrm{H}]^{+}$calculated for $\mathrm{C}_{17} \mathrm{H}_{30} \mathrm{BrO}_{5} \mathrm{Si}: 421.1046$, found: $421.1076 ;[\alpha]_{\mathrm{D}}^{23}=-70^{\circ}\left(\mathrm{c}=0.1, \mathrm{CHCl}_{3}\right)$.

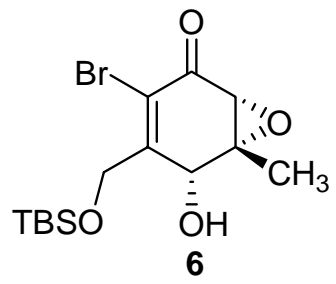

Epoxy ketone 6. Compound 15 (980.0 mg, $2.3 \mathrm{mmol})$ was dissolved in 45 $\mathrm{mL}$ of anhydrous $\mathrm{CH}_{2} \mathrm{Cl}_{2}$ and $\mathrm{K}-10$ clay $(2.3 \mathrm{~g})$ was added in 3 portions at $\mathrm{rt}$ over $2 \mathrm{~h}$. After stirring for an additional $2 \mathrm{~h}$ at $\mathrm{rt}$, the reaction mixture was filtered through a Celite pad and washed with $\mathrm{CH}_{2} \mathrm{Cl}_{2}$. The combined 
organic layers were washed with sat. $\mathrm{NaHCO}_{3}$, brine, and dried over $\mathrm{MgSO}_{4}$ and $\mathrm{KHCO}_{3} .{ }^{\mathrm{S} 4}$ The solution was filtered and concentrated in vacuo. Purification on silica gel (hexane : EtOAc $=5: 1$ ) provided $740 \mathrm{mg}(2.0 \mathrm{mmol}, 90 \%)$ of 6 as a colorless oil. ${ }^{1} \mathrm{H}$ NMR $4.69(\mathrm{~d}, 1 \mathrm{H}, J=16.0 \mathrm{~Hz})$, $4.64(\mathrm{~s}, 1 \mathrm{H}), 4.56(\mathrm{~d}, 1 \mathrm{H}, J=16.0 \mathrm{~Hz}), 4.12(\mathrm{~s}, 1 \mathrm{H}), 3.42(\mathrm{~s}, 1 \mathrm{H}), 1.60(\mathrm{~s}, 3 \mathrm{H}), 0.90(\mathrm{~s}, 9 \mathrm{H}), 0.10$ $(\mathrm{s}, 3 \mathrm{H}), 0.09(\mathrm{~s}, 3 \mathrm{H}) ;{ }^{13} \mathrm{C} \mathrm{NMR}\left(100.0 \mathrm{MHz}, \mathrm{CDCl}_{3}\right) \delta 187.2,155.5,116.8,70.8,66.8,60.5$, 58.9, 26.0, 25.7, 19.4, 18.3, -5.3, -5.4; IR (thin film) vmax 3492, 2934, 2860, 1694, 1609, 1464, 1382, 1256, 1178, 1099, 938, $837 \mathrm{~cm}^{-1}$; CIHRMS $[\mathrm{M}+\mathrm{H}]^{+}$calculated for $\mathrm{C}_{14} \mathrm{H}_{24} \mathrm{BrO}_{4} \mathrm{Si}$ : 363.0627, found: $363.0647 ;[\alpha]_{\mathrm{D}}^{23}=-31^{\mathrm{o}}\left(\mathrm{c}=0.08, \mathrm{CHCl}_{3}\right)$.<smiles>COc1cccc2c1C(=O)C=C(Br)C2=O</smiles>

mmol, 85\%) of 17 as a yellow solid. $\mathrm{mp} 145-146{ }^{\circ} \mathrm{C} ;{ }^{1} \mathrm{H}$ NMR $\left(400 \mathrm{MHz}, \mathrm{CDCl}_{3}\right) 7.89(\mathrm{~d}, 1 \mathrm{H}$, $J=8.0 \mathrm{~Hz}), 7.67(\mathrm{t}, 1 \mathrm{H}, J=8.0 \mathrm{~Hz}), 7.57(\mathrm{~d}, 1 \mathrm{H}, J=8.0 \mathrm{~Hz}), 7.41(\mathrm{~s}, 1 \mathrm{H}), 5.37(\mathrm{~s}, 2 \mathrm{H}), 3.54(\mathrm{~s}$, $3 \mathrm{H}) ;{ }^{13} \mathrm{C} \mathrm{NMR}\left(100.0 \mathrm{MHz}, \mathrm{CDCl}_{3}\right) \delta 181.5,178.3,157.7,142.5,142.2,137.3,135.0,133.2$, 122.9, 122.1, 95.3, 56.9; IR (thin film) vmax 2965, 2862, 1675, 1655, 1604, 1582, 1461, 1236, 1156, 1087, 994, $881 \mathrm{~cm}^{-1}$; CIHRMS $[\mathrm{M}+\mathrm{H}]^{+}$calculated for $\mathrm{C}_{12} \mathrm{H}_{10} \mathrm{BrO}_{4}$ : 296.9762, found: 296.9786.<smiles>COc1cc(Br)cc(OC)c1OC</smiles>

Bromonaphthalene 18. A suspension of 17 (3.84 g, $12.8 \mathrm{mmol})$ in $100 \mathrm{~mL}$ of $\mathrm{Et}_{2} \mathrm{O}$ was shaken in a separatory funnel with a freshly prepared solution of sodium dithionate $\left(\mathrm{Na}_{2} \mathrm{~S}_{2} \mathrm{O}_{4}, 11.1 \mathrm{~g}, 64.0 \mathrm{mmol}\right)$ in $50 \mathrm{~mL}$ of water. After the mixture was shaken for $10 \mathrm{~min}$, the organic layer was separated, washed with brine, dried over $\mathrm{MgSO}_{4}$, filtered, and concentrated in vacuo to provide the desired hydroquinone intermediate as a grey solid. ${ }^{\mathrm{S} 5}$ The crude product (3.84 g, $12.8 \mathrm{mmol}$ ) was dissolved in $50 \mathrm{~mL}$ of anhydrous $\mathrm{CH}_{2} \mathrm{Cl}_{2}$. DIEA $(11.0 \mathrm{~mL}, 64.0 \mathrm{mmol})$ was added at $0{ }^{\circ} \mathrm{C}$ followed by $\mathrm{MOMCl}(3.9 \mathrm{~mL}, 51.2 \mathrm{mmol})$. The reaction mixture was stirred at $\mathrm{rt}$ for $24 \mathrm{~h}$, then quenched with water, and extracted with $\mathrm{CH}_{2} \mathrm{Cl}_{2}$. The combined organic layers were washed with brine, dried over $\mathrm{MgSO}_{4}$, filtered, and concentrated in vacuo. Purification on silica gel (hexane : EtOAc $=2: 1)$ provided $3.45 \mathrm{~g}(9.0$ mmol, $70 \%$ ) of 17 as a yellow oil. ${ }^{1} \mathrm{H}$ NMR (400 MHz, $\left.\mathrm{CDCl}_{3}\right) 7.85(\mathrm{~d}, 1 \mathrm{H}, J=8.0 \mathrm{~Hz}), 7.43$ (t, $1 \mathrm{H}, J=8.0 \mathrm{~Hz}), 7.21(\mathrm{~s}, 1 \mathrm{H}), 7.13(\mathrm{~d}, 1 \mathrm{H}, J=8.0 \mathrm{~Hz}), 5.27(\mathrm{~s}, 2 \mathrm{H}), 5.24(\mathrm{~s}, 2 \mathrm{H}), 5.19(\mathrm{~s}, 2 \mathrm{H})$, $3.72(\mathrm{~s}, 3 \mathrm{H}), 3.59(\mathrm{~s}, 3 \mathrm{H}), 3.58(\mathrm{~s}, 3 \mathrm{H}) ;{ }^{13} \mathrm{C} \mathrm{NMR}\left(100.0 \mathrm{MHz}, \mathrm{CDCl}_{3}\right) \delta 154.2,150.8,145.9$, $132.7,129.3,128.4,127.8,117.5,116.7,113.5,100.6,97.0,96.5,58.8,58.5,56.8$, ; IR (thin film) vmax 2944, 2829, 1580, 1459, 1369, 1253, 1157, 1051, 1001, 958, $810 \mathrm{~cm}^{-1}$; CIHRMS $[\mathrm{M}]^{+}$calculated for $\mathrm{C}_{16} \mathrm{H}_{19} \mathrm{BrO}_{6}: 386.0365$, found: 386.0317 .

\footnotetext{
S4 Shotwell, J. B.; Hu, S.; Medina, E.; Abe, M.; Cole, R.; Crews, C. M.; Wood, J. L. Tetrahedron Lett. 2000, 41, 9639

S5 Jung, M.; Hagenah, J. A. J. Org. Chem. 1987, 52, 1889
} 
<smiles>CCCSc1cc(OC)c2cccc(OC)c2c1OC</smiles>

Stannane 7. $\mathrm{Pd}\left(\mathrm{PPh}_{3}\right)_{4}(560.0 \mathrm{mg}, 0.48 \mathrm{mmol})$ was placed in a dry Schlenk flask, and compound 18 (1.86 g, $4.8 \mathrm{mmol})$ in $15 \mathrm{~mL}$ of anhydrous toluene was added to the flask at $\mathrm{rt}$. The reaction mixture was degassed using three "freeze-pump-thaw" cycles. The reaction mixture was heated at $110{ }^{\circ} \mathrm{C}$ for $10 \mathrm{~min}$, and bis(tributyltin) $(3.1 \mathrm{~mL}$, $6.0 \mathrm{mmol}$ ) was added. (Note: The order of addition of bis(tributyltin) was found to be critical for success of the stannylation). After stirring for $24 \mathrm{~h}$ at $110^{\circ} \mathrm{C}$, the reaction mixture was concentrated in vacuo. Purification on silica gel (hexane $: \mathrm{Et}_{3} \mathrm{~N}=9: 1$, hexane $:$ EtOAc $\left.=5: 1\right)$ provided $1.9 \mathrm{~g}(3.3 \mathrm{mmol}, 70 \%)$ of 7 as a yellow oil. ${ }^{1} \mathrm{H}$ NMR $\left(400 \mathrm{MHz}, \mathrm{CDCl}_{3}\right) 7.86(\mathrm{~d}, 1 \mathrm{H}, J=8.0 \mathrm{~Hz}), 7.37(\mathrm{t}, 1 \mathrm{H}, J=8.0 \mathrm{~Hz}), 7.10(\mathrm{~d}, 1 \mathrm{H}, J$ $=8.0 \mathrm{~Hz}), 7.08(\mathrm{~s}, 1 \mathrm{H}), 5.27(\mathrm{~s}, 2 \mathrm{H}), 5.21(\mathrm{~s}, 2 \mathrm{H}), 5.03(\mathrm{~s}, 2 \mathrm{H}), 3.61(\mathrm{~s}, 3 \mathrm{H}), 3.60(\mathrm{~s}, 3 \mathrm{H}), 3.58(\mathrm{~s}$, $3 \mathrm{H}), 1.54(\mathrm{~m}, 6 \mathrm{H}), 1.34(\mathrm{~m}, 6 \mathrm{H}), 1.15(\mathrm{t}, 6 \mathrm{H}, J=8.0 \mathrm{~Hz}), 0.90(\mathrm{t}, 9 \mathrm{H}, J=8.0 \mathrm{~Hz})$; ${ }^{13} \mathrm{C} \mathrm{NMR}$ $\left(100.0 \mathrm{MHz}, \mathrm{CDCl}_{3}\right) \delta 154.7,153.9,149.7,131.3,131.1,126.2,121.7,117.6,113.2,100.9,97.8$, 96.7, 57.9, 56.5, 56.2, 30.9, 30.6, 29.5, 29.4, 29.3, 29.1, 27.9, 27.7, 27.4, 13.9, 13.7, 10.7, 10.4, 10.2 ; IR (thin film) vmax 2954, 2923, 1579, 1458, 1357, 1252, 1156, 1047, $975 \mathrm{~cm}^{-1}$; CIHRMS $[\mathrm{M}]^{+}$calculated for $\mathrm{C}_{28} \mathrm{H}_{46} \mathrm{O}_{6} \mathrm{Sn}: 598.2316$, found: 598.2345

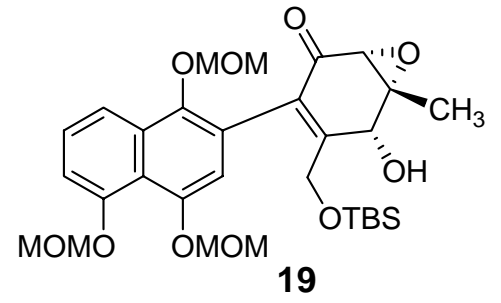

was added at $70{ }^{\circ} \mathrm{C}$, followed by DIEA $(250 \mu \mathrm{L}, 1.6 \mathrm{mmol})$. After stirring for $4 \mathrm{~h}$ at $70{ }^{\circ} \mathrm{C}$, the reaction mixture was concentrated in vacuo. Purification on silica gel (hexane : EtOAc $=2: 1$ ) provided $570 \mathrm{mg}(0.95 \mathrm{mmol}, 70 \%)$ of 19 as a yellow oil $\left(2: 1\right.$ mixture of rotamers by ${ }^{1} \mathrm{H}$ NMR at rt). ${ }^{1} \mathrm{H}$ NMR $\left(400 \mathrm{MHz}, \mathrm{CDCl}_{3}\right.$, major rotamer reported) $7.86(\mathrm{~d}, 1 \mathrm{H}, J=8.0 \mathrm{~Hz}), 7.40(\mathrm{t}, 1 \mathrm{H}$, $J=8.0 \mathrm{~Hz}), 7.14(\mathrm{~d}, 1 \mathrm{H}, J=8.0 \mathrm{~Hz}), 6.80(\mathrm{~s}, 1 \mathrm{H}), 5.28(\mathrm{~m}, 2 \mathrm{H}), 5.19(\mathrm{~m}, 2 \mathrm{H}), 4.86(\mathrm{~m}, 2 \mathrm{H})$, $4.60(\mathrm{~d}, 1 \mathrm{H}, J=14.8 \mathrm{~Hz}), 4.42(\mathrm{~s}, 1 \mathrm{H}), 4.23(\mathrm{~d}, 1 \mathrm{H}, J=14.8 \mathrm{~Hz}), 3.90(\mathrm{~s}, 1 \mathrm{H}), 3.59(\mathrm{~s}, 3 \mathrm{H}), 3.56$ $(\mathrm{s}, 3 \mathrm{H}), 3.48(\mathrm{~s}, 3 \mathrm{H}), 1.73(\mathrm{~s}, 3 \mathrm{H}), 0.85(\mathrm{~s}, 9 \mathrm{H}),-0.04(\mathrm{~s}, 6 \mathrm{H}) ;{ }^{13} \mathrm{C} \mathrm{NMR}\left(100.0 \mathrm{MHz}, \mathrm{CDCl}_{3}\right.$, both rotamers reported) $\delta 193.8,154.2,154.0,150.0,146.7,132.0,128.6,126.9,122.8,117.7$, $117.4,114.5,114.0,113.9,100.5,100.3,97.1,96.7,70.4,69.9,64.0,63.5,60.3,58.3,57.7,56.6$, 25.9, 25.6, 19.5, 18.3, -5.4; IR (thin film) vmax 3491, 2928, 2858, 1695, 1607, 1461, 1374, 1258, 1094, $834 \mathrm{~cm}^{-1}$; CIHRMS [M+Na] ${ }^{+}$calculated for $\mathrm{C}_{30} \mathrm{H}_{42} \mathrm{O}_{10} \mathrm{NaSi}$ : 613.2445, found: 613.2453. $[\alpha]_{\mathrm{D}}^{23}=+10^{\circ}\left(\mathrm{c}=0.10, \mathrm{CHCl}_{3}\right)$.

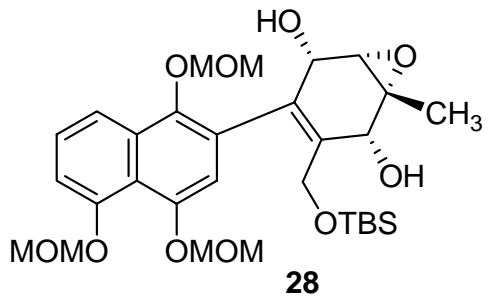

Epoxy alcohol 28. Compound 19 (405 $\mathrm{mg}, 0.69 \mathrm{mmol})$ was dissolved in $10.0 \mathrm{~mL}$ of anhydrous THF and $1.7 \mathrm{~mL}(1.7 \mathrm{mmol})$ Super-Hydride (1.0 $\mathrm{M}$ in THF) was slowly added at $-78{ }^{\circ} \mathrm{C}$. After stirring for $1 \mathrm{~h} \mathrm{~min}$ at $-78{ }^{\circ} \mathrm{C}$, the reaction mixture was quenched with sat. aqueous $\mathrm{NH}_{4} \mathrm{Cl}$ and extracted with EtOAc. The combined organic layers were washed with brine, dried over 
$\mathrm{MgSO}_{4}$, filtered, and concentrated in vacuo. Purification on silica gel (hexane : EtOAc $=1: 1$ ) provided $325 \mathrm{mg}(0.55 \mathrm{mmol}, 80 \%)$ of 28 as a yellow oil (single rotamer by ${ }^{1} \mathrm{H} \mathrm{NMR}$ at $\left.\mathrm{rt}\right) .{ }^{1} \mathrm{H}$ NMR $\left(400 \mathrm{MHz}, \mathrm{CDCl}_{3}\right) 7.62(\mathrm{~d}, 1 \mathrm{H}, J=8.0 \mathrm{~Hz}), 7.41(\mathrm{t}, 1 \mathrm{H}, J=8.0 \mathrm{~Hz}), 7.13(\mathrm{~d}, 1 \mathrm{H}, J=8.0$ $\mathrm{Hz}), 6.80(\mathrm{~s}, 1 \mathrm{H}), 5.27(\mathrm{~m}, 2 \mathrm{H}), 5.16(\mathrm{~m}, 4 \mathrm{H}), 4.87(\mathrm{~d}, 1 \mathrm{H}, J=6.4 \mathrm{~Hz}), 4.67(\mathrm{~d}, 1 \mathrm{H}, J=11.2 \mathrm{~Hz})$, $4.62(\mathrm{~d}, 1 \mathrm{H}, J=5.2 \mathrm{~Hz}), 4.39$ (d, 1H, $J=12.4 \mathrm{~Hz}), 4.12(\mathrm{~d}, 1 \mathrm{H}, J=7.6 \mathrm{~Hz}), 3.93(\mathrm{~d}, 1 \mathrm{H}, J=12.4$ $\mathrm{Hz}), 3.63(\mathrm{~s}, 3 \mathrm{H}), 3.56(\mathrm{~s}, 3 \mathrm{H}), 3.51(\mathrm{~s}, 3 \mathrm{H}), 3.39(\mathrm{~d}, 1 \mathrm{H}, J=6.4 \mathrm{~Hz}), 1.62(\mathrm{~s}, 3 \mathrm{H}), 0.79(\mathrm{~s}, 9 \mathrm{H})$, $-0.13(\mathrm{~s}, 3 \mathrm{H}),-0.15$ (s, 3H); ${ }^{13} \mathrm{C}$ NMR $\left(100.0 \mathrm{MHz}, \mathrm{CDCl}_{3}\right) \delta 154.2,150.8,147.1,134.5,131.8$, $129.5,127.3,127.2,120.1,117.1,117.0,113.7,111.8,100.2,100.0,97.0,96.8,96.7,69.8,67.6$, $62.9,62.4,60.3,58.8,56.6,56.5,26.0,20.2,18.3,-5.4,-5.5$; IR (thin film) vmax 3431, 2929, 2857, 1597, 1463, 1370, 1254, 1155, 1055, 979, $840 \mathrm{~cm}^{-1}$; CIHRMS [M+Na ${ }^{+}$calculated for $\mathrm{C}_{30} \mathrm{H}_{44} \mathrm{O}_{10} \mathrm{NaSi}$ : 615.2601, found: 615.2635. $[\alpha]_{\mathrm{D}}{ }^{23}=+45^{\circ}\left(\mathrm{c}=0.10, \mathrm{CHCl}_{3}\right)$.

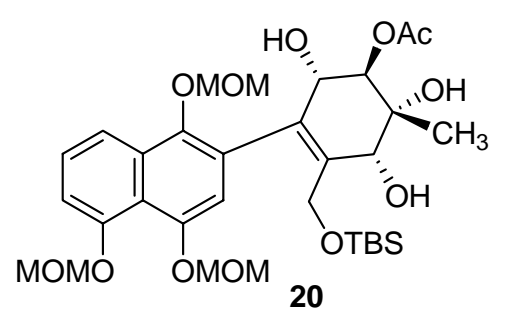

Triol 20. Compound 28 (240 $\mathrm{mg}, 0.40 \mathrm{mmol})$ and activated $4 \AA$ MS (60 mg) were dissolved in $2.0 \mathrm{~mL}$ of anhydrous $\mathrm{CH}_{2} \mathrm{Cl}_{2}$ and $\mathrm{Ti}^{i}(\mathrm{PrO})_{4}(240.0 \mu \mathrm{L}, 0.80 \mathrm{mmol})$ was added slowly at $\mathrm{rt}$. After stirring for $30 \mathrm{~min}$ at $\mathrm{rt}$, a solution of $\mathrm{Bu}_{4} \mathrm{NOAc}(360 \mathrm{mg}, 1.2$ mmol) in $2.0 \mathrm{~mL}$ of anhydrous $\mathrm{CH}_{2} \mathrm{Cl}_{2}$ was added to the reaction mixture dropwise at $0{ }^{\circ} \mathrm{C}$. Stirring was continued for $10 \mathrm{~h}$ at $\mathrm{rt}$, at which time the reaction was diluted with EtOAc and quenched with $0.3 \mathrm{~N}$ solution of aqueous acetic acid. The mixture was filtered through a Celite pad and washed with EtOAc. The combined organic layer was washed with sat. aqueous $\mathrm{NaHCO}_{3}$, brine, and dried over $\mathrm{MgSO}_{4}$ and $\mathrm{KHCO}_{3}$. The solution was filtered and concentrated in vacuo. Purification on silica gel (hexane : EtOAc $=1: 1$ ) provided $156 \mathrm{mg}$ $(0.24 \mathrm{mmol}, 60 \%)$ of 20 as a yellow oil (8:1 mixture of rotamers by ${ }^{1} \mathrm{H}$ NMR at $\left.\mathrm{rt}\right) .{ }^{1} \mathrm{H}$ NMR (400 MHz, $\mathrm{CDCl}_{3}$, major rotamer reported) $7.64(\mathrm{~d}, 1 \mathrm{H}, J=8.0 \mathrm{~Hz}), 7.43(\mathrm{t}, 1 \mathrm{H}, J=8.0 \mathrm{~Hz})$, $7.14(\mathrm{~d}, 1 \mathrm{H}, J=8.0 \mathrm{~Hz}), 6.69(\mathrm{~s}, 1 \mathrm{H}), 5.41(\mathrm{~d}, 1 \mathrm{H}, J=8.4 \mathrm{~Hz}), 5.29(\mathrm{~m}, 2 \mathrm{H}), 5.20(\mathrm{~m}, 2 \mathrm{H}), 5.12$ $(\mathrm{d}, 1 \mathrm{H}, J=6.8 \mathrm{~Hz}), 4.96(\mathrm{~d}, 1 \mathrm{H}, J=6.8 \mathrm{~Hz}), 4.30(\mathrm{~d}, 1 \mathrm{H}, J=6.4 \mathrm{~Hz}), 4.25(\mathrm{~s}, 1 \mathrm{H}), 3.96(\mathrm{~d}, 1 \mathrm{H}, J$ $=12.0 \mathrm{~Hz}), 3.78(\mathrm{~d}, 1 \mathrm{H}, J=12.0 \mathrm{~Hz}), 3.70(\mathrm{~s}, 3 \mathrm{H}), 3.59(\mathrm{~s}, 3 \mathrm{H}), 3.57(\mathrm{~s}, 3 \mathrm{H}), 3.20(\mathrm{~s}, 1 \mathrm{H}), 2.19$ $(\mathrm{s}, 3 \mathrm{H}), 1.29$ (s, 3H), 0.85 (s, $9 \mathrm{H}),-0.04(\mathrm{~s}, 3 \mathrm{H}),-0.07$ (s, 3H); ${ }^{13} \mathrm{C} \mathrm{NMR}\left(100.0 \mathrm{MHz}, \mathrm{CDCl}_{3}\right.$, both rotamers reported) $\delta 154.2,150.8,147.1,134.5,131.8,129.5,127.3,127.2,120.1,117.1$, 117.0, 113.7, 111.8, 100.2, 100.0, 97.0, 96.8, 96.7, 69.8, 67.6, 62.9, 62.4, 60.3, 58.8, 56.6, 56.5, 26.0, 20.2, 18.3, -5.4, -5.5; IR (thin film) vmax 3431, 2929, 2857, 1597, 1463, 1370, 1254, 1155 , 1055, 979, $840 \mathrm{~cm}^{-1}$; CIHRMS $[\mathrm{M}+\mathrm{Na}]^{+}$calculated for $\mathrm{C}_{32} \mathrm{H}_{48} \mathrm{O}_{12} \mathrm{NaSi}$ : 675.2813, found: 675.2846. $[\alpha]_{\mathrm{D}}^{23}=-18^{\circ}\left(\mathrm{c}=0.10, \mathrm{CHCl}_{3}\right)$.

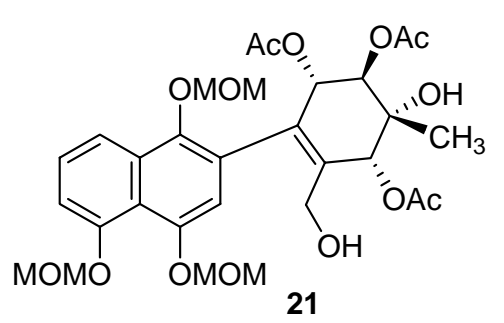

Alcohol 21. Compound 20 (120 mg, $0.18 \mathrm{mmol})$ was dissolved in $1.0 \mathrm{~mL}$ of anhydrous pyridine and acetic anhydride $(0.5 \mathrm{~mL})$ was added at $\mathrm{rt}$. After stirring for $2 \mathrm{~h}$ at $\mathrm{rt}$, the reaction mixture was quenched with sat. aqueous $\mathrm{NaHCO}_{3}$ and extracted with EtOAc. The combined organic layers were washed with sat. $\mathrm{NaHCO}_{3}$, brine, and dried over $\mathrm{MgSO}_{4}$. The solution was filtered and concentrated in vacuo to provide $140 \mathrm{mg}$ of the intermediate triacetate silyl ether as a yellow oil. The crude compound (140 $\mathrm{mg}, 0.18 \mathrm{mmol}$ ) was dissolved in $1.0 \mathrm{~mL}$ of anhydrous $\mathrm{CH}_{3} \mathrm{CN}$ and $\mathrm{Et}_{3} \mathrm{~N}-3 \mathrm{HF}(90 \mu \mathrm{L}, 0.57$ 
mmol) was added at $\mathrm{rt}$. After stirring for $12 \mathrm{~h}$ at $\mathrm{rt}$, the reaction mixture was concentrated in vacuo. Purification on silica gel (hexane : EtOAc $=1: 2)$ provided $78 \mathrm{mg}(0.12 \mathrm{mmol}, 67 \%)$ of 21 as a yellow oil (1.3:1 mixture of rotamers by ${ }^{1} \mathrm{H}$ NMR at $\left.\mathrm{rt}\right) .{ }^{1} \mathrm{H}$ NMR (400 $\mathrm{MHz}, \mathrm{CDCl}_{3}$, major rotamer reported) $7.89(\mathrm{~d}, 1 \mathrm{H}, J=8.0 \mathrm{~Hz}), 7.44(\mathrm{t}, 1 \mathrm{H}, J=8.0 \mathrm{~Hz}), 7.15(\mathrm{~d}, 1 \mathrm{H}, J=8.0 \mathrm{~Hz}), 6.71$ $(\mathrm{s}, 1 \mathrm{H}), 6.10(\mathrm{~d}, 1 \mathrm{H}, J=8.0 \mathrm{~Hz}), 5.69(\mathrm{~s}, 1 \mathrm{H}), 5.51(\mathrm{~d}, 1 \mathrm{H}, J=8.0 \mathrm{~Hz}), 5.29(\mathrm{~m}, 2 \mathrm{H}), 5.20(\mathrm{~m}$, 2H), $4.98(\mathrm{~m}, 2 \mathrm{H}), 4.14(\mathrm{~m}, 1 \mathrm{H}), 3.90(\mathrm{~s}, 1 \mathrm{H}), 3.60(\mathrm{~s}, 3 \mathrm{H}), 3.58(\mathrm{~s}, 3 \mathrm{H}), 3.54(\mathrm{~s}, 3 \mathrm{H}), 2.95(\mathrm{~s}$, $1 \mathrm{H}), 2.43(\mathrm{~s}, 1 \mathrm{H}), 2.22(\mathrm{~s}, 3 \mathrm{H}), 2.13(\mathrm{~s}, 3 \mathrm{H}), 1.64(\mathrm{~s}, 3 \mathrm{H}), 1.44(\mathrm{~s}, 3 \mathrm{H}) ;{ }^{13} \mathrm{C}$ NMR $(100.0 \mathrm{MHz}$, $\mathrm{CDCl}_{3}$, both rotamers reported) $\delta 171.6,171.0,169.8,154.0,136.1,135.4,132.1,131.7,130.0$, $127.1,123.8,117.7,116.2,113.9,113.2,112.2,111.5,101.0,100.0,97.2,97.0,96.7,75.0,72.8$, $72.5,72.1,61.1,60.5,58.1,56.7,56.6,25.9,25.7,21.5,21.2,20.6$; IR (thin film) vmax 3473 , 2929, 2857, 1738, 1650, 1597, 1459, 1372, 1231, 1156, $1044 \mathrm{~cm}^{-1}$; CIHRMS [M+H] $]^{+}$calculated for $\mathrm{C}_{30} \mathrm{H}_{39} \mathrm{O}_{14}: 623.2340$, found: $623.2312 .[\alpha]_{\mathrm{D}}^{23}=-5^{\mathrm{o}}\left(\mathrm{c}=0.20, \mathrm{CHCl}_{3}\right)$.

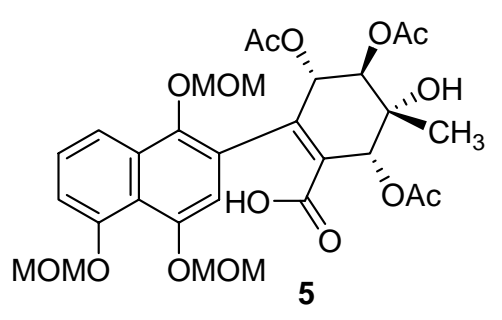

Acid 5. Compound $21 \quad(72 \quad \mathrm{mg}, 0.11 \quad \mathrm{mmol})$ and $N$-methylmorpholine $N$-oxide $(20 \mathrm{mg}, 0.18 \mathrm{mmol})$ were dissolved in $1.0 \mathrm{~mL}$ of anhydrous $\mathrm{CH}_{2} \mathrm{Cl}_{2}$ and tetrapropylammonium perruthenate $(8 \mathrm{mg}, 0.02 \mathrm{mmol})$ was added at $0{ }^{\circ} \mathrm{C}$. After stirring for $20 \mathrm{~min}$ at $\mathrm{rt}$, the reaction mixture was filtered through a short silica pad to provided $72 \mathrm{mg}$ of the desired aldehyde as a yellow oil. The crude aldehyde was directly used for the next step. Aldehyde (72 mg, $0.11 \mathrm{mmol})$ was dissolved in $1.0 \mathrm{~mL}$ of tert-butyl alcohol and $0.2 \mathrm{~mL}$ of 2-methyl-2-butene. A solution of $\mathrm{NaClO}_{2}(96 \mathrm{mg}, 1.1 \mathrm{mmol})$ and $\mathrm{NaH}_{2} \mathrm{PO}_{4}(96 \mathrm{mg}, 1.1 \mathrm{mmol})$ in $0.5 \mathrm{~mL}$ of water was slowly added to the reaction mixture at $0{ }^{\circ} \mathrm{C}$. After stirring at $\mathrm{rt}$ for $12 \mathrm{~h}$, the reaction mixture was diluted with water and extracted with EtOAc. The combined organic layers were washed with brine and dried over $\mathrm{MgSO}_{4}$. The solution was filtered and concentrated in vacuo. Purification on silica gel (hexane : EtOAc $=1: 1)$ provided $64 \mathrm{mg}(0.09 \mathrm{mmol}, 88 \%)$ of carboxylic acid 5 as a yellow oil (8:1 mixture of rotamers by ${ }^{1} \mathrm{H}$ NMR at $\mathrm{rt}$ ). ${ }^{1} \mathrm{H} \mathrm{NMR}$ (400 $\mathrm{MHz}, \mathrm{CDCl}_{3}$, major rotamer reported) $7.64(\mathrm{~m}, 2 \mathrm{H}), 7.32(\mathrm{~d}, 1 \mathrm{H}, J=8.0 \mathrm{~Hz}), 6.31(\mathrm{~s}, 1 \mathrm{H}), 6.09(\mathrm{~s}, 1 \mathrm{H}), 5.98(\mathrm{~d}, 1 \mathrm{H}$, $J=7.2 \mathrm{~Hz}), 5.53$ (d, 1H, $J=7.2 \mathrm{~Hz}), 5.27$ (m, 4H), 4.59 (d, 1H, $J=8.0 \mathrm{~Hz}), 4.49$ (d, 1H, $J=8.0$ $\mathrm{Hz}), 3.51(\mathrm{~s}, 6 \mathrm{H}), 3.20(\mathrm{~s}, 3 \mathrm{H}), 2.17(\mathrm{~s}, 3 \mathrm{H}), 2.13(\mathrm{~s}, 3 \mathrm{H}), 2.10(\mathrm{~s}, 3 \mathrm{H}), 1.31(\mathrm{~s}, 3 \mathrm{H}) ;{ }^{13} \mathrm{C} \mathrm{NMR}$ $\left(100.0 \mathrm{MHz}, \mathrm{CDCl}_{3}\right.$, both rotamers reported) $\delta 181.6,170.7,170.0,167.5,159.5,157.3,142.5$, $140.1,137.1,134.9,132.2,130.7,127.6,120.4,119.3,117.9,95.3,95.1,92.5,73.6,71.5,69.8$, 67.5, 56.6, 56.4, 20.8, 20.5, 20.0; IR (thin film) vmax 3466, 2925, 2854, 1748, 1661, 1594, 1460, 1372, 1229, 1156, 1032, $980 \mathrm{~cm}^{-1}$; CIHRMS $[\mathrm{M}+\mathrm{Na}]^{+}$calculated for $\mathrm{C}_{30} \mathrm{H}_{36} \mathrm{O}_{14} \mathrm{Na}: 659.1952$, found: $659.1937 .[\alpha]_{\mathrm{D}}^{23}=+44^{\mathrm{o}}\left(\mathrm{c}=0.10, \mathrm{CHCl}_{3}\right)$.

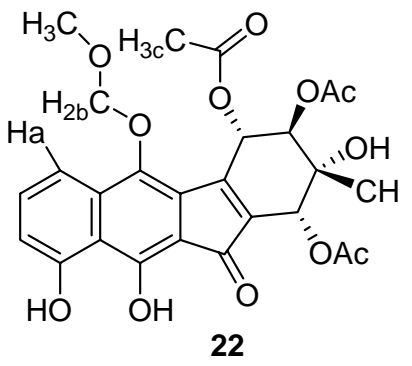

MOM-protected hydroquinone 22. Compound 5 (40 $\mathrm{mg}, 0.06 \mathrm{mmol}$ ) and activated $4 \AA \mathrm{MS}(10 \mathrm{mg})$ were dissolved in $1.0 \mathrm{~mL}$ of anhydrous DCE and TFAA $(18.0 \mu \mathrm{L}, 0.12 \mathrm{mmol})$ was slowly added at $0{ }^{\circ} \mathrm{C}$. After stirring for $1 \mathrm{~h}$ at $\mathrm{rt}$, the reaction mixture was quenched with $\mathrm{pH} 7$ buffer and extracted with EtOAc. The combined organic layers were washed with sat. pH 7 buffer, brine, and dried over $\mathrm{MgSO}_{4}$. The solution was filtered and concentrated in vacuo. Purification on silica 
gel $\left(\mathrm{CHCl}_{3}: \mathrm{MeOH}=10: 1\right)$ provided $30 \mathrm{mg}(0.057 \mathrm{mmol}, 90 \%)$ of $\mathrm{MOM}$-protected hydroquinone 22 as an orange oil. ${ }^{1} \mathrm{H}$ NMR $\left(400 \mathrm{MHz}, \mathrm{CDCl}_{3}\right) 11.9(\mathrm{~s}, 1 \mathrm{H}), 7.63(\mathrm{t}, 1 \mathrm{H}, J=8.0$ $\mathrm{Hz}), 7.46(\mathrm{~d}, 1 \mathrm{H}, J=8.0 \mathrm{~Hz}), 7.08(\mathrm{~d}, 1 \mathrm{H}, J=8.0 \mathrm{~Hz}), 6.41(\mathrm{~s}, 1 \mathrm{H}), 6.10(\mathrm{~s}, 1 \mathrm{H}), 6.01(\mathrm{~d}, 1 \mathrm{H}, J=$ $7.2 \mathrm{~Hz}), 5.53(\mathrm{~d}, 1 \mathrm{H}, J=7.2 \mathrm{~Hz}), 4.61(\mathrm{~d}, 1 \mathrm{H}, J=8.0 \mathrm{~Hz}), 4.47(\mathrm{~d}, 1 \mathrm{H}, J=8.0 \mathrm{~Hz}), 3.22(\mathrm{~s}, 3 \mathrm{H})$, $2.18(\mathrm{~s}, 3 \mathrm{H}), 2.15(\mathrm{~s}, 3 \mathrm{H}), 2.11(\mathrm{~s}, 3 \mathrm{H}), 1.32(\mathrm{~s}, 3 \mathrm{H})$; NOED $\left(400 \mathrm{MHz}, \mathrm{CDCl}_{3}\right)$ irrd. $\delta 4.61\left(\mathrm{H}_{\mathrm{b}}\right)$, $3.0 \%$ enhancement at $\mathrm{H}_{\mathrm{a}}, 2.0 \%$ enhancement at $-\mathrm{CH}_{3 \mathrm{c}}$; irrd. $\delta 7.46\left(\mathrm{H}_{\mathrm{a}}\right), 3.0 \%$ enhancement at $\mathrm{H}_{\mathrm{b}}$. For nOe spectra, see page S36. ${ }^{13} \mathrm{C} \mathrm{NMR}\left(100.0 \mathrm{MHz}, \mathrm{CDCl}_{3}\right) \delta 187.3,170.7,170.0,161.9$, $142.0,141.6,137.9,137.0,128.5,128.3,119.7,118.5,95.2,95.0,92.5,92.0,73.5,71.5,69.7$, 67.4, 66.0, 56.6, 20.8, 20.6, 20.1; IR (thin film) vmax 3473, 2925, 2855, 1747, 1650, 1613, 1457, 1371, 1226, 1171, 1031, $979 \mathrm{~cm}^{-1}$; CIHRMS [M+Na] calculated for $\mathrm{C}_{26} \mathrm{H}_{26} \mathrm{O}_{12} \mathrm{Na}$ : 553.1322, found: $553.1340 .[\alpha]_{\mathrm{D}}^{23}=+37^{\circ}\left(\mathrm{c}=0.10, \mathrm{CHCl}_{3}\right)$.

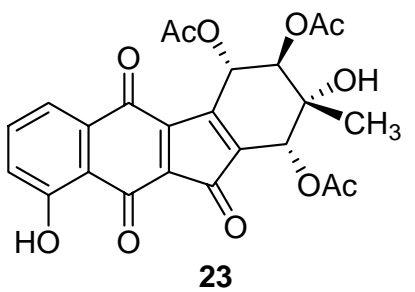

Quinone 23. Compound 22 (30 mg, $0.057 \mathrm{mmol})$ and $\mathrm{CBr}_{4}(4.0 \mathrm{mg}$, $0.012 \mathrm{mmol}$ ) were dissolved in $0.5 \mathrm{~mL}$ of anhydrous isopropyl alcohol. The reaction mixture was gently heated to reflux at $84{ }^{\circ} \mathrm{C}$. After stirring for $1 \mathrm{~h}$ at $84{ }^{\circ} \mathrm{C}$, the reaction mixture was cooled to $\mathrm{rt}$ and concentrated in vacuo. The crude MOM-deprotected hydroquinone product was dissolved in $1.0 \mathrm{~mL}$ of anhydrous EtOAc, and $\mathrm{Pd} / \mathrm{C}(15.0 \mathrm{mg}, 50 \mathrm{wt} \%)$ was added to the solution. The reaction mixture was exposed to air and stirred at rt for $30 \mathrm{~min}$ before being filtered and concentrated in vacuo. Purification on silica gel $\left(\mathrm{CHCl}_{3}: \mathrm{MeOH}=10: 1\right)$ provided $18 \mathrm{mg}(0.039 \mathrm{mmol}, 70 \%)$ of ketoquinone 23 as a brown oil. ${ }^{1} \mathrm{H} \operatorname{NMR}\left(400 \mathrm{MHz}, \mathrm{CDCl}_{3}\right) 11.50(\mathrm{~s}, 1 \mathrm{H}), 7.71(\mathrm{~d}, 1 \mathrm{H}, J=8.0$ $\mathrm{Hz}), 7.66(\mathrm{t}, 1 \mathrm{H}, J=8.0 \mathrm{~Hz}), 7.32(\mathrm{~d}, 1 \mathrm{H}, J=8.0 \mathrm{~Hz}), 6.46(\mathrm{~d}, 1 \mathrm{H}, J=6.0 \mathrm{~Hz}), 6.09(\mathrm{~s}, 1 \mathrm{H})$, $5.47(\mathrm{~d}, 1 \mathrm{H}, J=6.0 \mathrm{~Hz}), 2.16(\mathrm{~s}, 3 \mathrm{H}), 2.14(\mathrm{~s}, 3 \mathrm{H}), 1.93(\mathrm{~s}, 3 \mathrm{H}), 1.36(\mathrm{~s}, 3 \mathrm{H}) ;{ }^{13} \mathrm{C} \mathrm{NMR} \quad(100.0$ $\left.\mathrm{MHz}, \mathrm{CDCl}_{3}\right) \delta 180.4,179.7,178.5,171.0,170.4,169.1,162.5,156.2,154.9,146.3,142.6$, $138.4,132.0,128.2,125.3,120.4,75.2,73.2,71.0,69.9,21.2,20.9,20.8,20.7$; IR (thin film) vmax 3472, 2933, 1750, 1652, 1621, 1568, 1456, 1372, 1226, 1164, $1036 \mathrm{~cm}^{-1}$; HRTOFMS $[\mathrm{M}+\mathrm{H}]^{+}$calculated for $\mathrm{C}_{24} \mathrm{H}_{21} \mathrm{O}_{11}: 485.1084$, found: $485.1070 ;[\alpha]_{\mathrm{D}}^{23}=-80^{\circ}\left(\mathrm{c}=0.1, \mathrm{CHCl}_{3}\right)$.

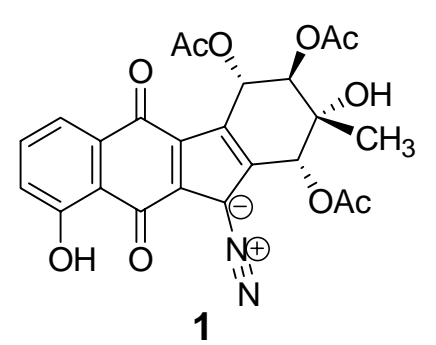

1

Synthetic Kinamycin $\mathbf{C}$ 1. A freshly prepared solution of scandium trifluoromethanesulfonate in anhydrous $\mathrm{CH}_{3} \mathrm{CN}(0.01 \mathrm{M}, 6 \mu \mathrm{L}$, 0.01 equiv.) was transferred to a $5 \mathrm{~mL}$ round-bottom flask. The solvent was evaporated by argon, and the flask was further evacuated in vacuo for $15 \mathrm{~min}$. Keto quinone $23(3.0 \mathrm{mg}, 0.0062$ mmol) in $0.1 \mathrm{~mL}$ of anhydrous $\mathrm{CH}_{2} \mathrm{Cl}_{2}$ was added to the reaction flask. The reaction mixture was cooled to $-78{ }^{\circ} \mathrm{C}$, and 1,2-Bis(tert-butyldimethylsilyl)hydrazine ${ }^{\mathrm{S} 6}(2.0 \mu \mathrm{L}, 0.0063 \mathrm{mmol}$, 1.05 equiv.) in $0.1 \mathrm{~mL}$ of anhydrous $\mathrm{CH}_{2} \mathrm{Cl}_{2}$ was slowly added. The reaction was allowed to slowly warm to $\mathrm{rt}$, and carefully monitored by TLC, at which time the quinone 23 was consumed. One portion of $0.5 \mathrm{~mL}$ of cold anhydrous hexane was added, and the mixture was quickly filtered through a pipette column with cotton. The solution was

\footnotetext{
${ }^{\mathrm{S} 6}$ For the preparation of 1,2-bis(tert-butyldimethylsilyl)hydrazine, see: Furrow, M. E.; Myers, A. G. J. Am. Chem. Soc. 2004, $126,5436$.
} 
collected and concentrated in vacuo. The corresponding $N$-tert-butyldimethylsilylhydrazone was directly used for the next step without further purification. The crude hydrazone and activated $4 \AA \mathrm{MS}(3.0 \mathrm{mg})$ were dissolved in $0.1 \mathrm{~mL}$ of anhydrous $\mathrm{CH}_{2} \mathrm{Cl}_{2}$, and the mixture was cooled to $-78{ }^{\circ} \mathrm{C}$. To this solution was added 2-chloropyridine $(4.0 \mathrm{~mL}, 0.038 \mathrm{mmol}, 6.0$ equiv.), followed by freshly prepared $0.1 \mathrm{M}$ solution of iodobenzenedifluoride $\left(\mathrm{PhIF}_{2}\right)^{\mathrm{S} 7}$ in $\mathrm{CH}_{2} \mathrm{Cl}_{2}(180 \mathrm{~mL}$, $0.018 \mathrm{mmol}, 3.0$ equiv.) dropwise. The reaction mixture was stirred at $-78{ }^{\circ} \mathrm{C}$ for $4 \mathrm{~h}$, at which point the cooling bath was allowed to warmed gradually to rt over $3 \mathrm{~h}$. After stirring for $2 \mathrm{~h}$ at rt, the reaction mixture was quenched with water and extracted with $\mathrm{CH}_{2} \mathrm{Cl}_{2}$. The combined organic layers were washed with brine, and dried over $\mathrm{MgSO}_{4}$. The solution was filtered and concentrated in vacuo. Purification on silica gel (hexane : EtOAc $=1: 1)$ provided $1.1 \mathrm{mg}(0.0022$ mmol, $35 \%$ ) of kinamycin $\mathrm{C} 1$ as an orange solid. mp 149-150 ${ }^{\circ} \mathrm{C} .{ }^{1} \mathrm{H}$ NMR (400 MHz, $\mathrm{CDCl}_{3}$ ) 12.09 (s, 1H), $7.63(\mathrm{~d}, 1 \mathrm{H}, J=8.4 \mathrm{~Hz}), 7.52$ (t, $1 \mathrm{H}, J=8.4 \mathrm{~Hz}), 7.15$ (d, $1 \mathrm{H}, J=8.4 \mathrm{~Hz}), 6.19$ $(\mathrm{d}, 1 \mathrm{H}, J=7.2 \mathrm{~Hz}), 5.57(\mathrm{~d}, 1 \mathrm{H}, J=7.2 \mathrm{~Hz}), 5.46(\mathrm{~s}, 1 \mathrm{H}), 2.66$ (bs, $1 \mathrm{H}), 2.18(\mathrm{~s}, 3 \mathrm{H}), 2.16(\mathrm{~s}$, $3 \mathrm{H}), 2.08(\mathrm{~s}, 3 \mathrm{H}), 1.24(\mathrm{~s}, 3 \mathrm{H}) ;{ }^{13} \mathrm{C} \mathrm{NMR} \quad\left(100.0 \mathrm{MHz}, \mathrm{CDCl}_{3}\right) \delta 184.2,178.2,172.1,171.1$, 170.3, 162.2, 136.4, 134.5, 132.7, 130.1, 129.2, 126.8, 123.9, 120.1, 115.7, 78.0, 75.6, 73.6, 71.1, 68.2, 21.2, 21.0, 20.8, 18.7; IR (thin film) vmax 3461, 2977, 2936, 2150, 1742, 1659, 1621, $1458,1370,1232,1158,1075,1039 \mathrm{~cm}^{-1}$; HRTOFMS $[\mathrm{M}+\mathrm{Na}]^{+}$calculated for $\mathrm{C}_{24} \mathrm{H}_{20} \mathrm{~N}_{2} \mathrm{NaO}_{10}$ : 519.1016, found: $519.1055 ;[\alpha]_{\mathrm{D}}^{23}=-26^{\circ}\left(\mathrm{c}=0.1, \mathrm{CHCl}_{3}\right)$.

${ }^{\text {S7 }}$ For the preparation of $\mathrm{PhIF}_{2}$ in $\mathrm{CH}_{2} \mathrm{Cl}_{2}$, see: Furrow, M. E.; Myers, A. G. J. Am. Chem. Soc. 2004, 126, 12222. 


\section{c) Detailed procedure for the preparation of kinamycin $\mathrm{C}$ from natural kinamycin D:}

Kinamycin C (1) was obtained by acylation of natural kinamycin D with acetic anhydride using the procedure ${ }^{\mathrm{S} 8}$ reported for acylation of kinamycin D using S-2-methylbutyric anhydride.

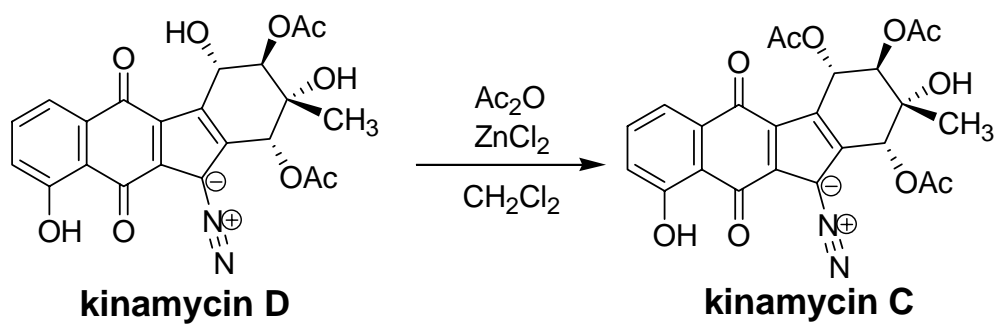<smiles>CC(=O)OC1C2=C(C(=O)c3cccc(O)c3C2=O)[C@@H](OC(C)=O)C1[N+]#N</smiles>

Natural Kinamycin $C$ 1. In a $5 \mathrm{~mL}$ round bottom flask was placed anhydrous $\mathrm{ZnCl}_{2}(30.0 \mathrm{mg}, 0.22 \mathrm{mmol})$ and acetic acid $(24.0 \mathrm{~mL}$, $0.15 \mathrm{mmol}$ ) in $0.5 \mathrm{~mL}$ of anhydrous $\mathrm{CH}_{2} \mathrm{Cl}_{2}$ was added at rt. After stirring for $1 \mathrm{~h}$ at $\mathrm{rt}$, the reaction mixture was cooled to $-78{ }^{\circ} \mathrm{C}$, and natural kinamycin $\mathrm{D}(6.0 \mathrm{mg}, 0.013 \mathrm{mmol})$ in $0.2 \mathrm{~mL}$ of anhydrous $\mathrm{CH}_{2} \mathrm{Cl}_{2}$ was slowly added. The reaction was slowly warmed to 0 ${ }^{\circ} \mathrm{C}$, and stirred for an additional $1 \mathrm{~h}$. The reaction was diluted with anhydrous $\mathrm{CH}_{2} \mathrm{Cl}_{2}$, washed with water, dried over $\mathrm{MgSO}_{4}$, filtered and concentrated in vacuo. Purification on silica gel (hexane : EtOAc $=1: 1$ ) provided $3.0 \mathrm{mg}$ $(0.06 \mathrm{mmol}, 50 \%)$ of kinamycin $\mathrm{C}$ as an orange solid. mp 151-153 ${ }^{\circ} \mathrm{C} .{ }^{1} \mathrm{H}$ NMR $(400 \mathrm{MHz}$, $\left.\mathrm{CDCl}_{3}\right) 12.09(\mathrm{~s}, 1 \mathrm{H}), 7.63(\mathrm{~d}, 1 \mathrm{H}, J=8.4 \mathrm{~Hz}), 7.52(\mathrm{t}, 1 \mathrm{H}, J=8.4 \mathrm{~Hz}), 7.15(\mathrm{~d}, 1 \mathrm{H}, J=8.4 \mathrm{~Hz})$, 6.19 (d, 1H, J=7.2 Hz), 5.57 (d, 1H, J=7.2 Hz), 5.46 (s, 1H), 2.66 (bs, 1H), 2.18 (s, 3H), 2.16 $(\mathrm{s}, 3 \mathrm{H}), 2.08(\mathrm{~s}, 3 \mathrm{H}), 1.24(\mathrm{~s}, 3 \mathrm{H}) ;{ }^{13} \mathrm{C} \mathrm{NMR} \quad\left(100.0 \mathrm{MHz}, \mathrm{CDCl}_{3}\right) \delta 184.2,178.2,172.1,171.1$, $170.3,162.2,136.4,134.5,132.7,130.1,129.2,126.8,123.9,120.1,115.7,78.0,75.6,73.6,71.1$, 68.2, 21.2, 21.0, 20.8, 18.7; IR (thin film) vmax 3461, 2977, 2936, 2150, 1742, 1659, 1621, 1458, 1370, 1232, 1158, 1075, $1039 \mathrm{~cm}^{-1}$; HRTOFMS [M+Na] ${ }^{+}$calculated for $\mathrm{C}_{24} \mathrm{H}_{20} \mathrm{~N}_{2} \mathrm{NaO}_{10}$ : 519.1016, found: $519.1022 ;[\alpha]_{\mathrm{D}}^{23}=-24^{\mathrm{o}}\left(\mathrm{c}=0.1, \mathrm{CDCl}_{3}\right)$.

Synthetic and natural kinamycin $\mathrm{C}$ gave the same $\mathrm{R}_{f}$ value in the following three solvent systems: $\mathrm{R}_{f}=0.50\left(\mathrm{CHCl}_{3}: \mathrm{MeOH}=10: 1\right), \mathrm{R}_{f}=0.23($ hexane $:$ EtOAc $=1: 1), \mathrm{R}_{f}=0.16\left(\mathrm{CHCl}_{3}: \mathrm{EtOAc}=\right.$ $5: 1)$.

s8 Gould, S. J.; Tamayo, N.; Melville, C. R.; Cone, M. C. J. Am. Chem. Soc. 1994,116, 2207 


\section{II) Comparison of natural and synthetic kinamycin C}

\begin{tabular}{|c|c|c|c|}
\hline \multicolumn{4}{|c|}{ NMR data (in $\mathrm{CDCl}_{3}$ ) comparison of natural and synthetic kinamycin $\mathrm{C}$} \\
\hline \multicolumn{2}{|c|}{${ }^{1} \mathrm{H}$ NMR (Hz) } & \multicolumn{2}{|c|}{${ }^{13} \mathrm{C}$ NMR $(\mathrm{Hz})$} \\
\hline Natural (400 MHz) & Synthetic (400 MHz) & Natural (100 MHz) & Synthetic (100.0 MHz) \\
\hline $12.09(\mathrm{~s}, 1 \mathrm{H})$ & $12.09(\mathrm{~s}, 1 \mathrm{H})$ & 184.0 & 184.2 \\
\hline $7.63(\mathrm{~d}, 1 \mathrm{H}, J=8.4 \mathrm{~Hz})$ & $7.63(\mathrm{~d}, 1 \mathrm{H}, J=8.4 \mathrm{~Hz})$ & 178.0 & 178.2 \\
\hline $7.52(\mathrm{t}, 1 \mathrm{H}, J=8.4 \mathrm{~Hz})$ & $7.52(\mathrm{t}, 1 \mathrm{H}, J=8.4 \mathrm{~Hz})$ & 172.0 & 172.1 \\
\hline $7.15(\mathrm{~d}, 1 \mathrm{H}, J=8.4 \mathrm{~Hz})$ & $7.15(\mathrm{~d}, 1 \mathrm{H}, J=8.4 \mathrm{~Hz})$ & 171.1 & 171.1 \\
\hline $6.19(\mathrm{~d}, 1 \mathrm{H}, J=7.2 \mathrm{~Hz})$ & $6.19(\mathrm{~d}, 1 \mathrm{H}, J=7.2 \mathrm{~Hz})$ & 170.2 & 170.3 \\
\hline $5.57(\mathrm{~d}, 1 \mathrm{H}, J=7.2 \mathrm{~Hz})$ & $5.57(\mathrm{~d}, 1 \mathrm{H}, J=7.2 \mathrm{~Hz})$ & 162.0 & 162.2 \\
\hline $5.46(\mathrm{~s}, 1 \mathrm{H})$ & $5.46(\mathrm{~s}, 1 \mathrm{H})$ & 136.2 & 136.4 \\
\hline $2.66(\mathrm{bs}, 1 \mathrm{H})$ & $2.66(\mathrm{bs}, 1 \mathrm{H})$ & 134.2 & 134.5 \\
\hline $2.18(\mathrm{~s}, 3 \mathrm{H})$ & $2.18(\mathrm{~s}, 3 \mathrm{H})$ & 132.5 & 132.7 \\
\hline $2.16(\mathrm{~s}, 3 \mathrm{H})$ & $2.16(\mathrm{~s}, 3 \mathrm{H})$ & 130.1 & 130.1 \\
\hline $2.08(\mathrm{~s}, 3 \mathrm{H})$ & $2.08(\mathrm{~s}, 3 \mathrm{H})$ & 128.9 & 129.2 \\
\hline \multirow[t]{13}{*}{$1.24(\mathrm{~s}, 3 \mathrm{H})$} & $1.24(\mathrm{~s}, 3 \mathrm{H})$ & 126.6 & 126.8 \\
\hline & & 123.7 & 123.9 \\
\hline & & 119.9 & 120.1 \\
\hline & & 115.5 & 115.7 \\
\hline & & $78.5^{\mathrm{S} 9}$ & 78.0 \\
\hline & & 75.4 & 75.6 \\
\hline & & 73.5 & 73.6 \\
\hline & & 70.9 & 71.1 \\
\hline & & 68.1 & 68.2 \\
\hline & & 21.1 & 21.2 \\
\hline & & 21.0 & 21.0 \\
\hline & & 20.9 & 20.8 \\
\hline & & 18.6 & 18.7 \\
\hline
\end{tabular}

$[\alpha]_{D}$ for Natural and Synthetic kinamycin C:

\begin{tabular}{|c|c|c|}
\hline & Natural kinamycin C & Synthetic kinamycin C \\
\hline$[\alpha]_{\mathrm{D}}$ & $-24^{\circ}\left(c=0.1, \mathrm{CHCl}_{3}\right)$ & $-26^{\circ}\left(c=0.1, \mathrm{CHCl}_{3}\right)$ \\
\hline
\end{tabular}

s9 The diazo-bearing carbon (formerly cyanamide) has a ${ }^{13} \mathrm{C}$ chemical shift of $\delta 78.5 \mathrm{ppm}$ in $\mathrm{CDCl}_{3}$, see: (a). Sato, Y.; Gould, S. J. J. Am. Chem. Soc. 1986, 108, 4625. (b). Seaton, P. J.; Gould, S. J. J. Am. Chem. Soc. 1988, 110, 5912. 


\section{HPLC data for natural and synthetic kinamycin $C^{a}$}

Natural:

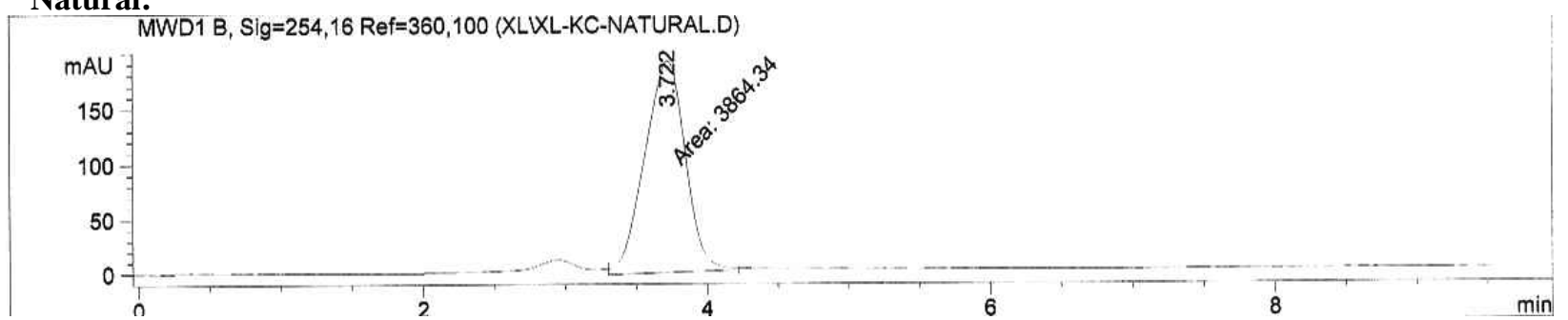

Synthetic:

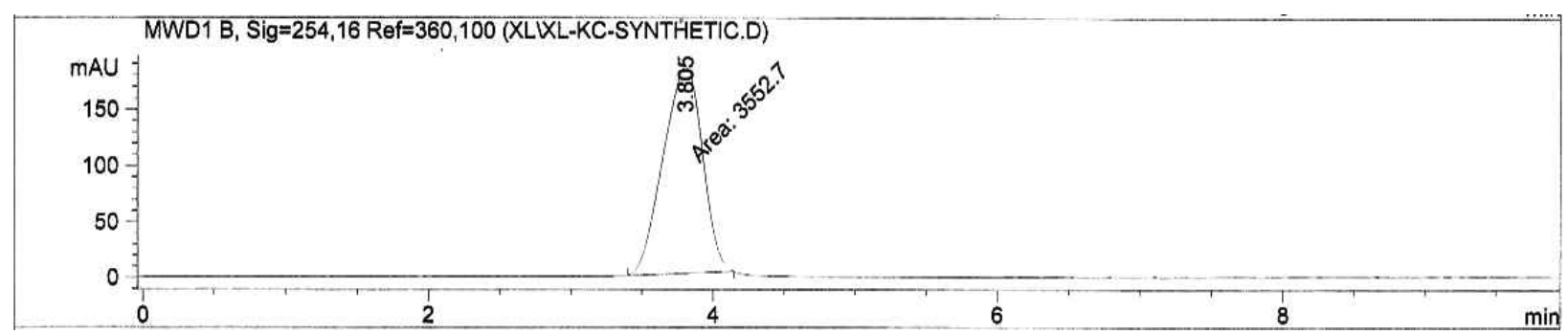

Natural+Synthetic:

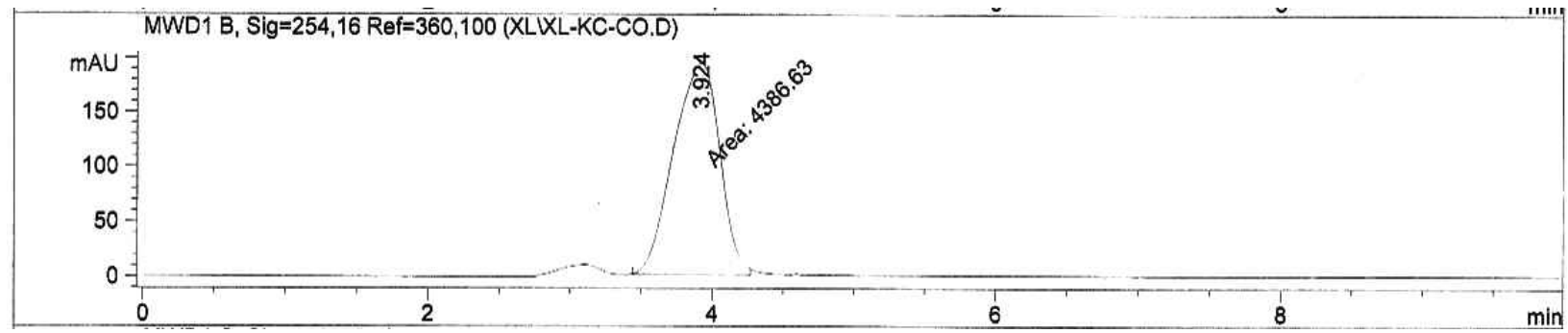

\begin{tabular}{|c|c|}
\hline Sample Name & $\mathrm{r}_{\mathrm{t}}(\mathrm{min})$ \\
\hline Natural kinamycin C & 3.722 \\
\hline Synthetic kinamycin C & 3.805 \\
\hline Natural and synthetic kinamycin C (co-injection) & 3.924 \\
\hline
\end{tabular}

${ }^{a}$ Experimental condition:

Column: Agilent Zorbax SB-C18 (4.6mm ID x 7.5cm) $3.5 \mu \mathrm{L}$

Eluent: $35 \% \mathrm{MeCN}, 65 \%$ water

Detector wavelength: $254 \mathrm{~nm}$

Flow rate: $1.0 \mathrm{~mL} / \mathrm{min}$. 


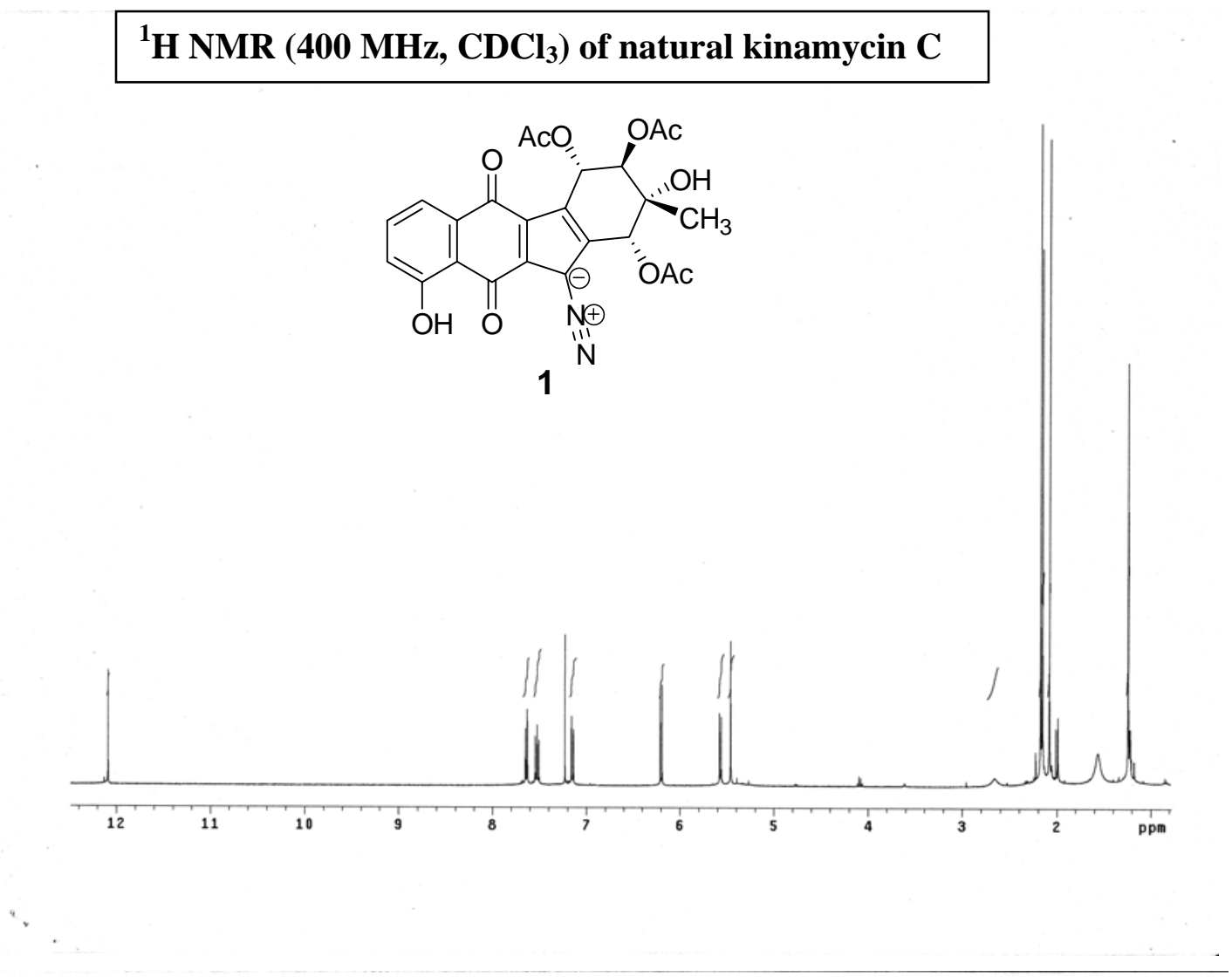

${ }^{1} \mathrm{H}$ NMR (400 MHz, $\mathrm{CDCl}_{3}$ ) of synthetic kinamycin C

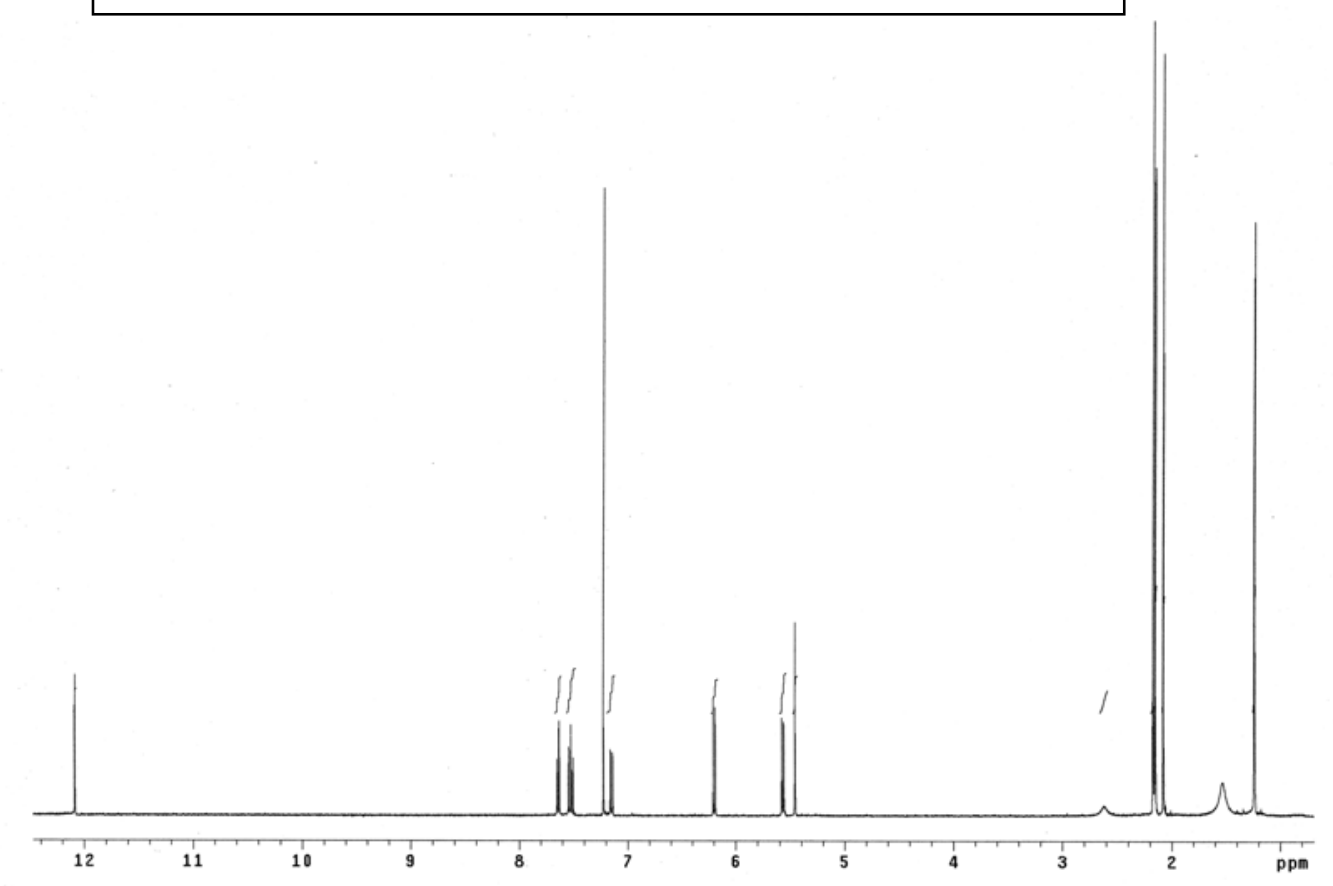

S 16 
${ }^{13} \mathrm{C}$ NMR (100 MHz, $\left.\mathrm{CDCl}_{3}\right)$ of natural kinamycin C

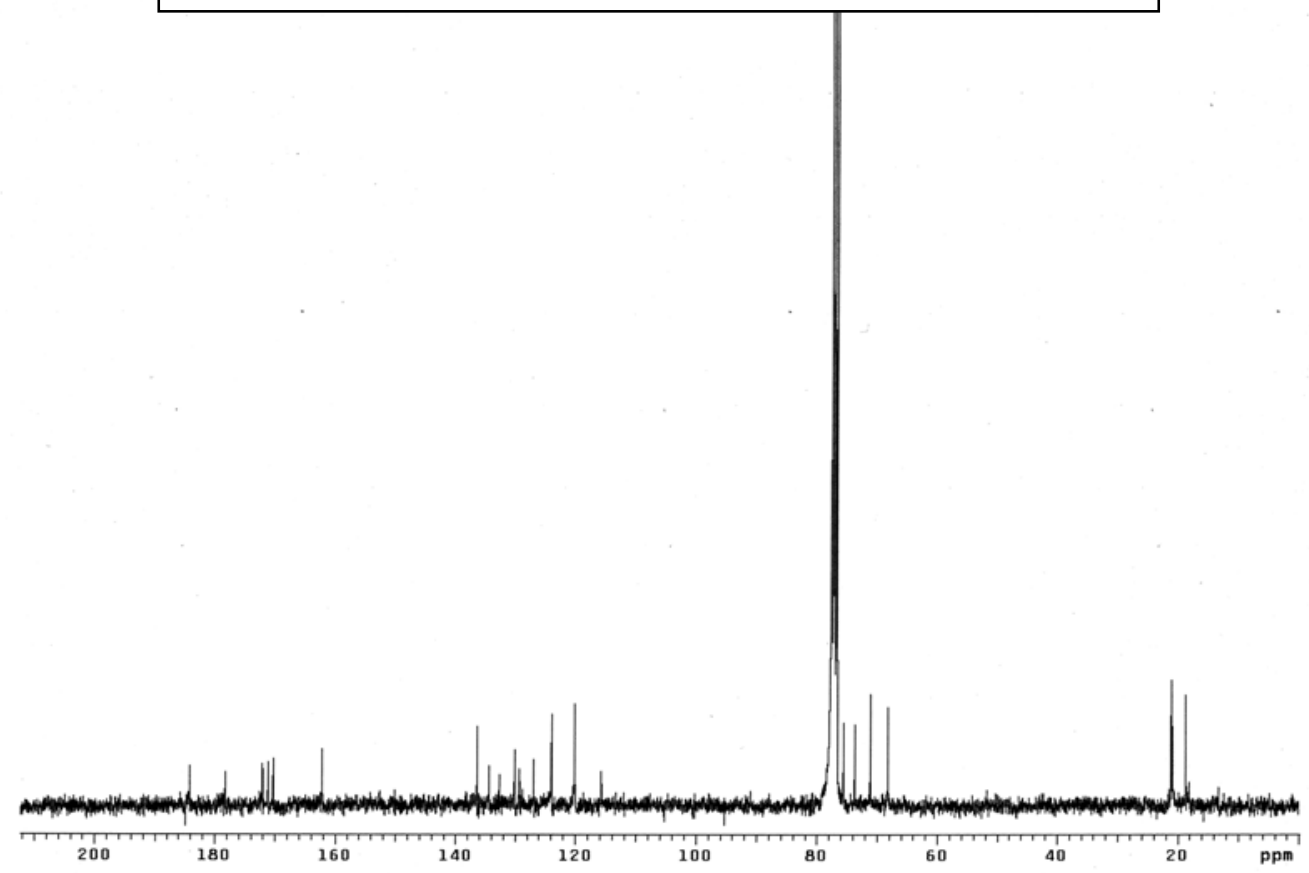

${ }^{13} \mathrm{C}$ NMR (100 MHz, $\left.\mathrm{CDCl}_{3}\right)$ of synthetic kinamycin C

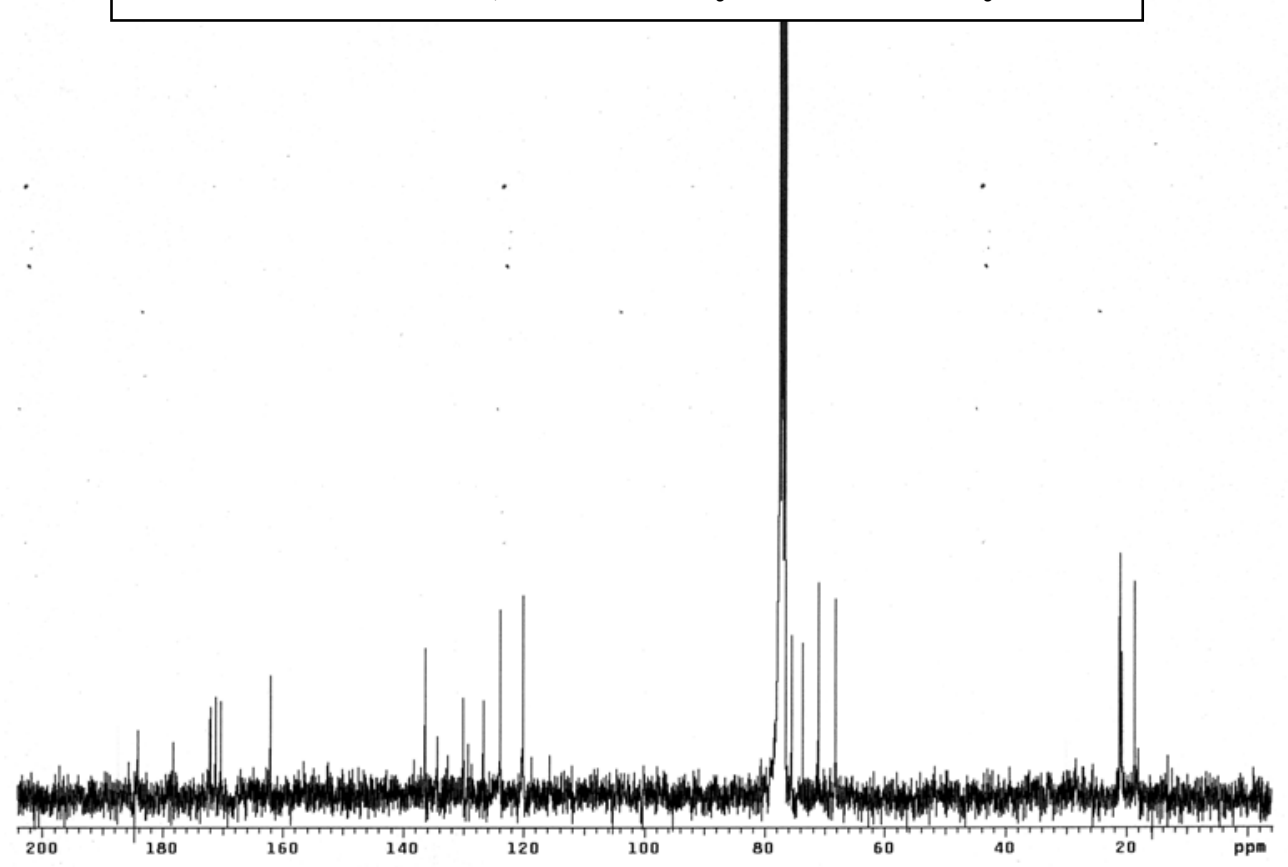




\section{IR of natural kinamycin C}

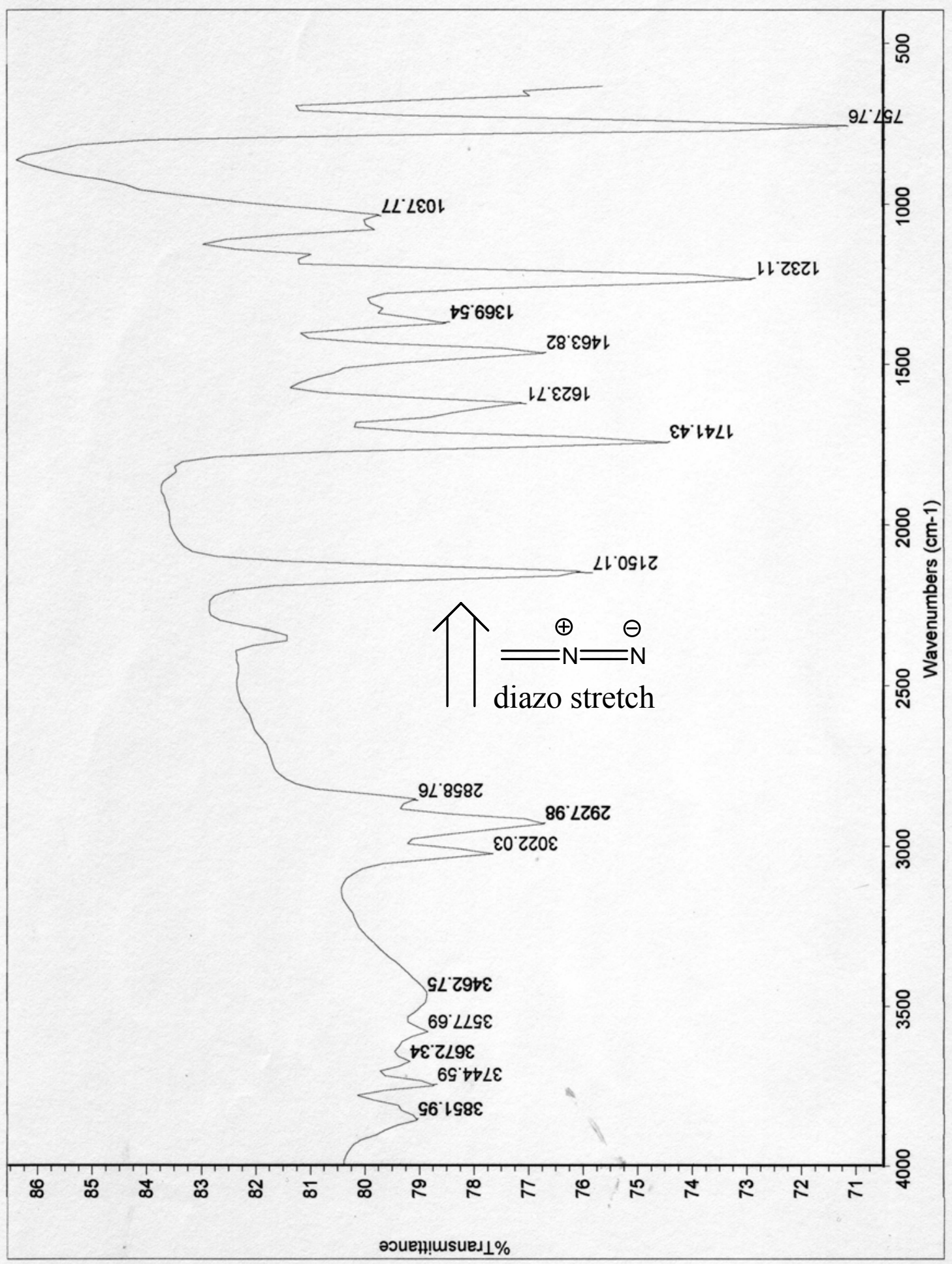




\section{IR of synthetic kinamycin C}

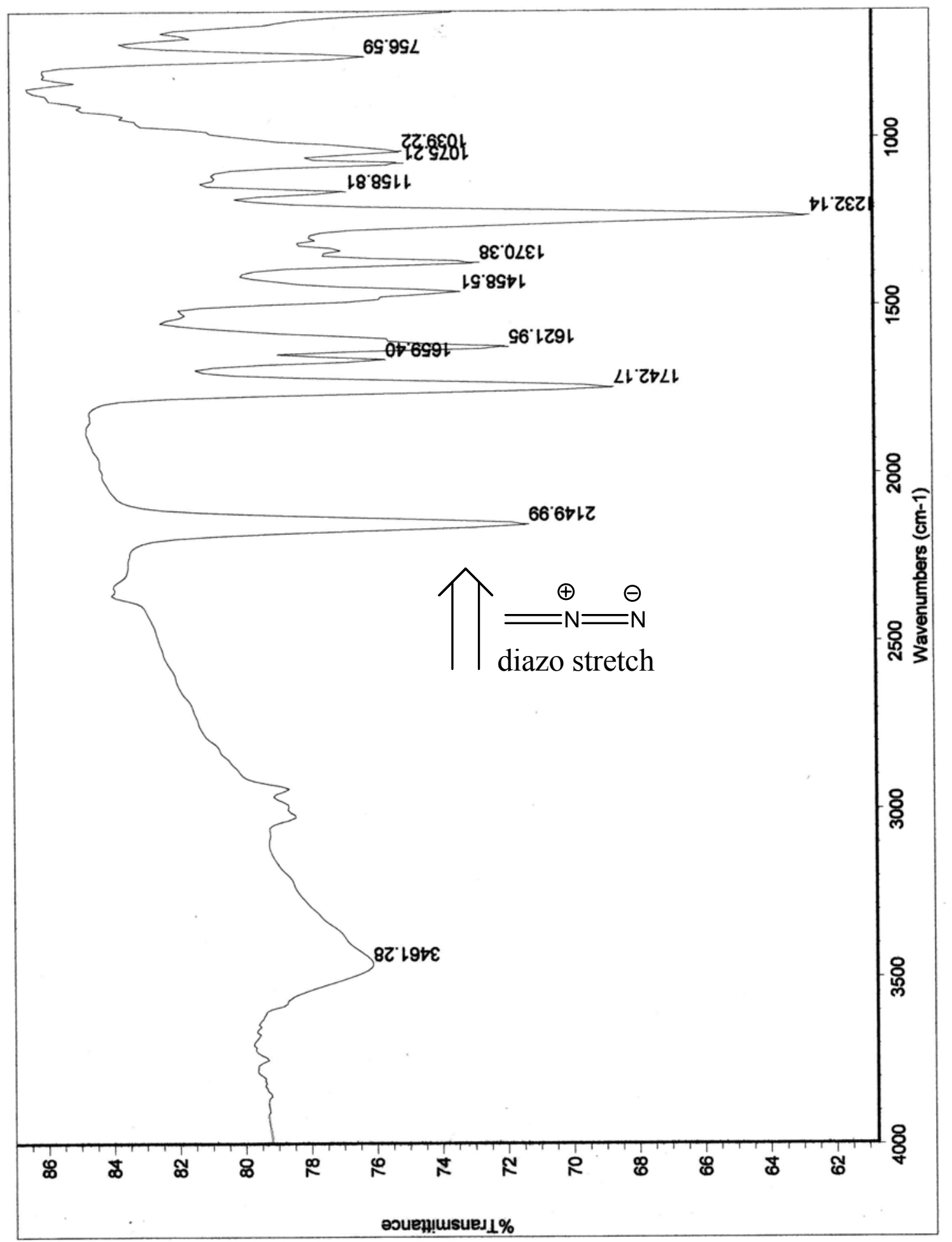




\section{III) ${ }^{1} \mathrm{H}$ and ${ }^{13} \mathrm{C}$ NMR spectra}
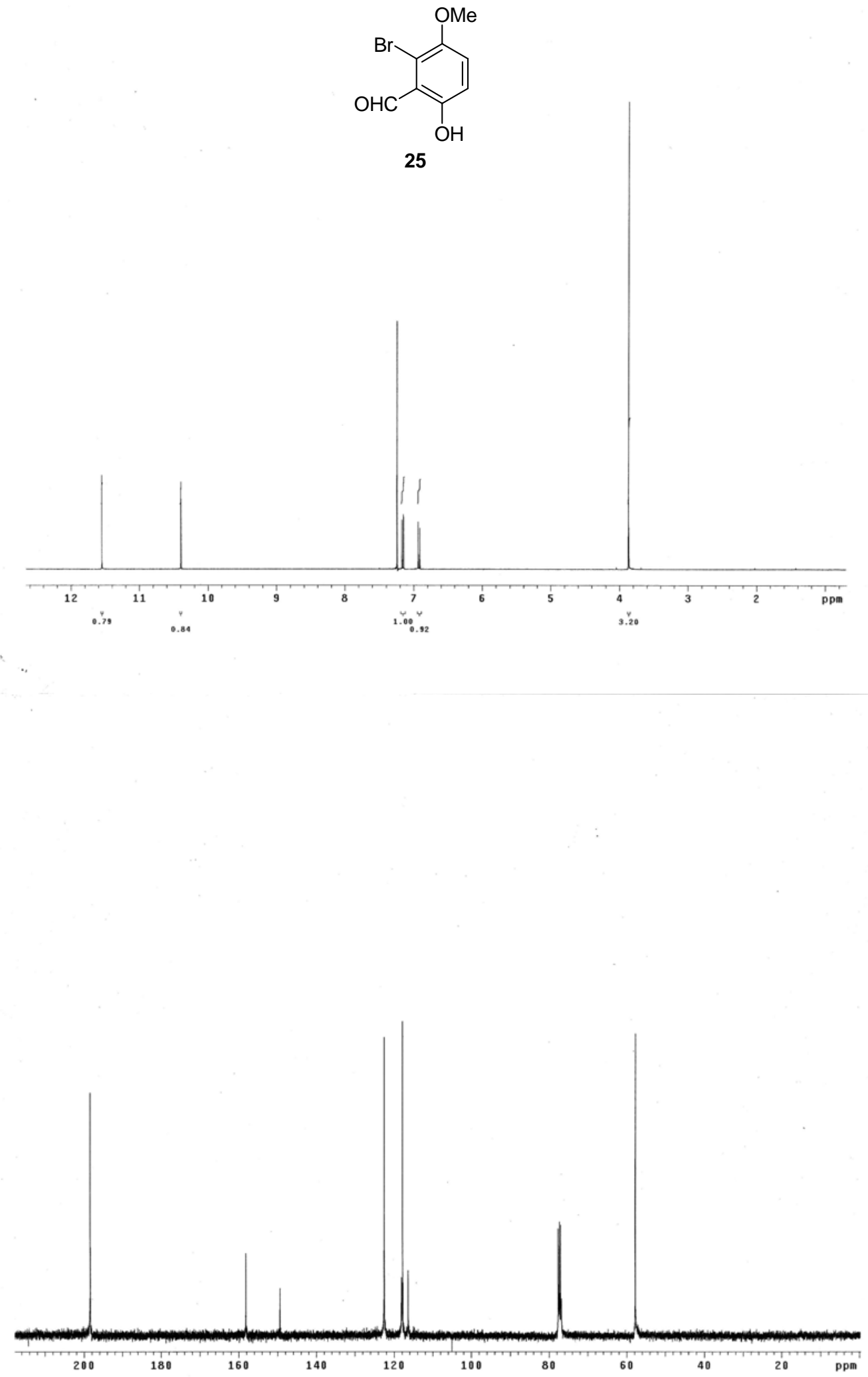


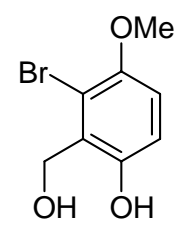

11
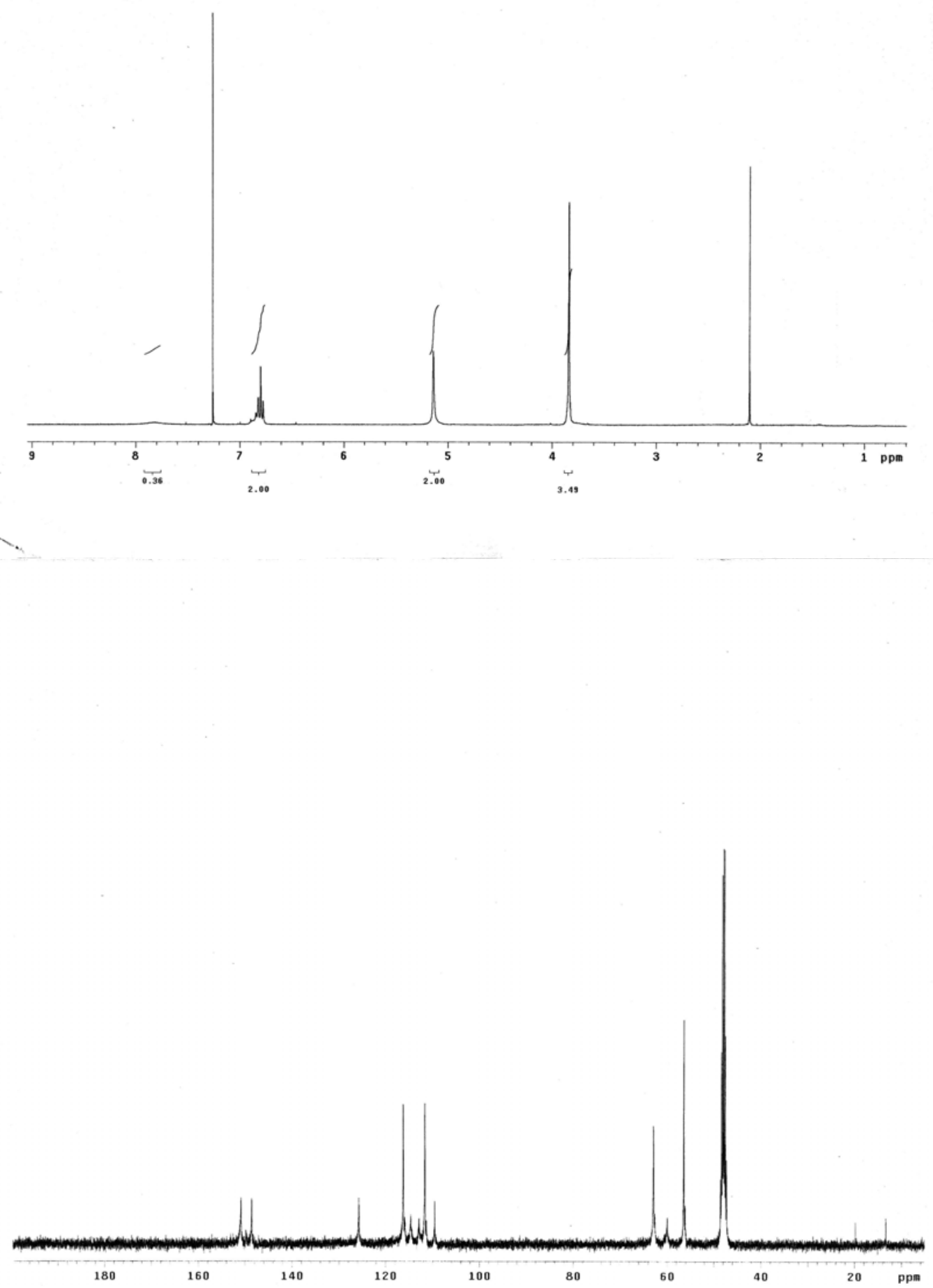

S 21 


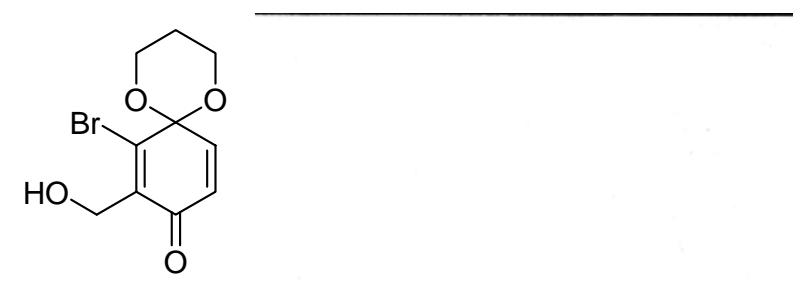

26
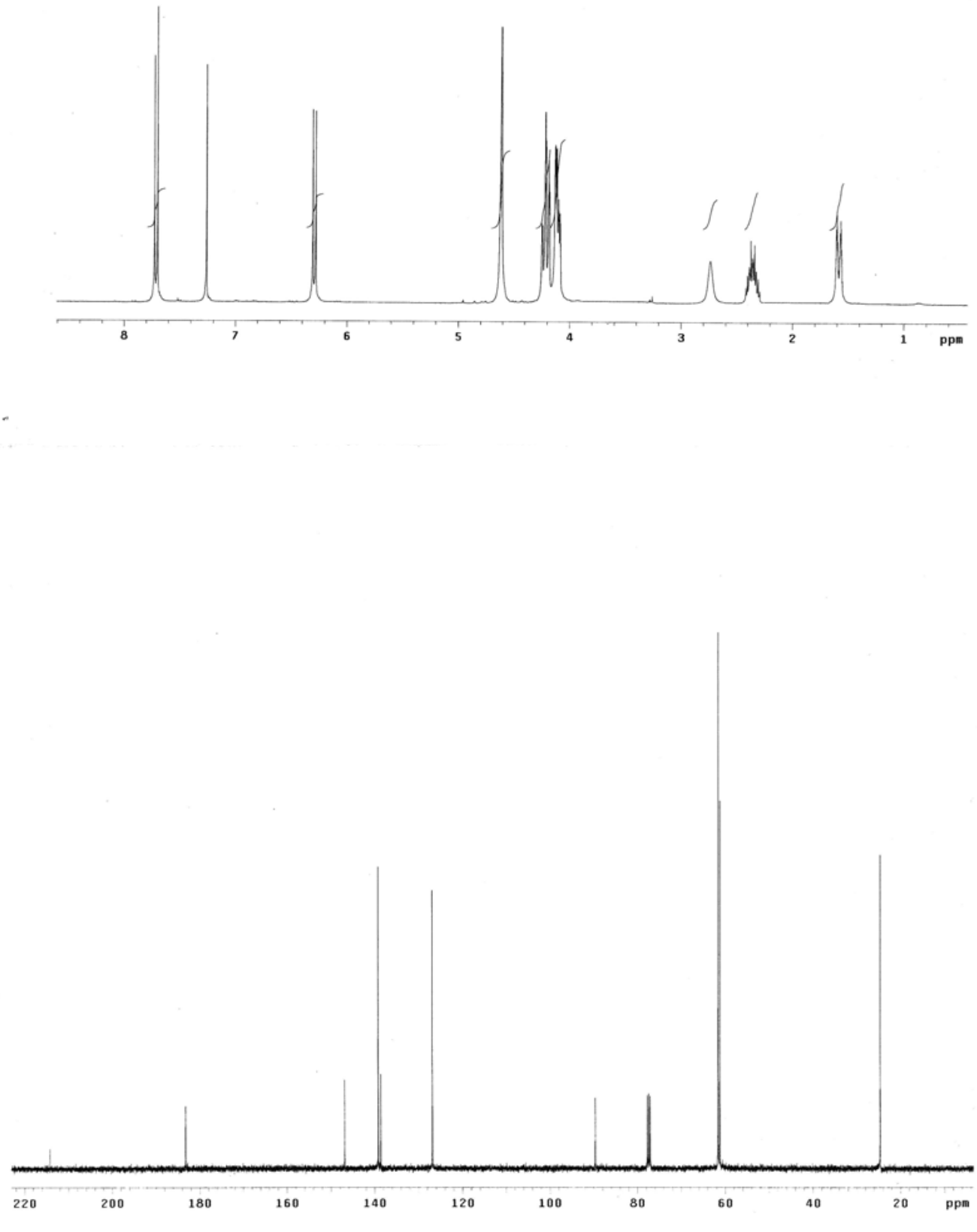

S 22 

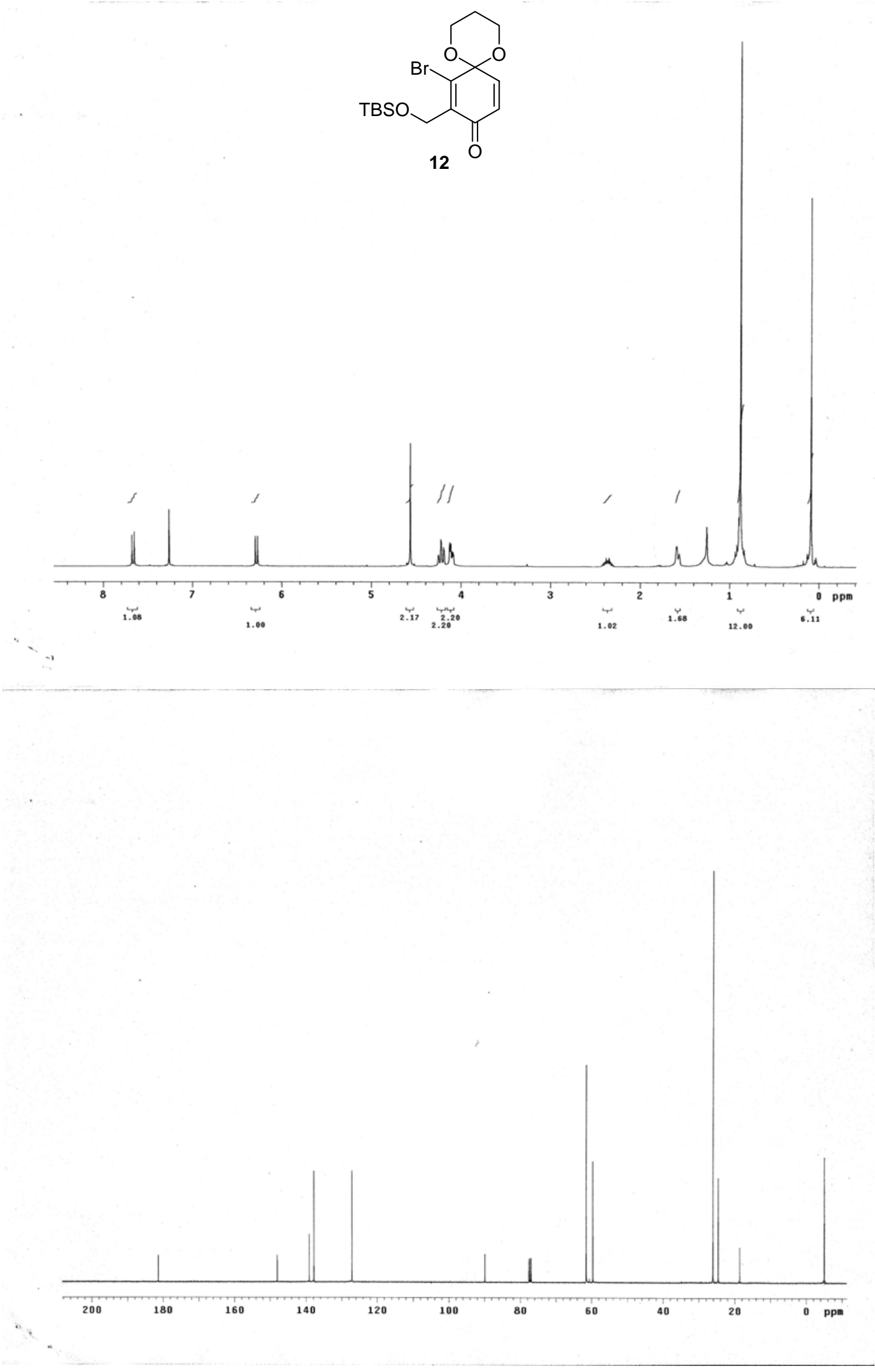

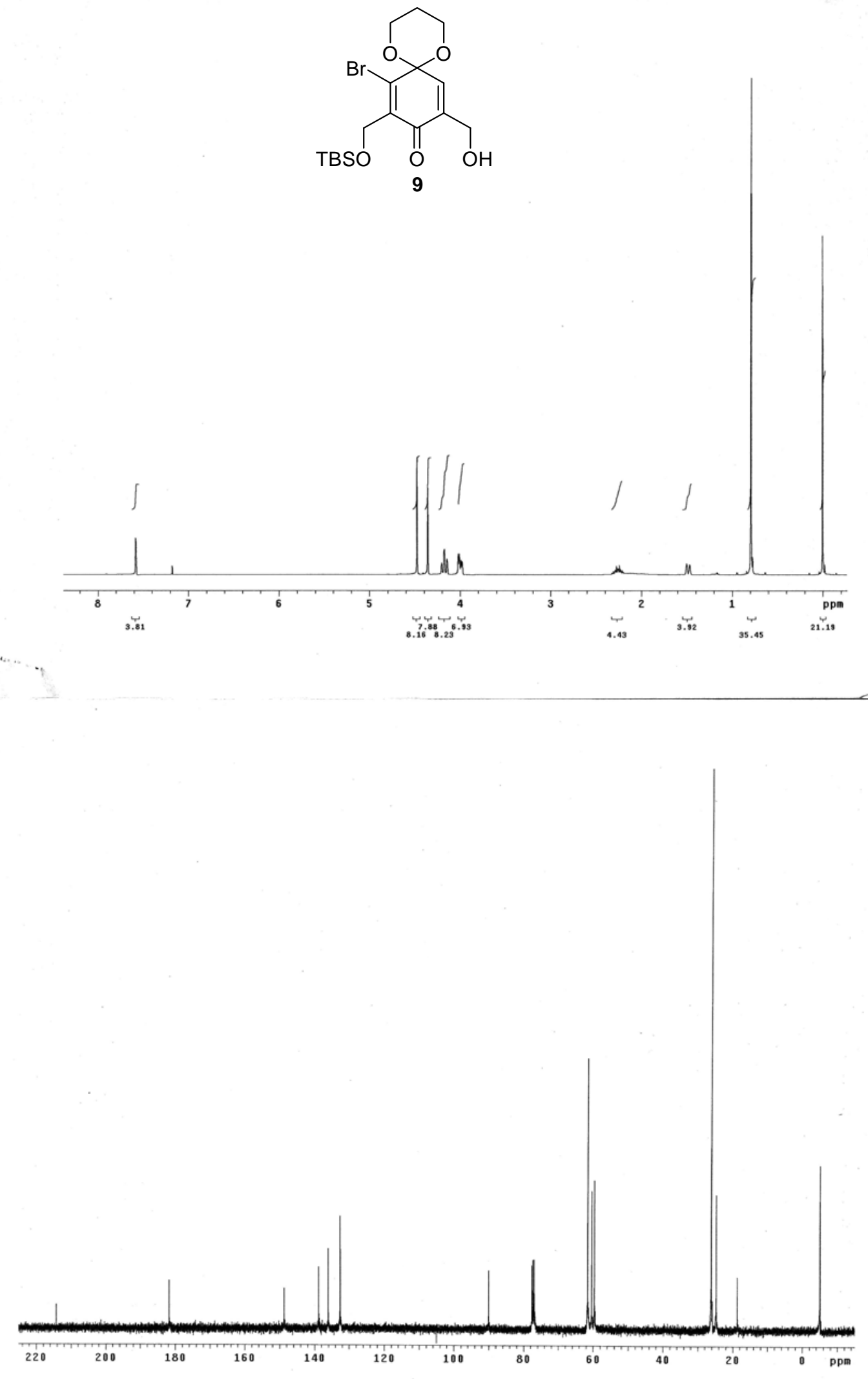

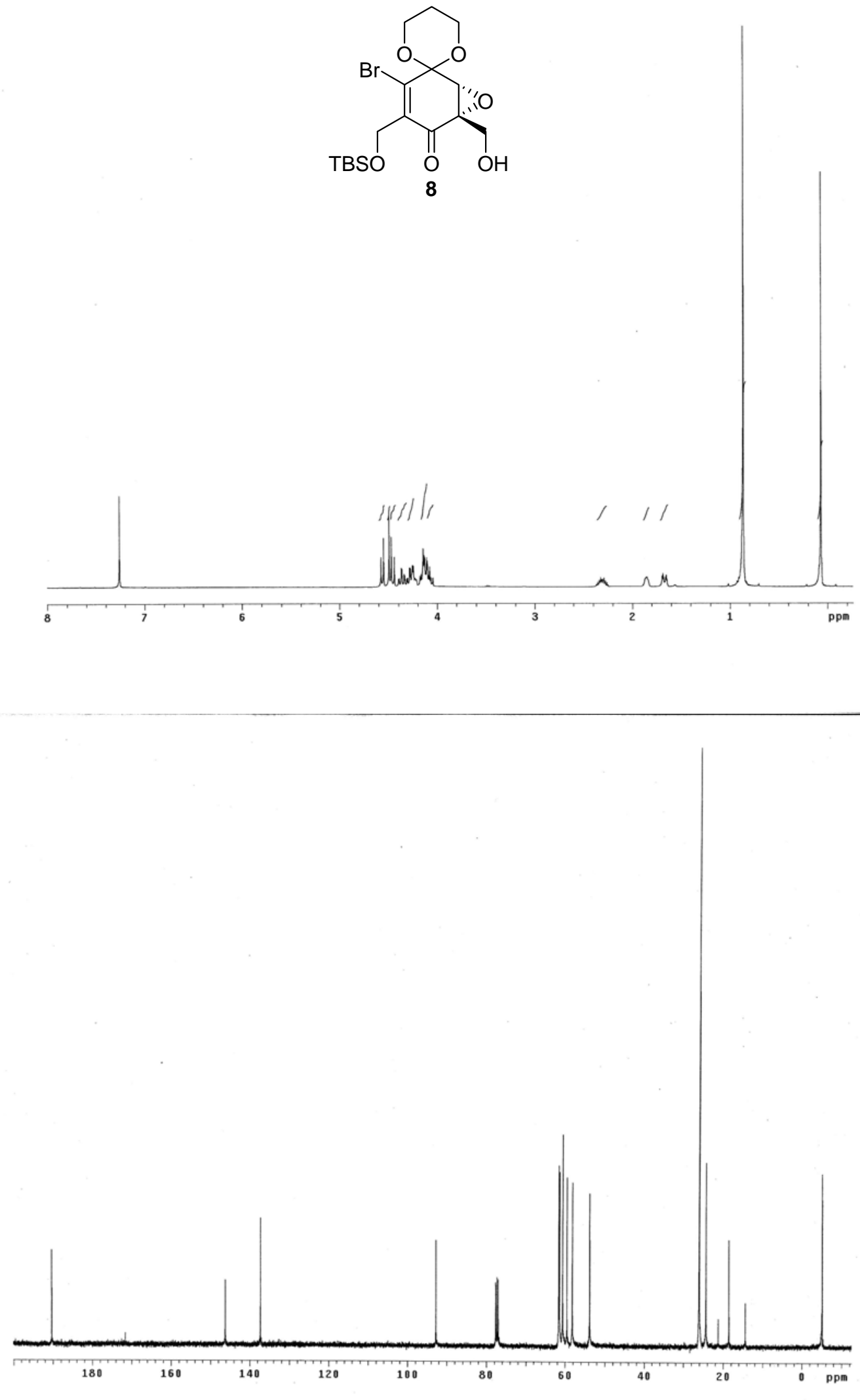

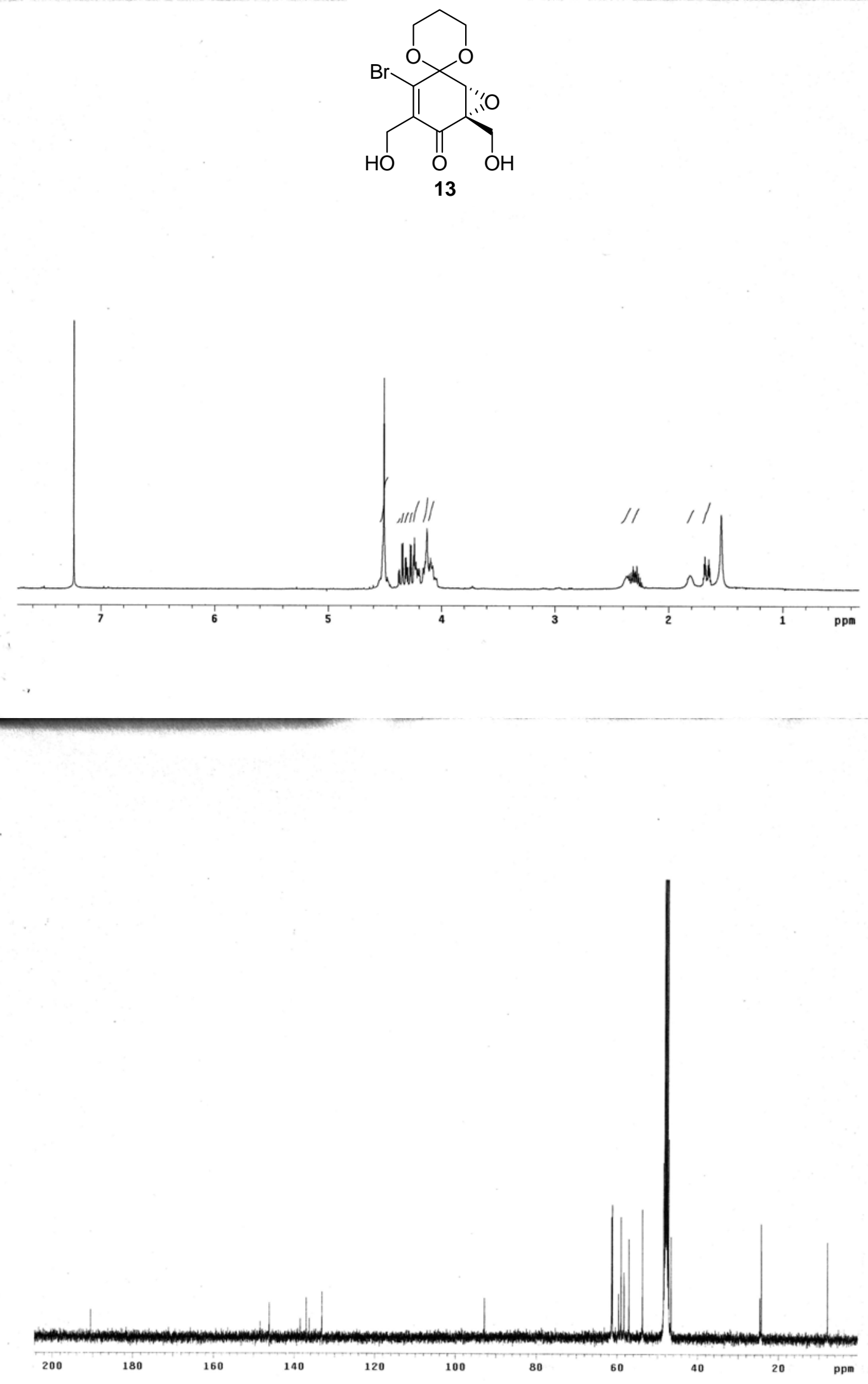

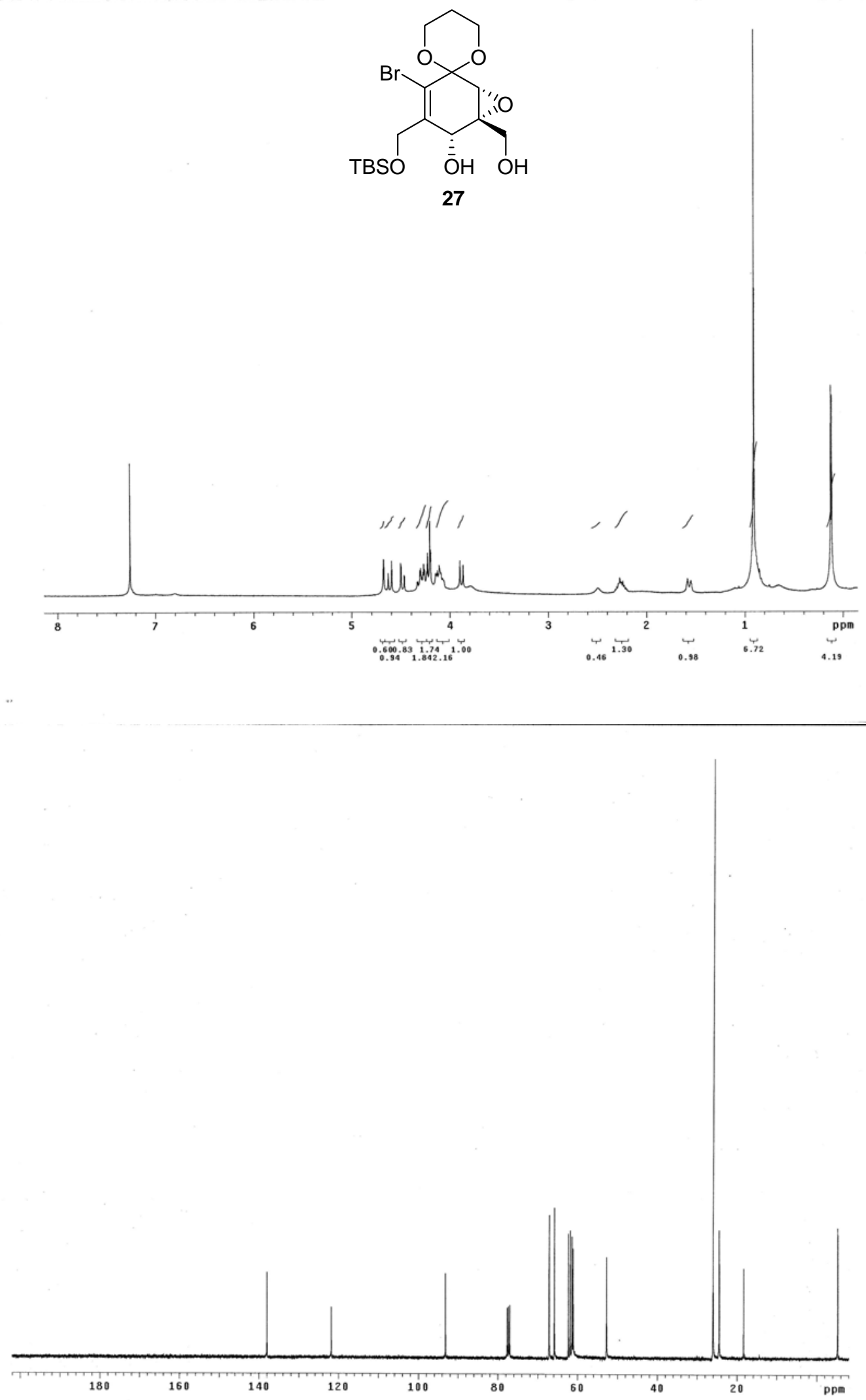


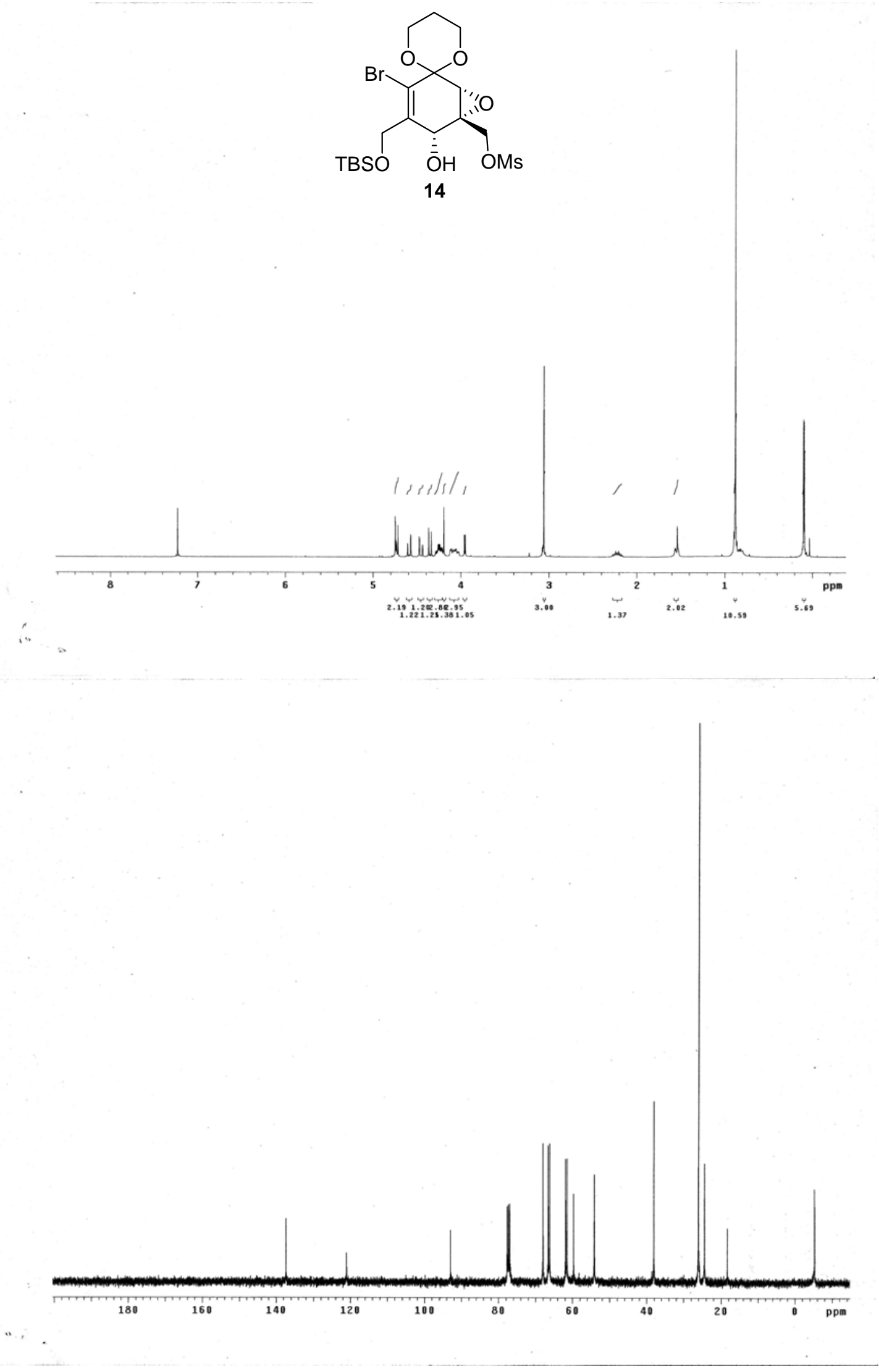



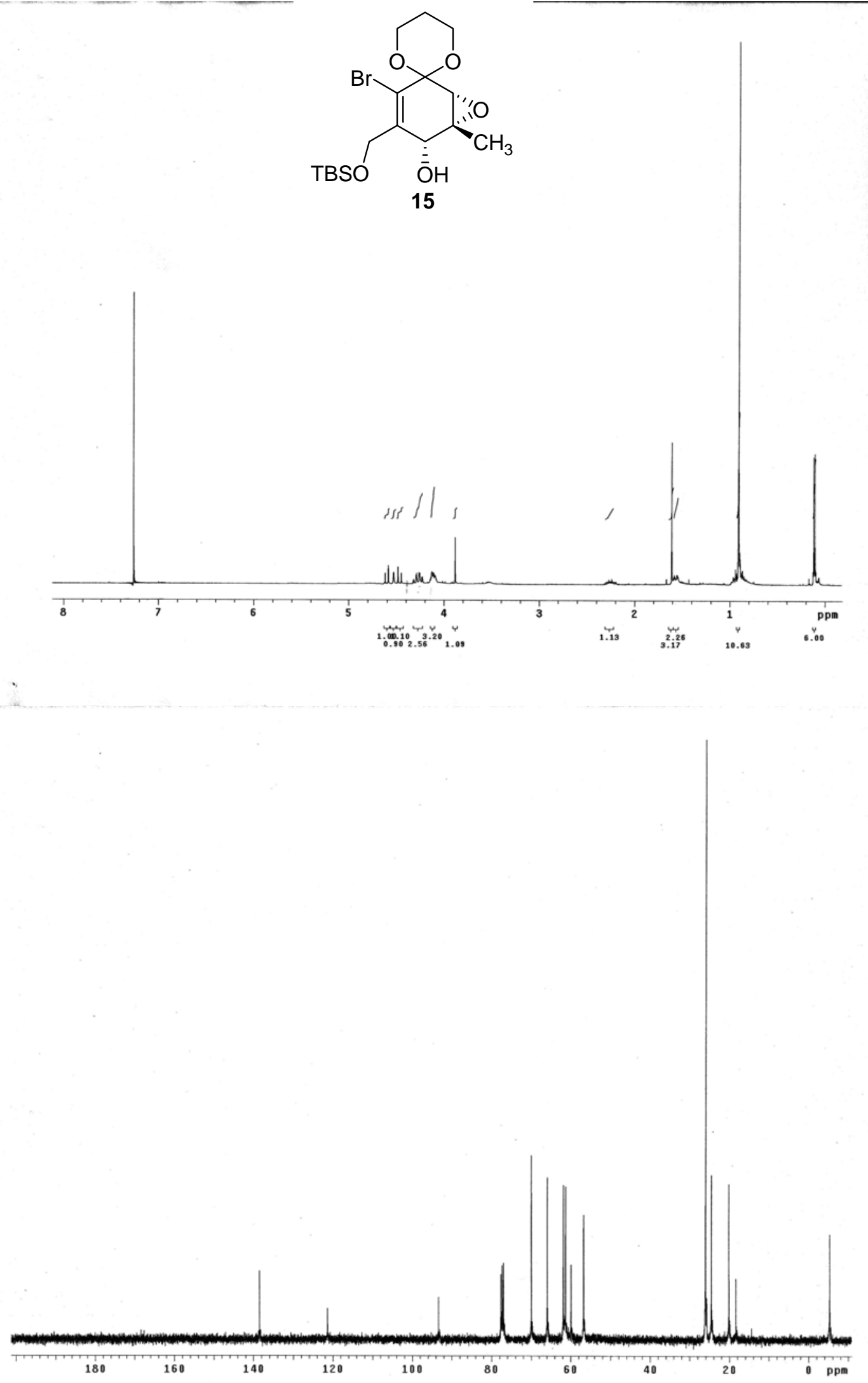

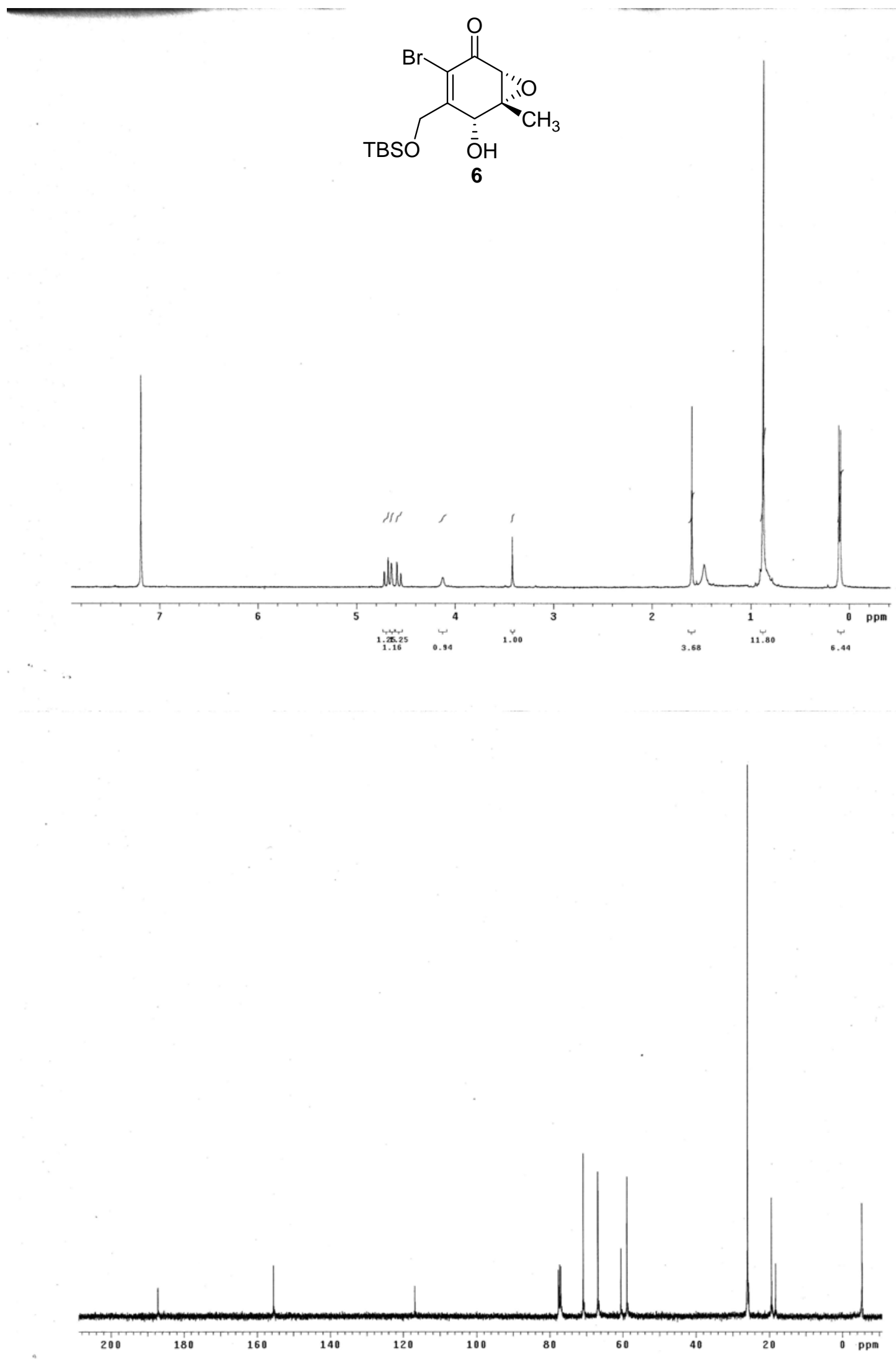

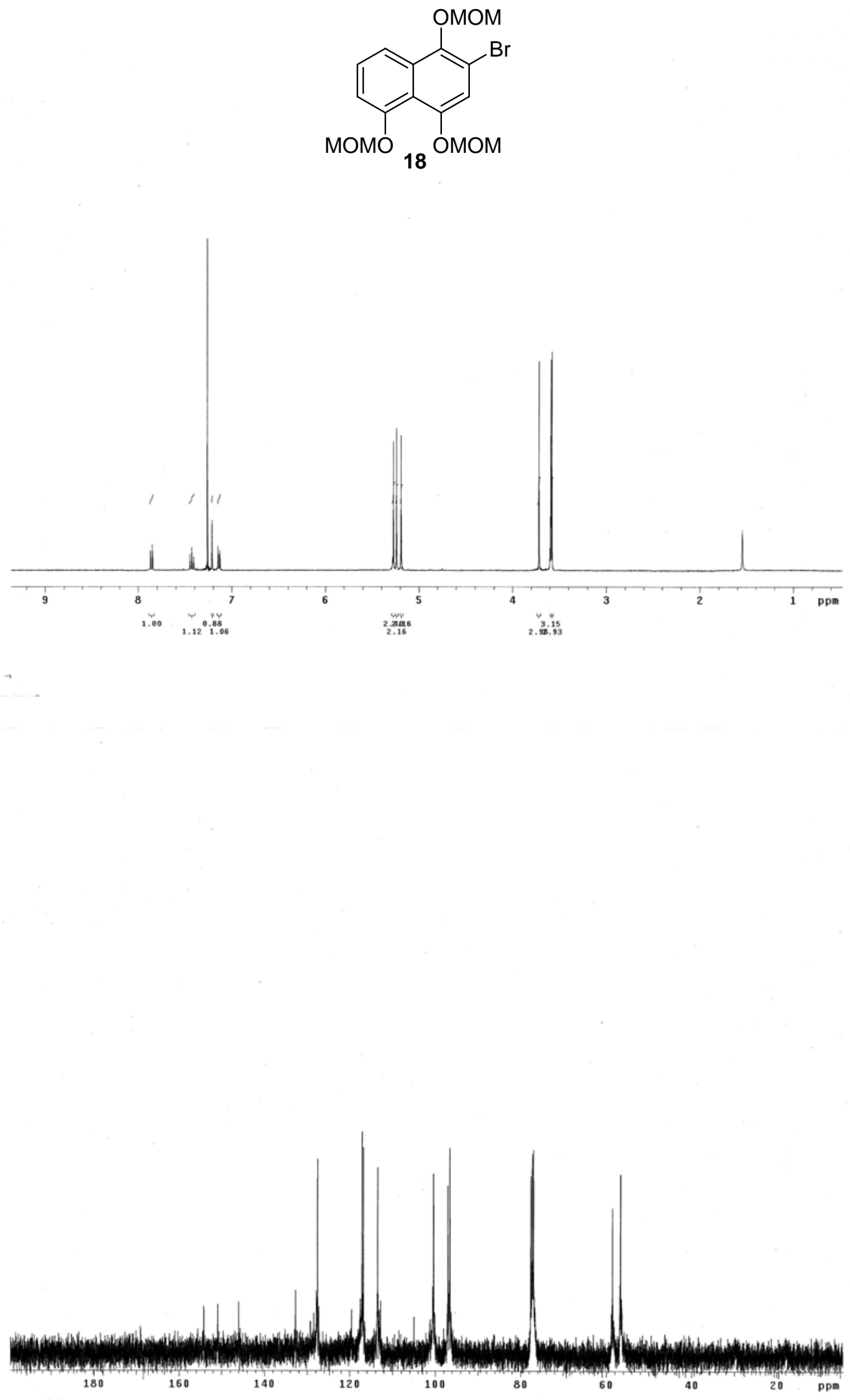

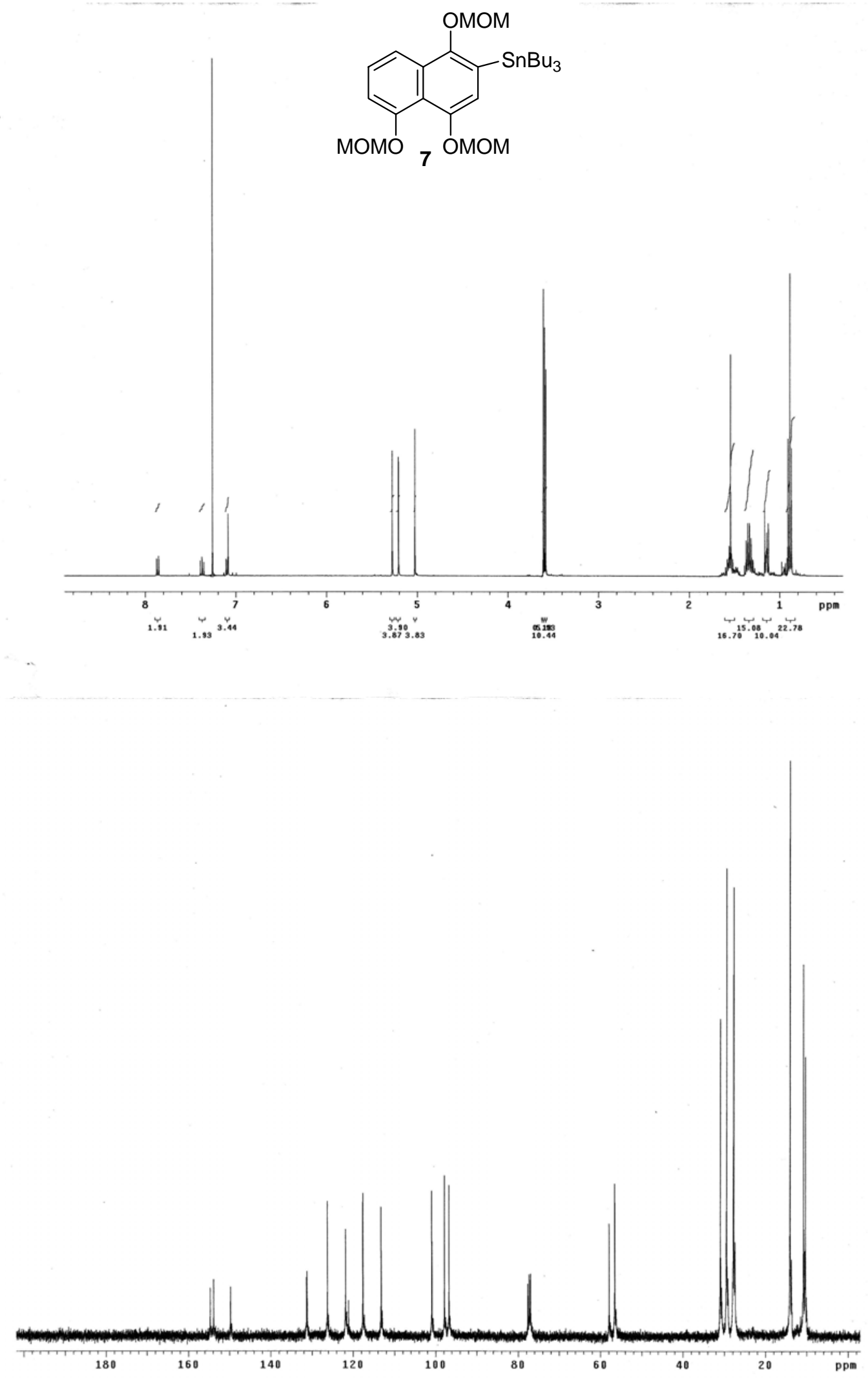

S 32 
2:1 mixture of rotamers
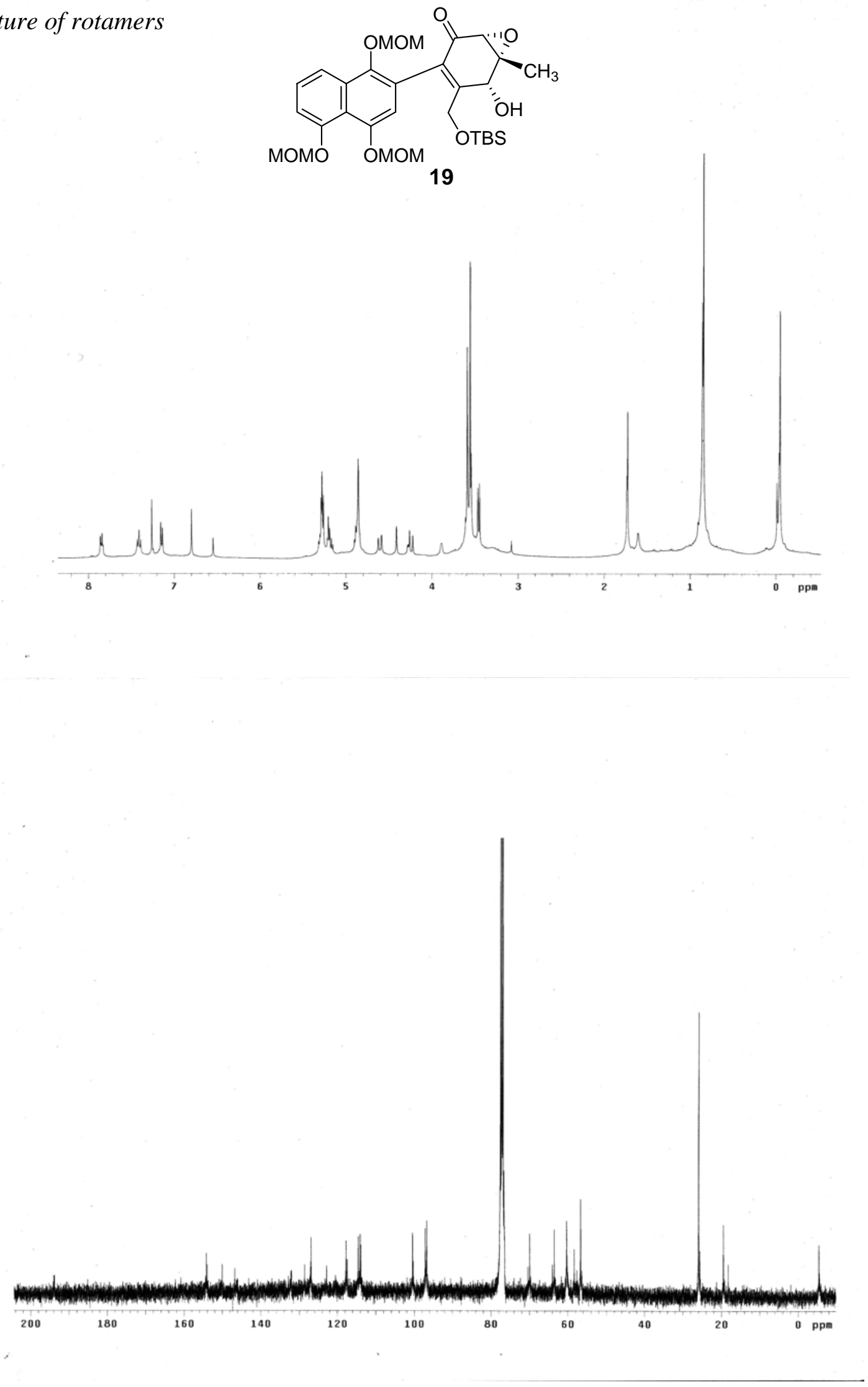

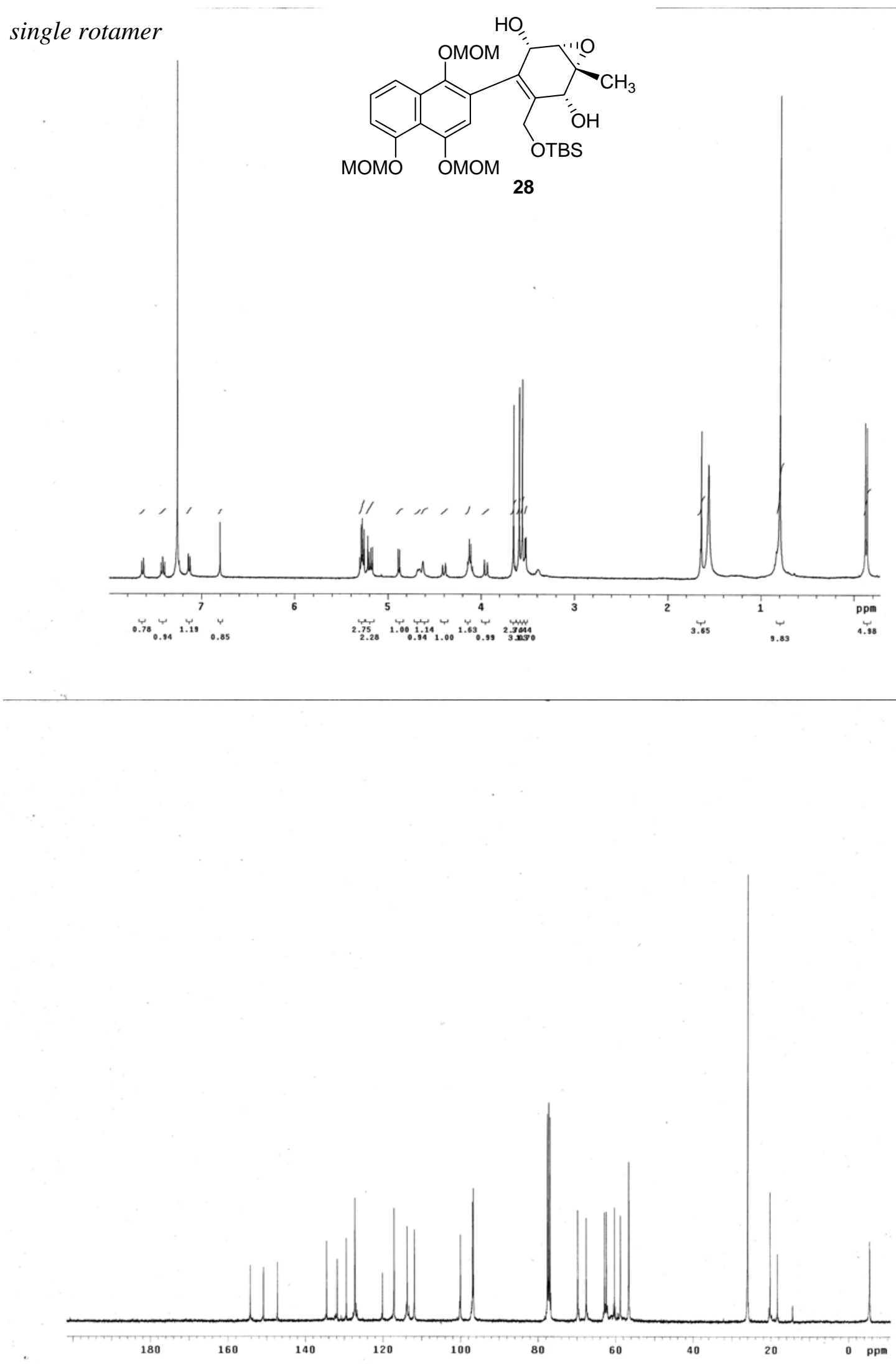
8:1 mixture of rotamers
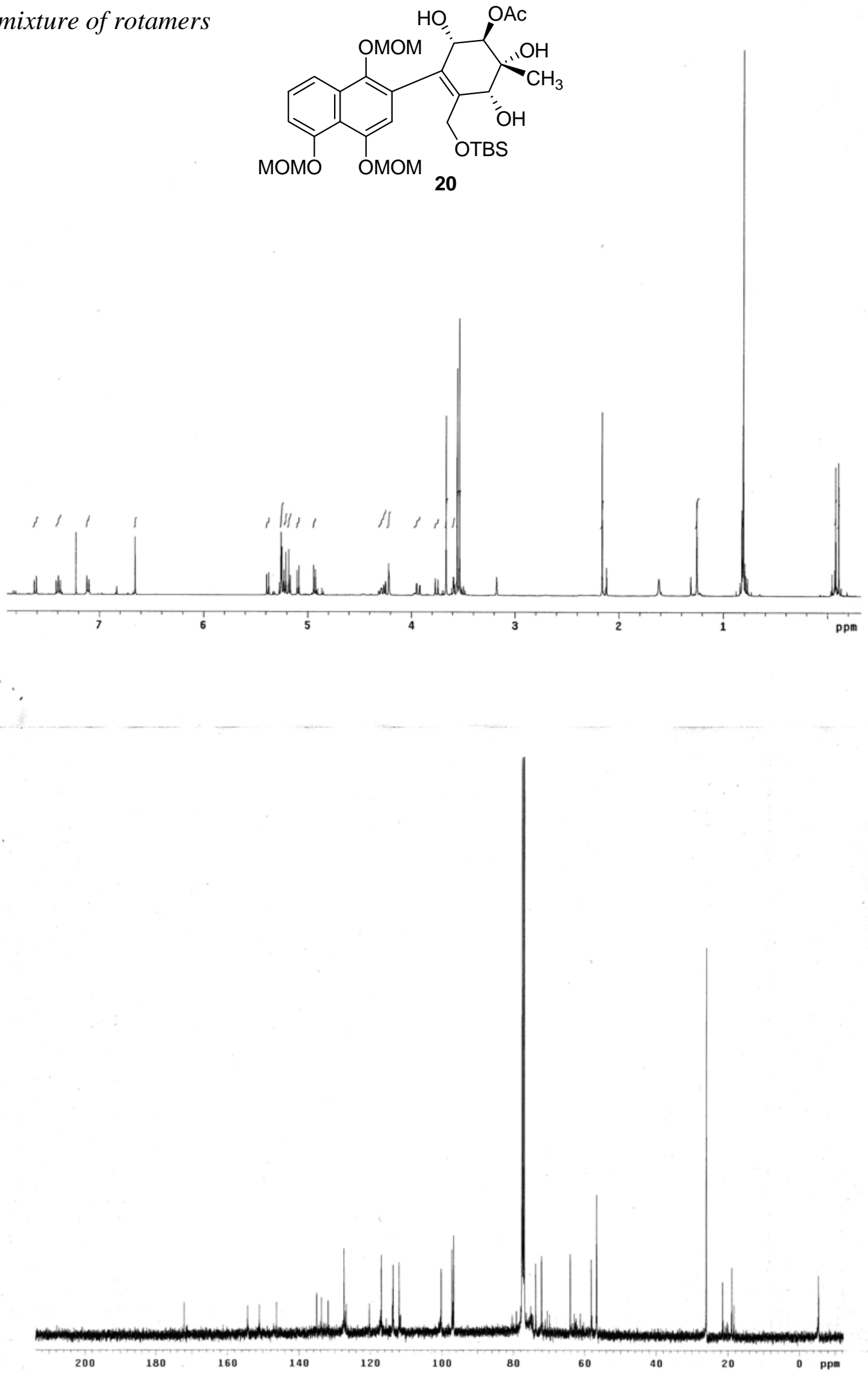


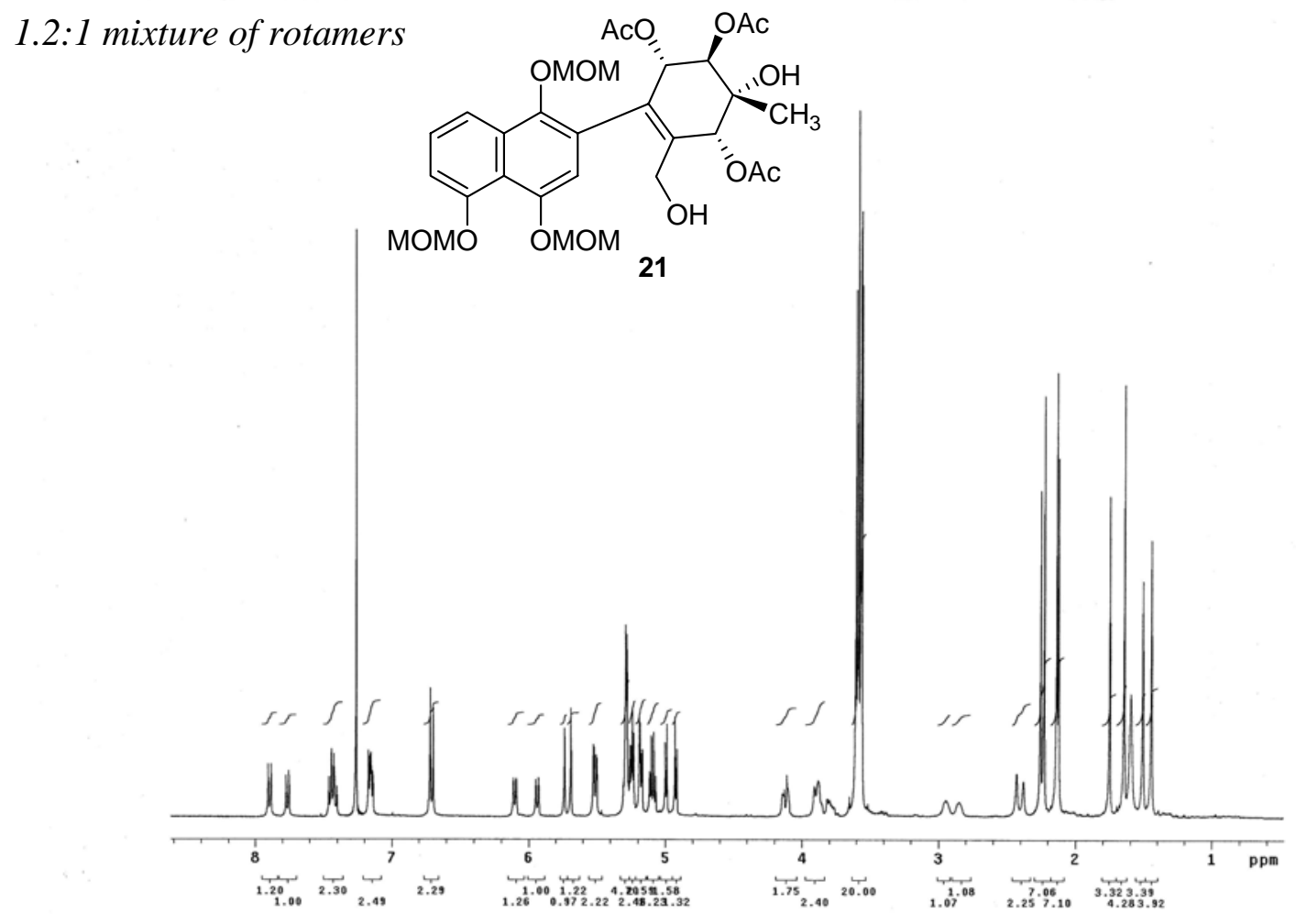



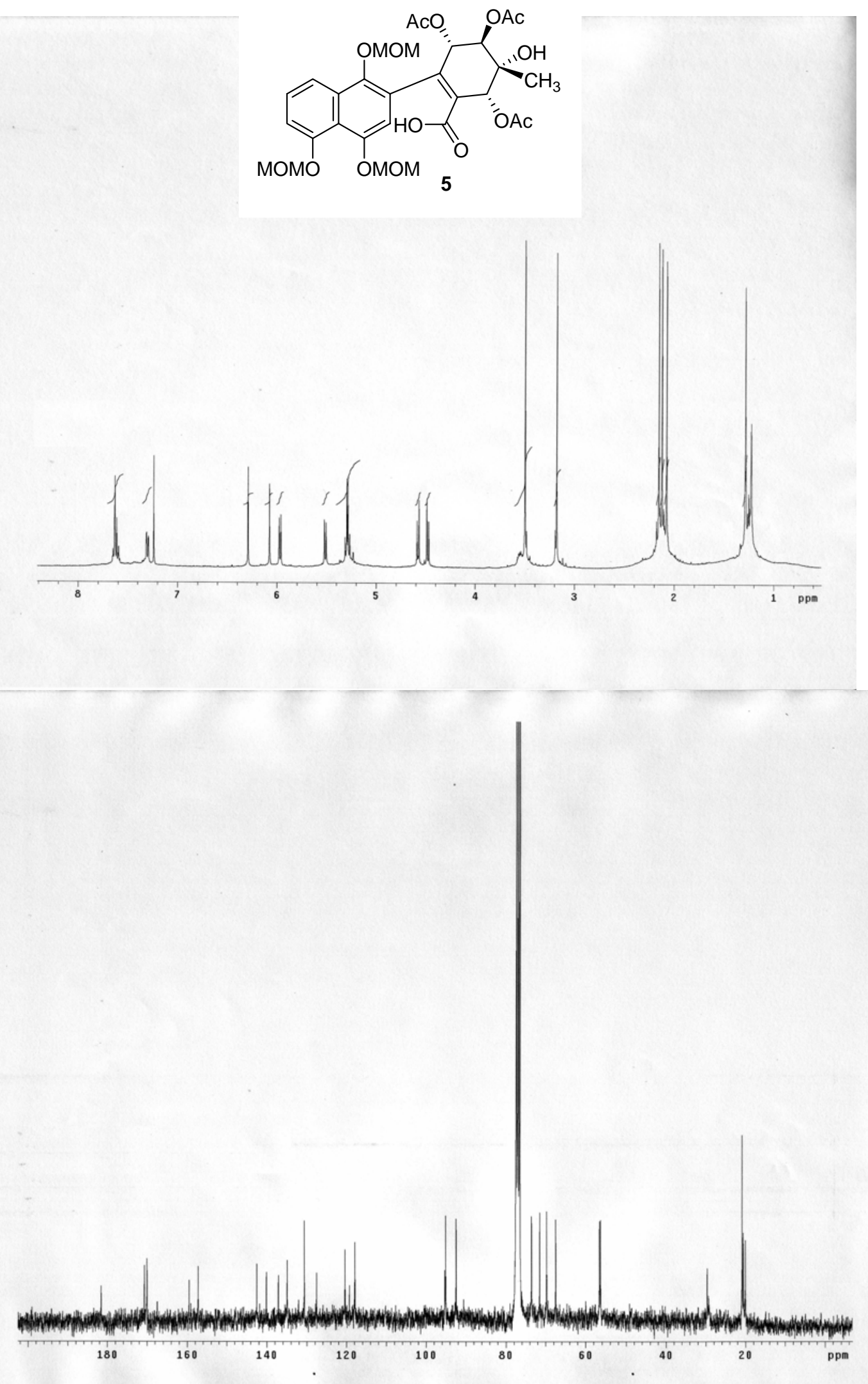

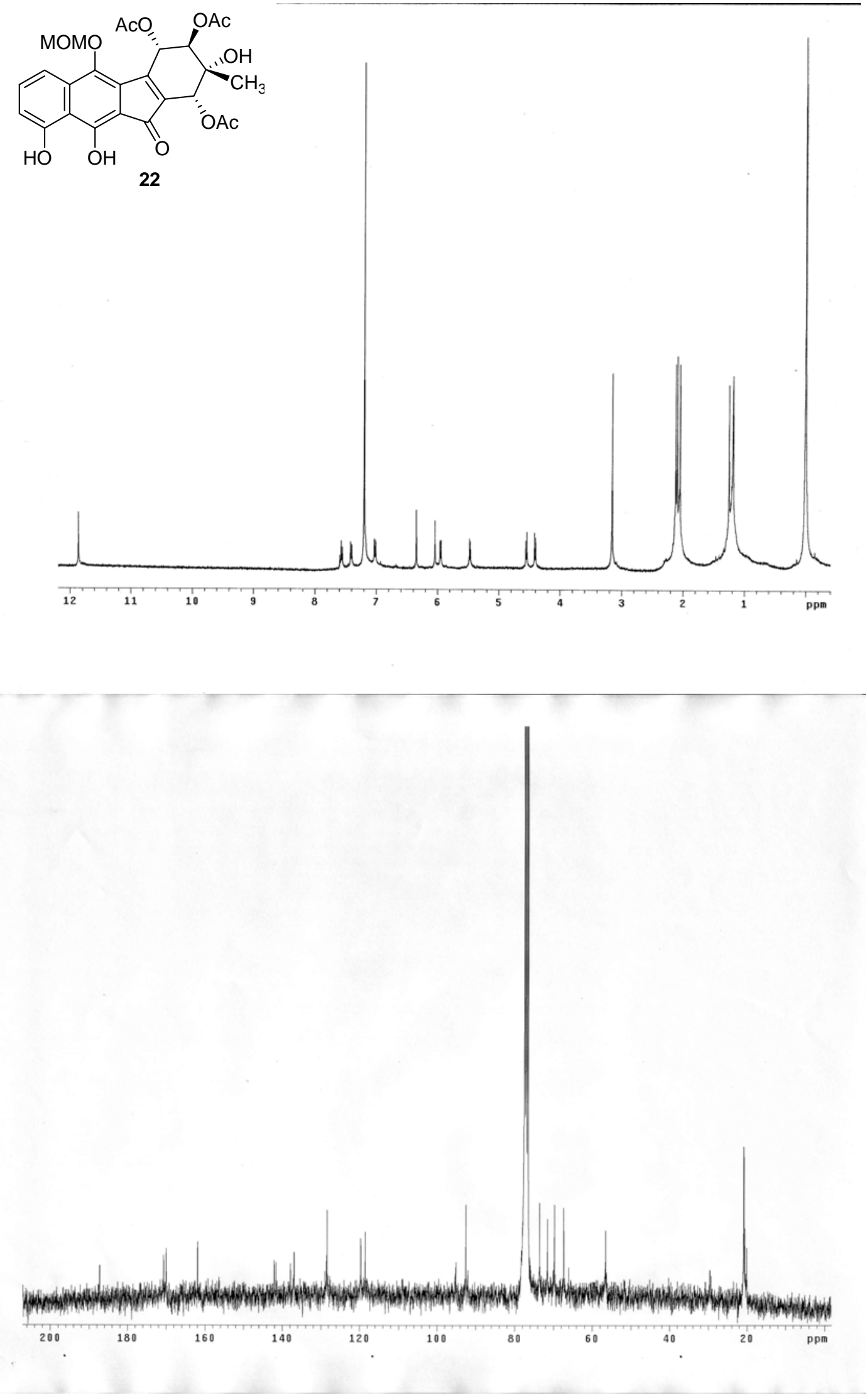
nOe Studies For compound 22
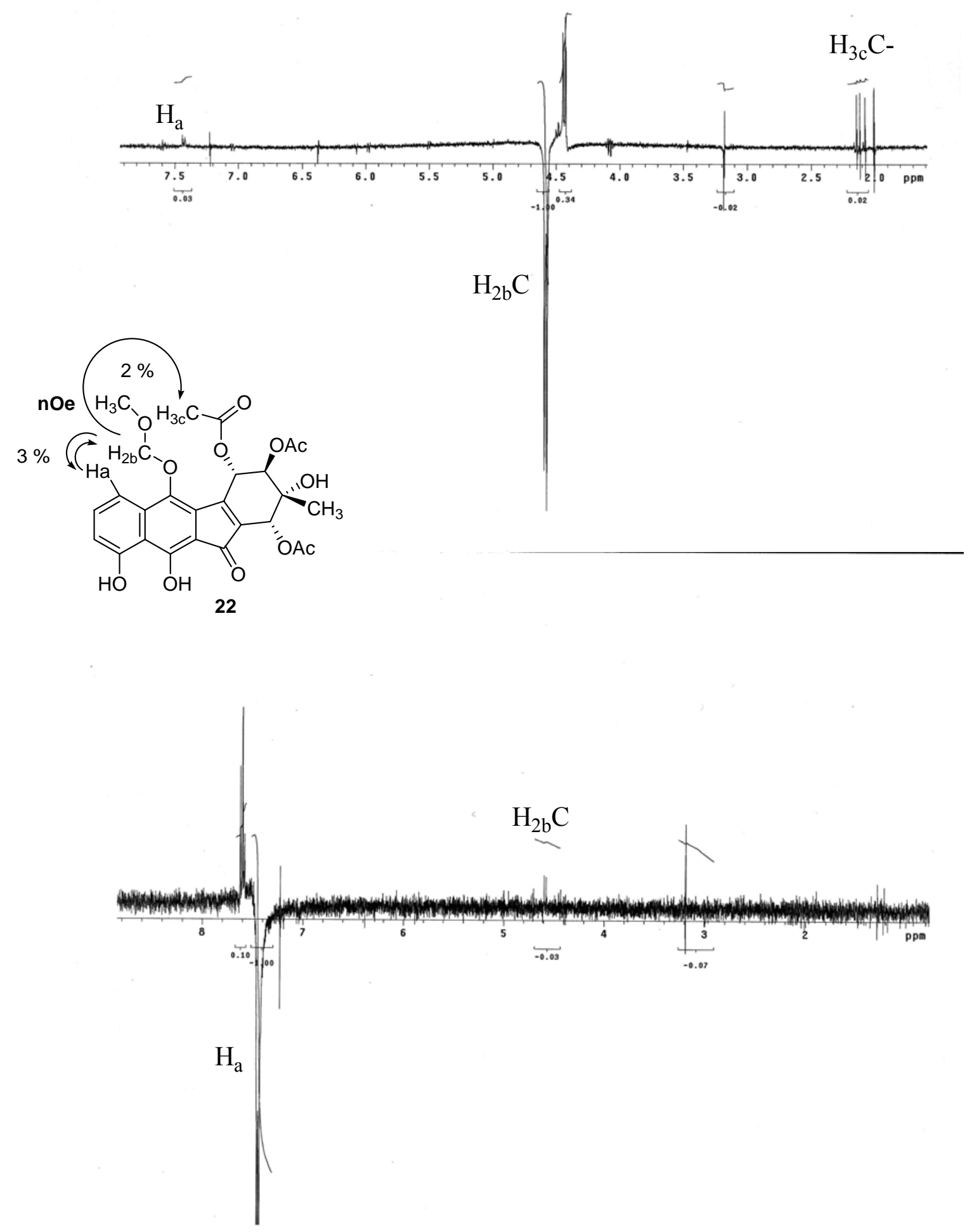

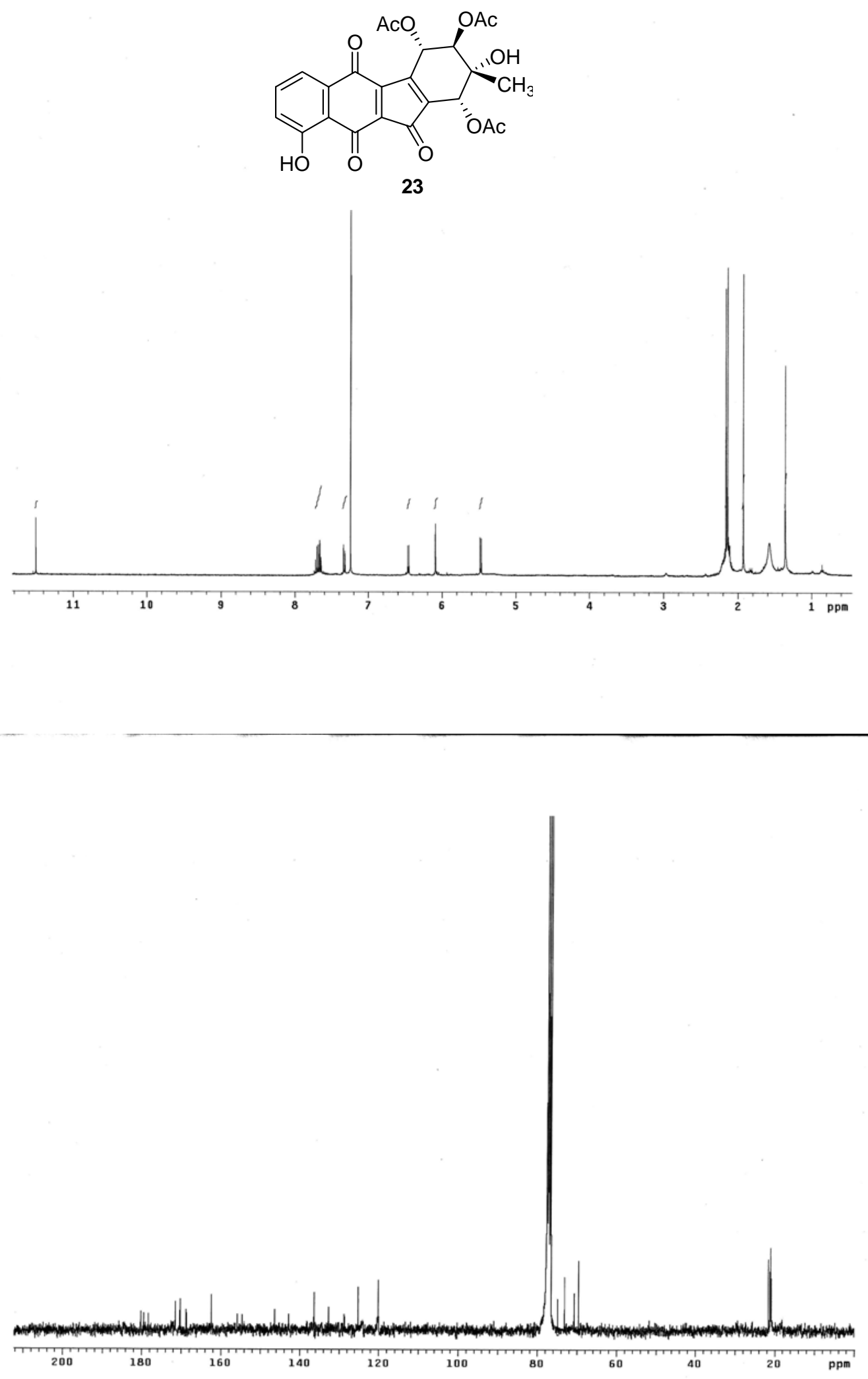


\section{IV) X-ray crystallographic data for 13}

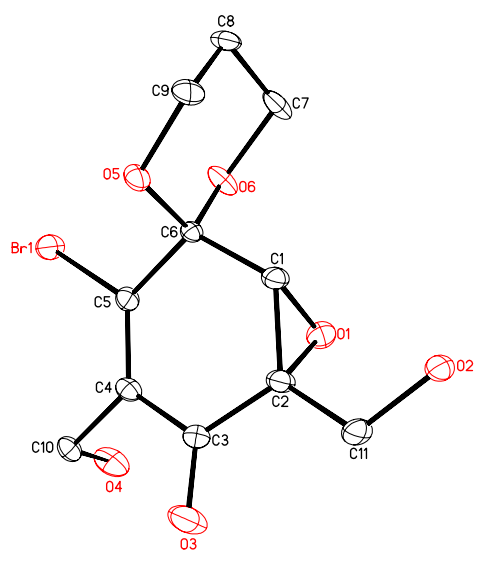

Crystals of compound 13 suitable for x-ray analysis were obtained by slow evaporation from methanol. Crystallographic data have been deposited with the Cambridge Crystallographic Data Centre (CCDC 606400). Copies of the data can be obtained free of charge on application to the CCDC, 12 Union Road, Cambridge CB21EZ, UK (fax: (+44)-1223-336-033; e-mail: deposit@ccdc.cam.ac.uk.

Table 1. Crystal data and structure refinement for $\mathbf{1 3 .}$

Identification code

Empirical formula

Formula weight

Temperature

Wavelength

Crystal system

Space group

Unit cell dimensions

Volume

Z

Density (calculated)

Absorption coefficient

$\mathrm{F}(000)$

Crystal size

\section{3 (CCDC 606400)}

C22 H26 Br2 O12

642.25

173(2) K

$0.71073 \AA$

Triclinic

P1

$\mathrm{a}=8.2717(6) \AA \quad \alpha=72.459(3)^{\circ}$.

$\mathrm{b}=8.2798(5) \AA \quad \beta=88.762(4)^{\circ}$.

$\mathrm{c}=9.1507(7) \AA \quad \gamma=75.142(3)^{\circ}$.

576.54(7) $\AA^{3}$

1

$1.850 \mathrm{Mg} / \mathrm{m}^{3}$

$3.583 \mathrm{~mm}^{-1}$

324

$0.45 \times 0.30 \times 0.15 \mathrm{~mm}^{3}$ 
Theta range for data collection

Index ranges

Reflections collected

Independent reflections

Completeness to theta $=30.51^{\circ}$

Absorption correction

Max. and min. transmission

Refinement method

Data / restraints / parameters

Goodness-of-fit on $\mathrm{F}^{2}$

Final $\mathrm{R}$ indices $[\mathrm{I}>2 \operatorname{sigma}(\mathrm{I})]$

$\mathrm{R}$ indices (all data)

Absolute structure parameter

Largest diff. peak and hole
2.34 to $30.51^{\circ}$.

$-11<=\mathrm{h}<=11,-11<=\mathrm{k}<=11,-13<=\mathrm{k}<=13$

13320

$6044[\mathrm{R}($ int $)=0.0232]$

$98.9 \%$

Semi-empirical from equivalents

0.6155 and 0.2954

Full-matrix least-squares on $\mathrm{F}^{2}$

6044 / 3 / 429

1.062

$\mathrm{R} 1=0.0257, \mathrm{wR} 2=0.0650$

$\mathrm{R} 1=0.0286, \mathrm{wR} 2=0.0658$

$0.047(6)$

0.453 and -0.430 e. $\AA^{-3}$

Table 2. Atomic coordinates $\left(\times 10^{4}\right)$ and equivalent isotropic displacement parameters $\left(\AA^{2} \times 10^{3}\right)$ for 13. $U(e q)$ is defined as one third of the trace of the orthogonalized $U^{i j}$ tensor.

\begin{tabular}{|c|c|c|c|c|}
\hline & $\mathrm{x}$ & $\mathrm{y}$ & $\mathrm{z}$ & $\mathrm{U}(\mathrm{eq})$ \\
\hline $\operatorname{Br}(1)$ & 1394(1) & $18976(1)$ & $6546(1)$ & $26(1)$ \\
\hline $\operatorname{Br}(2)$ & $-5692(1)$ & 19119(1) & $9459(1)$ & $27(1)$ \\
\hline $\mathrm{O}(1)$ & $-2073(2)$ & $17885(2)$ & $3343(2)$ & $23(1)$ \\
\hline $\mathrm{O}(2)$ & $-4278(3)$ & $15744(3)$ & $3491(3)$ & $20(1)$ \\
\hline $\mathrm{O}(3)$ & $-4915(3)$ & $19784(4)$ & $5520(4)$ & $38(1)$ \\
\hline $\mathrm{O}(4)$ & $-2191(4)$ & $22515(3)$ & $4719(3)$ & $30(1)$ \\
\hline $\mathrm{O}(5)$ & $372(3)$ & 15353(3) & $7027(2)$ & $21(1)$ \\
\hline $\mathrm{O}(6)$ & $1263(3)$ & $16702(3)$ & $4630(3)$ & $23(1)$ \\
\hline $\mathrm{O}(7)$ & $-1489(2)$ & $22258(2)$ & $9546(2)$ & $21(1)$ \\
\hline $\mathrm{O}(8)$ & $3(3)$ & $22319(4)$ & $12419(3)$ & $25(1)$ \\
\hline $\mathrm{O}(9)$ & $624(3)$ & $18035(3)$ & 10704(3) & $33(1)$ \\
\hline $\mathrm{O}(10)$ & $-2106(4)$ & $15624(3)$ & $11122(3)$ & $31(1)$ \\
\hline $\mathrm{O}(11)$ & $-5169(3)$ & $21179(3)$ & $11583(3)$ & $22(1)$ \\
\hline $\mathrm{O}(12)$ & $-5025(3)$ & $22725(3)$ & $9005(3)$ & $23(1)$ \\
\hline $\mathrm{C}(1)$ & $-1510(3)$ & $16456(4)$ & $4754(4)$ & $21(1)$ \\
\hline $\mathrm{C}(2)$ & $-3225(3)$ & $17611(4)$ & $4600(3)$ & $20(1)$ \\
\hline
\end{tabular}




\begin{tabular}{lrrrr}
$\mathrm{C}(3)$ & $-3518(4)$ & $19030(4)$ & $5334(4)$ & $17(1)$ \\
$\mathrm{C}(4)$ & $-2032(4)$ & $19502(4)$ & $5822(4)$ & $17(1)$ \\
$\mathrm{C}(5)$ & $-500(4)$ & $18399(4)$ & $5952(4)$ & $17(1)$ \\
$\mathrm{C}(6)$ & $-74(4)$ & $16684(4)$ & $5597(4)$ & $15(1)$ \\
$\mathrm{C}(7)$ & $1946(4)$ & $15057(5)$ & $4330(4)$ & $24(1)$ \\
$\mathrm{C}(8)$ & $2500(4)$ & $13637(5)$ & $5818(4)$ & $29(1)$ \\
$\mathrm{C}(9)$ & $1075(5)$ & $13611(4)$ & $6886(4)$ & $26(1)$ \\
$\mathrm{C}(10)$ & $-2384(4)$ & $21257(4)$ & $6097(4)$ & $18(1)$ \\
$\mathrm{C}(11)$ & $-4718(4)$ & $17132(5)$ & $4151(5)$ & $23(1)$ \\
$\mathrm{C}(12)$ & $-2629(4)$ & $21904(4)$ & $10738(3)$ & $19(1)$ \\
$\mathrm{C}(13)$ & $-958(4)$ & $20723(4)$ & $10916(3)$ & $19(1)$ \\
$\mathrm{C}(14)$ & $-749(4)$ & $19038(4)$ & $10546(4)$ & $19(1)$ \\
$\mathrm{C}(15)$ & $-2244(4)$ & $18663(4)$ & $9995(3)$ & $15(1)$ \\
$\mathrm{C}(16)$ & $-3762(4)$ & $19716(4)$ & $9944(3)$ & $15(1)$ \\
$\mathrm{C}(17)$ & $-4166(4)$ & $21461(4)$ & $10304(3)$ & $15(1)$ \\
$\mathrm{C}(18)$ & $-5750(5)$ & $24391(4)$ & $9257(5)$ & $28(1)$ \\
$\mathrm{C}(19)$ & $-6925(5)$ & $24157(5)$ & $10539(5)$ & $34(1)$ \\
$\mathrm{C}(20)$ & $-6011(5)$ & $22757(5)$ & $11943(4)$ & $27(1)$ \\
$\mathrm{C}(21)$ & $-1907(4)$ & $16886(4)$ & $9711(4)$ & $19(1)$ \\
$\mathrm{C}(22)$ & $419(4)$ & $20811(5)$ & $11911(4)$ & $20(1)$ \\
\hline
\end{tabular}

